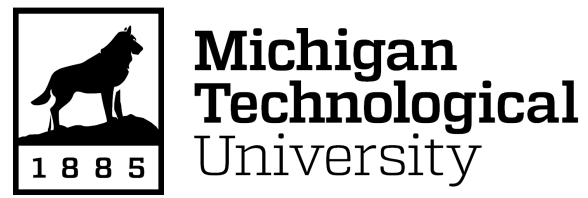

Michigan Technological University Digital Commons @ Michigan Tech

Dissertations, Master's Theses and Master's Reports

2016

\title{
A PETROPHYSICAL EVALUATION FOR PERMEABILITY OF A GAS RESERVOIR IN THE TARANAKI BASIN, NEW ZEALAND
}

Musa Cetin

Michigan Technological University, mcetin@mtu.edu

Copyright 2016 Musa Cetin

Recommended Citation

Cetin, Musa, "A PETROPHYSICAL EVALUATION FOR PERMEABILITY OF A GAS RESERVOIR IN THE TARANAKI BASIN, NEW ZEALAND", Open Access Master's Thesis, Michigan Technological University, 2016.

https://doi.org/10.37099/mtu.dc.etdr/154

Follow this and additional works at: https://digitalcommons.mtu.edu/etdr

Part of the Mining Engineering Commons, and the Petroleum Engineering Commons 


\title{
A PETROPHYSICAL EVALUATION FOR PERMEABILITY OF A GAS RESERVOIR IN THE TARANAKI BASIN, NEW ZEALAND
}

\author{
By \\ Musa Cetin
}

\begin{abstract}
A THESIS
Submitted in partial fulfillment of the requirements for the degree of

MASTER OF SCIENCE

In Geophysics
\end{abstract}

MICHIGAN TECHNOLOGICAL UNIVERSITY

2016

(C) 2016 Musa Cetin 
This thesis has been approved in partial fulfillment of the requirements for the Degree of MASTER OF SCIENCE in Geophysics.

Department of Geological and Mining Engineering and Sciences

Thesis Advisor: Wayne D. Pennington

Committee Member: Mir Sadri

Committee Member: Gregory P. Waite

Department Chair: John S. Gierke 


\section{Table of Contents}

List of Figures .................................................................................................................. vi

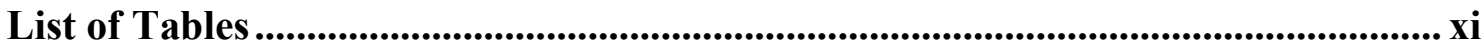

List of Abbreviations ......................................................................................................... xii

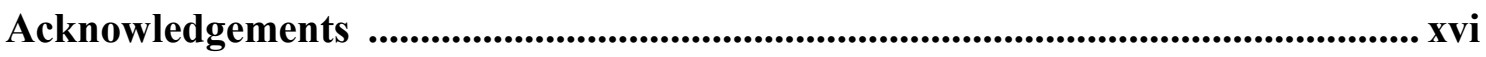

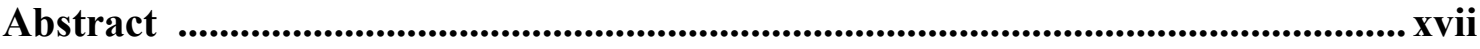

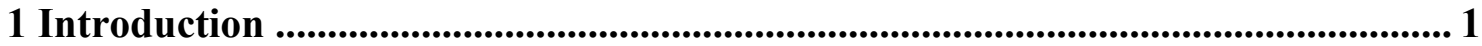

2 Geology of Mangaa C1 Sandstone Formation ...................................................... 3

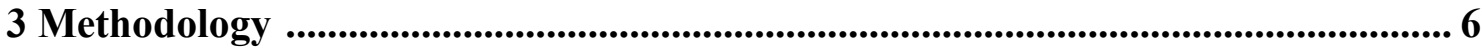

3.1 Zones and Depth Shifts................................................................ 7

3.2 Mineral Identification Crossplots ….................................................. 16

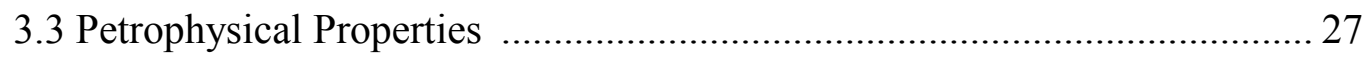

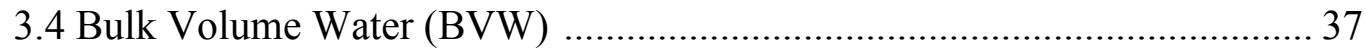

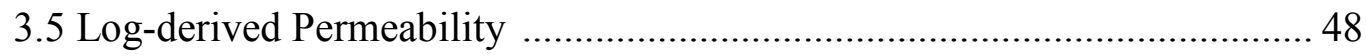

3.6 Flow Unit Characterization ............................................................... 53

3.6.1 Flow Zone Indicator .......................................................... 53

3.6.2 Winland (R35) Empirical Correlation .................................... 55

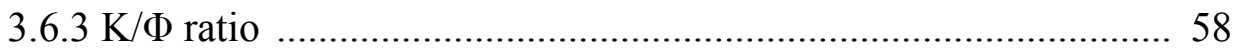

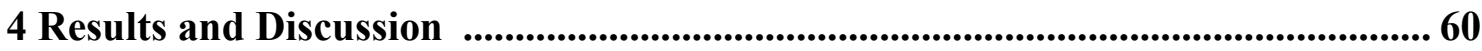

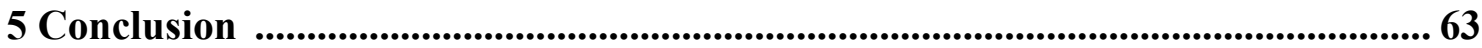

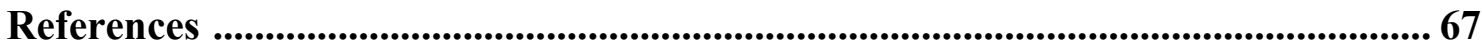

Appendix A: Mineralogy Crossplots ....................................................................... 70

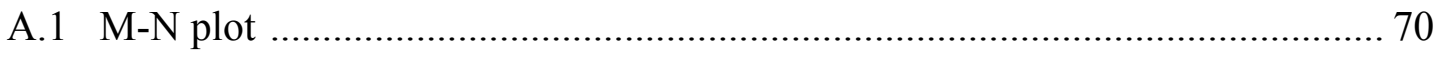




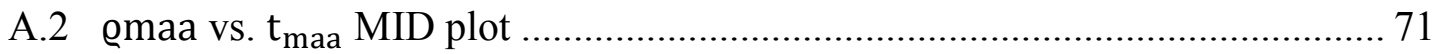

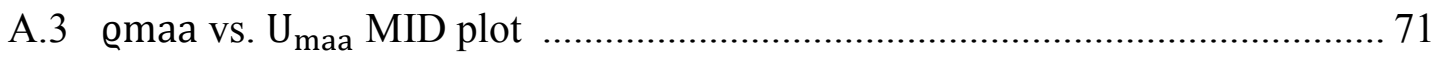

Appendix B: Petrophysical Formation Properties ............................................. 72

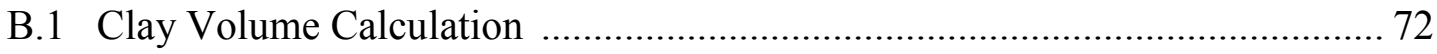

B.2 Effective and Total Porosity ................................................................ 74

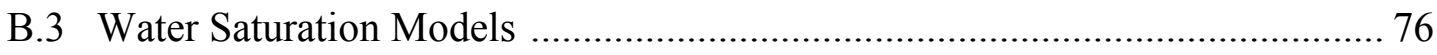

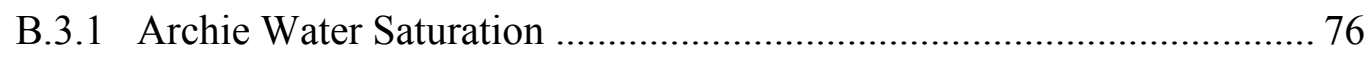

B.3.2 Simandoux Water Saturation ...................................................... 76

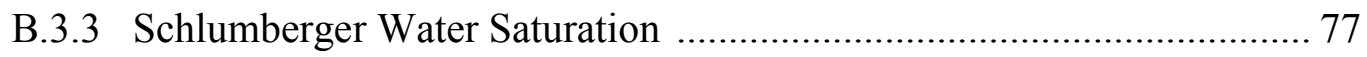

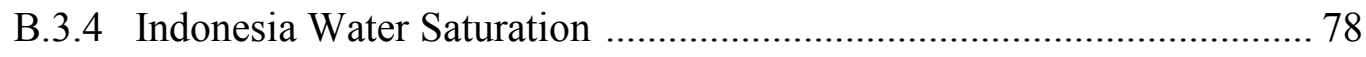

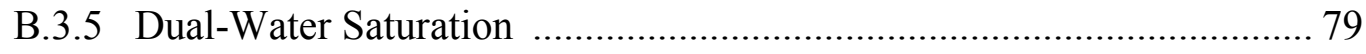

Appendix C: Bulk Volume Water and Flow Zone Indicator ..................................... 80

C.1 Bulk Volume Water and Bulk Volume Water Irreducible ............................. 80

C.2 Grain size from Bulk Volume Water ......................................................... 81

Appendix D: Permeability Calculations ...................................................................... 82

D.1 Permeability Calculations from Swi \& $\Phi$ e ................................................ 82

D.1.1 Timur Absolute Permeability ...................................................... 82

D.1.2 Morris-Biggs Gas Absolute Permeability ....................................... 84

D.1.3 Coates-Denoo Absolute Permeability ........................................... 85

D.1.4 Coates-Dumanoir Absolute Permeability …................................... 85

D.2 Multi-linear Regression Absolute Permeability ….................................... 86

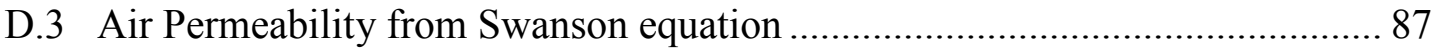

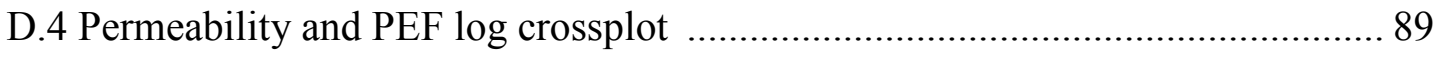


E.1 Flow Zone Indicator (FZI) and Reservoir Quality Index (RQI) ...................... 90

E.2 Winland Empirical Correlation.................................................................. 91

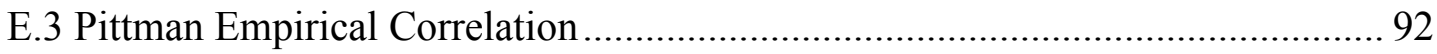




\section{List of Figures}

Figure 1 The location map of the two wells in Taranaki Basin, New Zealand 3

Figure 2 Full log suite of the Karewa-1 well (1930.9-1941m). On the left side, gammaray (GRI), caliper (CLD), and bit size (BIT) curves were shown whereas in the middle, uninvaded deep lateralog (LLD), shallow lateralog (LLS), and invaded zone resistivity (RXO) logs were plotted together. On the right side, bulk density (FDC), sonic compressional (DTC), neutron (TNPH), and photo-electric factor (PEF) logs were indicated.

Figure 3 Full log suite of the Kahawai-1 well (1849.2-1852.7m). On the left track, standard gamma-ray (SGR), computed gamma-ray (CGR), caliper (CALI), bit size (BS), and three spectral gamma-ray (thorium (THOR), potassium (K), and uranium (URAN)) curves were displayed, while in the middle track, deep lateralog (LLD), shallow lateralog (LLS), and micro-spherical focused (MSFL) logs were shown. On the right track, bulk density (RHOB), sonic compressional (DT), neutron (TNPH), and photoelectric factor (PEF) logs were demonstrated

Figure 4 Karewa-1 well. (a) Original PEF and FDC logs were plotted. (b) After shifting the PEF log, depth shifted PEF log (PEFshft) and FDC logs were plotted. Correlation of these two logs were improved after depth-correction was applied.

Figure 5 Karewa-1 well. (a) Depth-shifted PEF (PEFshft) and original invaded zone resistivity (RXO) logs were shown on the crossplot. (b) After shifting the RXO log, PEFshft and depth-shifted invaded resistivity (RXOds) logs were plotted together to show the improvement of the correlation between these two logs

Figure 6 Karewa-1 (Zones A to H) well logs. On the right side, pink dashed line showed the original PEF log. PEFshft log (purple curve) is the depth-shifted PEF log. In the middle, RXOds (aqua solid line) log is the depth-shifted version of the invaded zone resistivity log (RXO log- blue dashed line). Arrows show how much depth-shift applied to the PEF and RXO logs. On the resistivity track, depth-shifted invaded zone resistivity (RXOds) shows better correlation with the true resistivity log (Rt). Similarly, the depthshifted PEF log (PEFshft) displayed better correlation with bulk density (FDC) and lithology-corrected neutron (PHIns) logs on the right side 15

Figure 7 Karewa-1 well (Zones A to H). (a) The crossplot of the neutron (TNPH)-density (FDC) logs displays the gas trend (solid circles) and high calcite cemented zone (zone Fhollow circles). (b) M-N crossplot shows the gas trend (solid circles), high calcite cemented zone (zone F-hollow circles), and secondary porosity (hollow triangles and cross signs) 18

Figure 8 Kahawai-1 well (Zone K, L, and M). (a) Neutron (TNPH)-density (FDC) logs crossplot shows the increasing gas saturation trend (solid circles). (b) M-N crossplot did 
not display the gas trend clearly because sonic log used to calculate "M" might be affected by cycle-skipping effects. Zone M (triangle signs) includes higher water saturation and approaches to the mineral points

Figure 9 Karewa-1 well (Zones A to H). (a) Apparent matrix grain density (Qmaa) and apparent matrix transit time $\left(\Delta \mathrm{t}_{\text {maa }}\right)$ MID crossplot displays the gas trend and calcite cemented zone (hollow circles). (b) Apparent matrix grain density (Qmaa) and apparent matrix volumetric cross section ( $\left.\mathrm{U}_{\mathrm{maa}}\right)$ MID crossplot indicates the gas effects and calcite cementation 20

Figure 10 Kahawai-1 well (Zones K, L, and M). (a) Apparent matrix grain density (@maa) and apparent matrix transit time $\left(\Delta \mathrm{t}_{\text {maa }}\right)$ MID crossplot shows the gas trend. Zone $M$ has less gas effects and approaches to the mineral points. (b) Apparent matrix grain density (Qmaa) and apparent matrix volumetric cross section $\left(\mathrm{U}_{\text {maa }}\right)$ MID crossplot exhibits increasing gas saturation points (solid circles) and increasing water saturation points (solid triangles) .23

Figure 11 Karewa-1 well (Zones A to H). PEF-FDC crossplot. Increasing density and PEF log values showed the calcite cementation zones (hollow circles). Higher gas saturation is seen with lower density values on the upper side

Figure 12 Kahawai-1 well (Zone K, L, and M). PEF-FDC logs crossplot displays slightly higher gas saturation points with solid circles

Figure 13 Kahawai-1 well (Zone K, L, and M). (a) Potassium (K)-PEF logs crossplot shows clay mineral type as illite and montmorillonite. (b) Potassium-thorium logs crossplot clearly proves that the clay minerals in thin gas formation are illite, primarily

Figure 14 Kahawai-1 well (Zone K, L, and M). Thorium-potassium ratio and the PEF log crossplot shows the points among illite, muscovite, and mixed layer (illite/montmorillonite) minerals

Figure 15 Karewa-1 well (Zones A to H). Comparison of the clay volumes from thin sections (VCLThin) and well logs (Vsh)

Figure 16 Karewa-1 well (Zones A to $\mathrm{H}$ ). Comparison of effective porosity from thin sections (PHIThinsect) and well logs (PHIe)

Figure 17 Karewa-1 (1930.9-2020m) and Kahawai-1 (1849.2-1852m) wells. Pickett plot to find the water resistivity ( $\mathrm{Rw}$ ) and cementation component (m). Arrows show the higher water saturation zones with different trends. More or less constant true resistivity and decreasing total porosity are attributed to a high calcite cementation zone. On the other hand, constant total porosity and dramatic decrease of true resistivity are thought to 
be the zones having ineffective dissolution porosity and some authigenic clay minerals

Figure 18 Karewa-1 well (Zones A to H). (a) The Thomas-Stieber crossplot for the clay type in the gas sand reservoir by thin section porosity (PHIThinsect) and clay volume (VCLThin). At four depths, the plot shows some dispersed and laminated shale. (b) The Thomas-Stieber crossplot for the clay type in the gas sand reservoir by well log porosity (PHIe) and clay volume (Vsh). The plots displays laminated shale in the formation. The Thomas-Stieber method is accurate when porosity is only decreased by shale. In zone $\mathrm{F}$ (hollow circles), calcite cementation decreased the porosity. There is no dispersed shale in zone $\mathrm{F}$ even though there seems to be some dispersed shale on the plot

Figure 19 Kahawai-1 well (Zone K, L, and M). The Thomas-Stieber crossplot by well log porosity (PHIe) and clay volume (Vsh) presents that shale in the gas formation is laminated. Zone L shows some dispersed shale which might result from the alteration of unstable minerals (feldspar minerals).....

Figure 20 Comparison of the non-Archie models with the Archie equation. (a) Karewa-1 well (Zones A to $\mathrm{H}$ ) water saturation models. (b) Kahawai-1 well (Zones K, L, and M) water saturation models. In both wells, the water saturation models gave similar results. The Dual Water model (asterisk signs) shows the lowest water saturation results in low irreducible water saturation zones (zones A, C, E, G, and K). The results of Indonesia and Archie models are similar. Simandoux and Schlumberger models give similar results, but differ from other three models 35

Figure 21 Karewa-1 well (Zones A to H). Lithology logs from different water saturation models show that zone B, D, and $\mathrm{H}$ are high water saturated zones. Other zones showed low water saturation results. Zone F exhibits higher rock volume which is interpreted as high degree of calcite cements 36

Figure 22 Kahawai-1 well (Zone K, L, and M). Lithology logs from different water saturation models. Zone L shows higher water saturation. Dramatic increase in water saturation is observed for zone $\mathrm{M}$ which is likely to be gas-water transition zone. Zone $\mathrm{K}$ showed minimum water saturation. Gas showings are misleading above zone $\mathrm{K}$ and below zone $\mathrm{M}$ due to the poor quality of well log measurements at those depths 36

Figure 23 Karewa-1 well (Zones A to H). Bulk volume water (BVW) plots (Swe from Schlumberger model) with lithology logs to observe the transition zone and irreducible water saturation levels. Big circle covering hollow circle points on the left shows high calcite cemented zone (zone F). Zone F (hollow circles) has minimum bulk volume water and shows similar bulk volume water values with other low irreducible water saturation zones (zones A, C, E, and G) symbolized with solid circles. On the other hand, another large circle on the left shows zones B, D, and $\mathrm{H}$ (hollow perpendicular, hollow triangle, and cross signs). These scattered points are caused by ineffective dissolution porosity (microporosity and secondary porosity). (a) Logarithmic scale. (b) Linear scale.... 
Figure 24 Dissolution of feldspar minerals (diagenesis) and forming of micro pores, secondary pores, and authigenic clay cements within pores

Figure 25 Karewa-1 well (Zones $\mathrm{A}$ to $\mathrm{H}$ ). Three thin section intergranular porosity (removed for secondary and micro pores in zones B, D, and $\mathrm{H}$ ) and water saturation from the Schlumberger equation adjusting the Rt $\log$ and effective porosity (dissolution porosity removed) were added to the bulk volume water plot to show the true places of the diagenetic zones (zones B, D, and $\mathrm{H}$ ). Before removing the dissolution porosity, these diagenetic zones (triangle, perpendicular, and cross signs) marked with a large circle on the right misleadingly correspond to mobile water or transition zone. Yet, after removing the dissolution porosity (known from thin sections at three depths), the true bulk volume water values of these zones marked with a large circle on the left are seen to be similar to low irreducible water saturation zones (solid circles and hollow circles). Removing ineffective dissolution porosity moved the points to lower bulk volume water values shown with an arrow. Logarithmic scale

Figure 26 Karewa-1 well (Zones A to $\mathrm{H}$ ). Three thin section intergranular porosity (removed for secondary and micro pores in zones B, D, and $\mathrm{H}$ ) and water saturation from the Schlumberger equation adjusting the Rt log and effective porosity (dissolution porosity removed) were added to the bulk volume water plot to show the true places of the diagenetic zones (zones B, D, and H). Linear scale

Figure 27 Kahawai-1 well (Zone K, L, and M). Bulk volume water (BVW) plots (Swe from Schlumberger model) with lithology logs to observe the transition zone and irreducible water saturation levels. Zone L (perpendicular signs) marked with a large circle shows constant bulk volume water values, affected by grain size. Smaller grain size (higher capillarity in the pores) caused high irreducible water saturation. On the other hand, drastic increase of bulk volume water shown with the arrow in zone $\mathrm{M}$ (triangle signs) indicates a typical transition zone. (a) Logarithmic scale. (b) Linear scale 47

Figure 28 Permeability results. Karewa-1 well for zones A to H. Permeability estimations from empirical models. Ktsch, Kmbgsch, Kcsch, Kcdsch, Ktairsch, Kmultisch, Kt, and Ktair are Timur, Morris-Biggs, Coates-Denoo, Coates-Dumanoir, air (converted from Timur permeability), multi-linear regression, Timur absolute (dissolution porosity removed), Air (dissolution porosity removed) permeability results calculated from the effective porosity and the irreducible water saturation of the Schlumberger model, respectively. Permeability results are high in zones A, C, E, and G whereas permeability results are too low in diagenetic zones (zones $\mathrm{B}, \mathrm{D}, \mathrm{F}$, and $\mathrm{H}$ ) 51

Figure 29 Permeability results. Kahawai-1 well for zones K and L. Permeability estimations from empirical models. Ktsch, Kmbgsch, Kcsch, Kcdsch, Ktairsch, and Kmultisch are Timur, Morris-Biggs, Coates-Denoo, Coates-Dumanoir, air (converted from Timur permeability), and multi-linear regression permeability results calculated from the effective porosity and the irreducible water saturation of the Schlumberger 
model, respectively. Within zone $\mathrm{M}$ (transition zone), permeability results are not reliable. Permeability results are high in zone $\mathrm{K}$

Figure 30 Flow zone indicator (FZI) plot. Karewa-1 (Zones A to H) and Kahawai-1 (Zones K and L) wells. FZI from Timur absolute permeability (Ktsch) found by Schlumberger water saturation equation. (a) Red color symbols show the low flow zone indicator values (diagenetic and smaller grain size rocks) whereas green color points display the high flow zone indicator values (high permeable and low irreducible water saturation zones). (b) It shows detailed version of the flow zone indicator plot 54

Figure 31 Karewa-1 well (Zones A to H). Winland (R35) plot. Pore throat size at 35\% mercury saturation (R35) from Timur air permeability (Ktairsch) (Logarithmic scale) 56

Figure 32 Kahawai-1 well (Zone K and M). Winland (R35) plot. Pore throat size at 35\% mercury saturation (R35) from Timur air permeability (Ktairsch) (Logarithmic scale) 56

Figure 33 (a) Karewa-1 well-permeability (K)-porosity $(\Phi)$ plot from Timur absolute permeability (Ktsch). Porosity-permeability ratio was dramatically reduced by diagenesis effects in zones B, D, F, and $\mathrm{H}$. After removing the dissolution porosity from the effective porosity, true places of the diagenetic zones (zone B, D, and $\mathrm{H}$ ) were indicated by an arrow. (b) Kahawai-1 well (Zone K and M) permeability (K)-porosity $(\Phi)$ plot from Timur absolute permeability (Ktsch). Zone L has a lower permeability-porosity ratio due to abundant smaller grain size and pore throat size 59

Figure B-1 Kahawai-1 well (Zone K, L, and M)-Potassium-thorium logs crossplot (different version)

Figure B-2 Kahawai-1 well (Zone K, L, and M)-Potassium-thorium logs crossplot..... 73

Figure C-1 The mean grain size determination from bulk volume of water using the table created by Asquith (1985) 82

Figure D-1 Karewa-1 well (Zones A to H). PEF log and Timur permeability (Ktsch) found by the Schlumberger water saturation results. The diagenetic minerals (displaying higher PEF values) in the zones (Zones B, D, F, and $\mathrm{H}$ ) decreased the permeability 90

Figure E-1 Karewa-1 well (Zones A to H). Pittman (R35) plot. (a) Pore throat size at 35\% mercury saturation (R35) from Timur air permeability (Ktairsch) (Linear lines) ......... 93

Figure E-2 Kahawai-1 well (Zone K and M). Pittman (R35) plot. (a) Pore throat size at $35 \%$ mercury saturation (R35) from Timur air permeability (Ktairsch) (Linear lines) . 93 


\section{List of Tables}

Table 1 Zone names and depths......................................................................... 7

Table 2 Estimated water saturation parameters ......................................................... 31

Table 3 Estimated shale properties from nearby shale formation ............................. 33 


\section{List of Abbreviations}

$\mathrm{a}$

BIT

BVI

BVW

CGR

CLD

DRH

DTC

FDC

FZI

GRI

$\mathrm{GR}_{\max }$

$\mathrm{GR}_{\min }$

$\mathrm{I} G R$

$\mathrm{K} \%$

$\mathrm{K}_{\text {air }}$

$\mathrm{K}_{c}$

$\mathrm{K}_{c d}$

$\mathrm{K}_{m b g}$

$\mathrm{K}_{t}$

LLD

LLS
Tortuosity component

Bit size

Bulk volume water irreducible

Bulk volume water

Computed gamma-ray

Caliper log

Density $\log$ correction

Sonic $\log$

Density $\log$

Flow Zone Indicator

Gamma ray log

Maximum gamma ray value for shale zone

Minimum gamma ray value for clean zone

Gamma ray index (linear)

Potassium log

Air permeability

Coates-Denoo gas absolute permeability

Coates-Dumanoir gas absolute permeability

Morris-Biggs gas absolute permeability

Timur gas absolute permeability

Laterolog deep resistivity

Laterolog shallow resistivity 
$\mathrm{m}$

$\mathrm{n}$

$\Phi_{\mathrm{d}}$

$\Phi_{\mathrm{dc}}$

$\Phi_{\mathrm{dsh}}$

$\Phi_{\mathrm{e}}$

$\Phi_{\mathrm{N}}$

$\Phi_{\mathrm{NC}}$

$\Phi_{\mathrm{Nf}}$

$\Phi_{\mathrm{NS}}$

$\Phi_{\mathrm{NSH}}$

$\Phi_{\text {thinsect }}$

$\Phi_{\mathrm{t}}$

$\Phi_{\text {ta }}$

$\Phi_{\mathrm{Z}}$

$\Phi_{\mathrm{tsh}}$

PEF

$\mathrm{PEF}_{\text {shft }}$

$\varrho_{b}$

$\varrho_{f}$

$\varrho_{e}$

$\varrho_{g}$
Cementation component

Saturation component

Density $\log$ porosity

Clay-corrected density log porosity

Density porosity of shale

Effective porosity (clay corrected)

Neutron porosity for water-saturated limestone

Clay-corrected neutron log porosity

Neutron porosity of the fluid

Neutron porosity (lithology corrected)

Neutron porosity of shale

Porosity from thin section data

Total porosity

Apparent total porosity

Normalized porosity

Total shale volume from density and neutron logs

PEF log

Depth-shifted PEF log

Bulk density of the formation

Density of the formation fluid

Electron density

Gas density 


\begin{tabular}{|c|c|}
\hline Qmaa & The apparent matrix density \\
\hline $\mathrm{t}_{\text {maa }}$ & The apparent matrix transit time \\
\hline R35 & Port size \\
\hline $\mathrm{R}_{\mathrm{b}}$ & Resistivity of clay bound water \\
\hline $\mathrm{R}_{\mathrm{cl}}$ & Resistivity of nearby clean water formation \\
\hline RHOC & Corrected density log \\
\hline RQI & Reservoir Quality Index \\
\hline $\mathrm{R}_{s h}$ & Shale resistivity at adjacent shale \\
\hline $\mathrm{R}_{\mathrm{w}}$ & Resistivity of the formation water \\
\hline $\mathrm{R}_{\mathrm{wa}}$ & Apparent water resistivity of the reservoir \\
\hline RXO & Invaded zone resistivity \\
\hline RXOds & Depth-shifted invaded zone resistivity \\
\hline SGR & Spectral gamma-ray \\
\hline Swarchie & Archie water saturation \\
\hline $\mathrm{Swe}_{\text {sim }}$ & Simandoux water saturation \\
\hline $\mathrm{Swe}_{s c h}$ & Schlumberger water saturation \\
\hline $\mathrm{Swe}_{\text {ind }}$ & Indonesia water saturation \\
\hline $\mathrm{Sw}_{\text {dual }}$ & Dual-Water saturation (total) \\
\hline $\mathrm{Swe}_{\text {dual }}$ & Dual-Water saturation (effective) \\
\hline Swi & Irreducible water saturation \\
\hline $\mathrm{t}$ & Sonic log transit time \\
\hline$t_{f}$ & Transit time of the formation fluid \\
\hline THOR & Thorium log \\
\hline
\end{tabular}


TNPH

$\mathrm{U}_{\mathrm{f}}$

$\mathrm{U}_{\text {maa }}$

URAN

VCLThin

$\mathrm{V}_{\text {sh }}$

W
Neutron log (limestone)

Volumetric section of the fluid

Apparent matrix volumetric cross section

Uranium log

Clay volume from thin section data

Clay volume from Larianov (tertiary rocks)

Textural component 


\section{Acknowledgements}

I would like to state my greatest respect and appreciation to my advisor, Dr. Wayne D. Pennington for his guidance, expertise and patience during my graduate years and this study. His thoughts and concerns about my thesis helped me to shape my study. The discussions that I have done with him and his encouraging attitude to me made this research possible.

I am also very thankful to my committee members Dr. Mir Sadri and Dr. Gregory P. Waite who shared their thoughts and supported me throughout my graduate years and this master research.

I owe many thanks to GNS Science Data Portal for providing the data and to LR Senergy for the use of their software called "Interactive Petrophysics" allowing me to analyze my data in this study.

My fiancé and my best friend always encouraged and believed me to finish this work. To have you in my life feels me peaceful and assists me succeed.

Most importantly, I would like to show my deep gratitude to my parents and my brothers, who always loved and supported me. I am really lucky to have you all in my lifetime. 


\begin{abstract}
The goal of this study was to evaluate permeability and study the controls on permeability in a gas saturated formation. Conventional well logs, mineral identification crossplots and empirical models were applied to analyze different lithologic and diagenetic features and to examine the effect that these features may have on the reservoir. An unusual feature was observed, and required detailed examination: there existed (in two wells) five zones of lower resistivity (higher water saturation) above the gas-water contact. This is unexpected, as above that contact, the water is usually at irreducible water saturation. I conclude that the lower resistivity (the higher water saturation) is due to unusual mineralogy containing small grain size, ineffective microporosity and secondary porosity within specific grains, and support this conclusion with a variety of indicators.
\end{abstract}

Two wells in New Zealand's Taranaki Basin were used for this study. First, various routinely applied methods were used to assign the boundaries of the gas-saturated zones of the Mangaa C-1 sandstone and to identify the mineralogy. From Archie and non-Archie (Simandoux, Schlumberger, Indonesia, and Dual-Water) models, four subzones in Karewa-1 well and two subzones in Kahawai-1 well were recognized as high water saturation intervals within the Mangaa C-1 gas saturated formation.

The analysis of saturation can be used to identify grain size (and pore size) distribution, which turned out to be critical in understanding the high water saturation zones. Bulk volume water analysis was used together with created lithology logs and with core descriptions that had been made available to recognize the detrimental diagenetic zones 
in the gas formation. Dissolution of minerals, grain size distributions, and different pore type characteristics increase bulk volume water in high water saturation zones while keeping the formation at irreducible water saturation, but at levels that are elevated in comparison with higher-quality (and lower irreducible water saturation) zones both above and below.

The various irreducible water saturation zones were then used to predict the absolute permeability of those zones using several empirical models. Then, different flow unit characterization methods were applied to better understand the different quality rocks within the formation. One approach represents a new attempt to compare results for pore size classifications. My results showed that diagenesis is more detrimental to reservoir quality than grain size within the Mangaa $\mathrm{C}-1$ gas sandstone, and that there is no transition or fully-water saturated zone under the gas reservoir at Karewa-1 well, while the transition zone exists for the same formation at Kahawai-1 well. 


\section{Introduction}

The Taranaki Basin, New Zealand hosts well known oil and gas reservoirs. These reservoirs are still being explored for potential hydrocarbon plays including detailed analysis of existing seismic and wireline log data. This study details petrophysical analysis of a shaly-sand gas reservoir. In particular, there are anomalies in the wireline logs that suggest unusual mineralogy. Two wells were analyzed in this study using suitable $\log$ measurements for the Mangaa C-1 shaly sand formation in the Taranaki Basin, New Zealand. This formation consists of mainly quartz in addition to plagioclase feldspar, K-feldspar, lithic fragments and considerable amount of clay minerals (mainly illite, chlorite, and mixed layers) (Karewa-1 well completion reports, 2002-2003).

The key problem investigated here is the existence of multiple low-resistivity zones within the neutron-density crossover, which at first glance, seem to be water-producing zones. But the reasons might be different and critical to identify different petrophysical parameters in this study. Higher capillary bound water, smaller grain size, lower pore size, poor sorting, higher clay content, diagenesis, the existence of some mobile water as the non-wetting fluid, the mobile water occluding the pores in the transition zone of the hydrocarbon reservoir, or any combination of those reasons could result in low resistivity zones (higher water saturation zones). The aim of the study is to understand the reasons of unusual low resistivity zones (higher water saturation zones) within the gas formation at irreducible water saturation by means of the combination of well logs and thin sections. According to the core descriptions at three different depths in the Karewa-1 well, clay minerals and diagenesis effects in the Mangaa $\mathrm{C}-1$ formation played a significant role in 
reservoir quality (Karewa-1 well completion reports, 2002-2003). Empirical models were used to identify lithology and pore type characteristics in this gas saturated zone to determine all diagenetic zones, the effects of the diagenesis on the well log responses and the reservoir quality. Gamma-ray (GRI, CGR, or SGR), density (FDC or RHOB), neutron (TNPH), resistivity (LLD, LLS, and MSFL), and photo-electric factor (PEF) are the main logs used in carrying out mineralogical and petrophysical analysis of the Mangaa C-1 gas sandstone.

In general, conventional well logs include neither nuclear magnetic resonance logs nor core permeability information to predict pay zones and quality of reserves. Use of conventional logs to determine irreducible water saturation (Swi) and effective porosity of the shaly sand gas reservoir will assist in calculating the absolute permeability of the Mangaa C-1 gas formation. Applied shaly sand non-Archie models in addition to the Archie equation to the shaly sand formation demonstrated that there are four intervals at different depths which have high water saturation values encountered in Karewa-1 well and two zones of high water saturation values found at various depths of Kahawai-1 well.

Bulk volume water analysis combined with lithology logs was applied to interpret the reasons for high water saturation zones and irreducible water saturation zones by well logs because different reasons will change the reliability of the absolute permeability estimations of the Mangaa C-1 gas sandstone. 
Different flow unit methods were used to classify different pore type zones of the gas reservoir. Using the Winland empirical model was a first attempt to characterize the flow units by using well logs rather than using core permeability and porosity.

\section{Geology of Mangaa C1 Sandstone Formation}

The Mangaa C-1 formation is an abyssal fan complex of sandstone of the latest Miocene to the earliest Pliocene age (King Thrasher, 1996). These fans provide massive sand beds formed by turbidity currents. The overlying Intra Giant Foresets Marker is a shale formation which seals the Mangaa C-1 formation and the underlying Mohakatino formation is volcanic (Hansen Kamp, 2002).

The Karewa-1 and Kahawai-1 wells were drilled in the northern part of the North Taranaki Graben seen below (Figure 1).

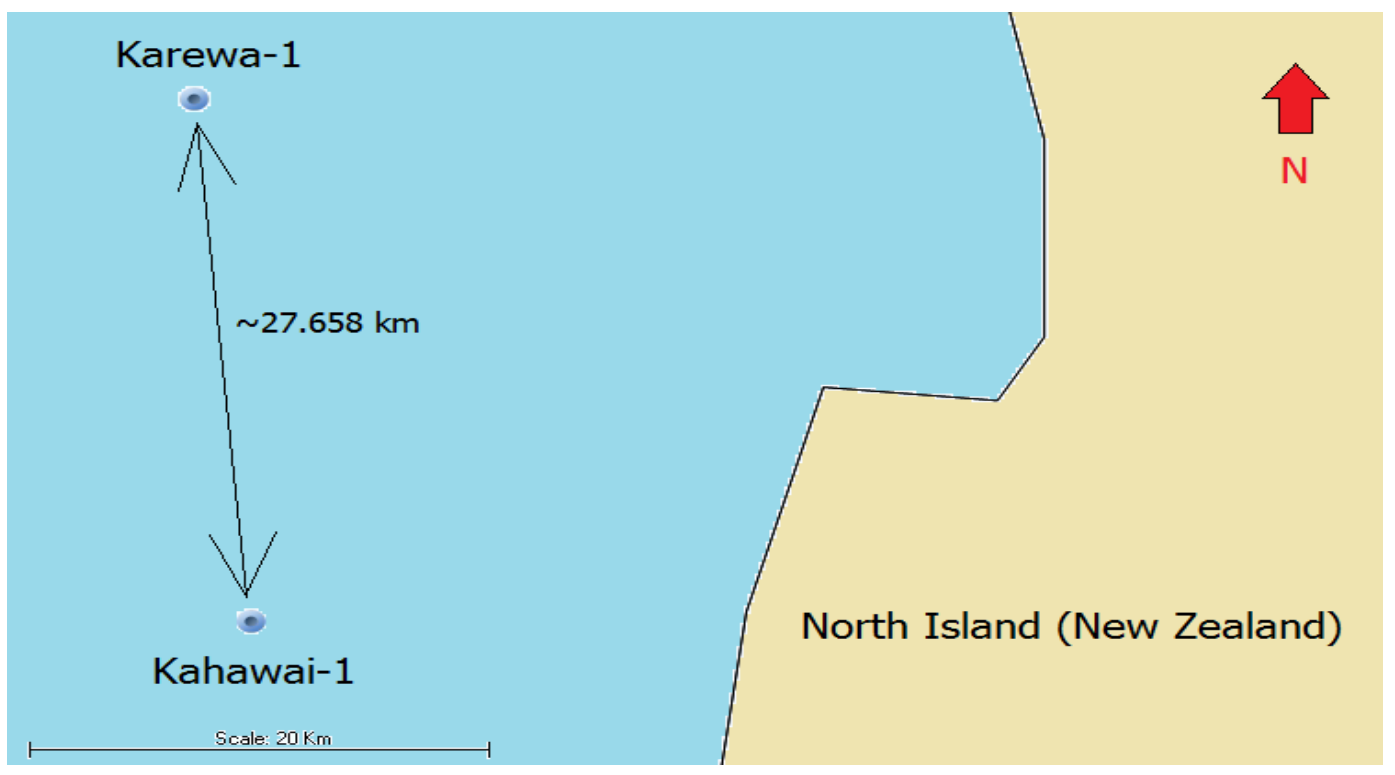

Figure 1 The location map of the two wells in Taranaki Basin, New Zealand. 
At the Karewa-1 well, the formations and markers from the top to the bottom are Whenuakura, Giant Foresets, Plio-Pleistocene Marker, Intra Giant Foresets Marker, Mangaa C-1, and Intra Mangaa C-1 Marker (Karewa-1 well completion reports, 20022003). At the Kahawai-1 well, Whenuakura, Giant Foresets, Mangaa C-1, and volcaniclastic Manganui formations were encountered (Kahawai-1 well completion report, 1990).

The permeability was not measured in either well encountering the Mangaa C-1 sandstone formation. In this study, I will attempt to predict reliable permeability results from well logs.

Almost eighty meters of the Mangaa C-1 sandstone is brine-saturated. On average, ten meters of the formation on the upper part have the potential gas bearing zone with no oil. This dry gas shows biogenic features with $98 \%$ methane, with small amount of ethane and propane (Karewa-1 well completion reports, 2002-2003).

At the Karewa-1 well, the Mangaa C-1 formation (1930-2020m) consists of very fine to fine grained argillaceous sandstone with interbedded silt and clay formations (King \& Thrasher, 1996). According to the thin section data of the core descriptions, the gas saturated part of the Mangaa C-1 formation (1930-1942m) in the Karewa-1 well has mainly quartz minerals with abundant feldspar minerals, lithic fragments, and some amount of clay minerals (illite minerals dominantly) (Karewa-1 well completion reports, 2002-2003). Rather than argillaceous sandstone, the Mangaa C-1 gas saturated formation 
was classified as arkose or lithic arkose depending on the volumes of feldspar minerals and lithic fragments in addition to quartz content observed on the thin section data (Karewa-1 well completion reports, 2002-2003).

According to the Bowen's reaction series, the presence of unstable minerals (feldspar minerals) within the Mangaa C-1 gas sandstone means conditions are favorable for diagenesis because these minerals will tend to transform to the more stable minerals (quartz, K-feldspar, illite, etc.) at low pressure and temperature conditions (Ali Sa, 2010). Abundant plagioclase minerals and K-feldspar minerals from the thin sections show the possibility of diagenesis. Lithic fragments also contained some K-feldspar minerals which might affect the well logs, misleading routine interpretations (Karewa-1 well completion reports, 2002-2003).

At the Kahawai-1 well, the Mangaa C-1 formation is composed mostly of shale with some interbedded sandstone and siltstone. In the gas saturated zone $(1849-1852 \mathrm{~m})$, the mineral composition was defined as fine grained lithic feldsarenite of the granite origin (Kahawai1 well completion report, 1990). The gas formation is poorly sorted and includes high authigenic clay cementation (Kahawai-1 well completion report, 1990).

The diagenesis effects at some depths within the Mangaa C-1 gas saturated formation in the Karewa-1 well were confirmed by the thin sections (Kahawai-1 well completion report, 1990). I will recognize the diagenesis effects on well logs and will show how these features affect reservoir quality. 


\section{Methodology}

To apply the shaly sand analysis to the Mangaa C-1 gas saturated sandstone, formation tops were located and mineral identification of the gas reservoirs was conducted. The clay volume found by the gamma-ray log was calibrated by means of the Larianov-young rocks equation (Larianov, 1969). The porosity of the gas reservoir is corrected for the clay in order to distinguish the effective porosity from the total porosity.

Among several wells encountering the Mangaa C-1 formation, two wells, Karewa-1 and Kahawai-1 have hydrocarbon-bearing zones. Gamma-ray, density, neutron, resistivity, and photo-electric factor logs were used to determine the gas saturated zones and the mineralogy of the reservoir at these two wells. The Thomas-Stieber method (1975) for both wells and crossplots of spectral gamma ray logs for Kahawai-1 well were applied to identify the clay types (laminated, dispersed, and/or structural) and clay minerals (illite, chlorite, montmorillonite, kaolinite, etc.), respectively. Considering the Mangaa C-1 gas sandstone as "shaly sand", non-Archie shaly sand water saturation models were used to estimate the effective water saturation.

Bulk volume water analysis was carried out for distinguishing the irreducible water saturation zones from other zones by including the lithology logs and core information within the gas formation at two wells. Then, absolute permeability predictions and flow unit characterizations were applied to identify different pore types, diagenetic zones, transition zone, and irreducible water saturation zones and to better classify the reservoir quality within the gas formation. 


\subsection{Zones and Depth Shifts}

The Mangaa C-1 gas saturated formation in the Karewa well was divided into several zones (Zones A to M), using the gamma-ray, density, neutron, PEF, and resistivity logs, knowing the expected diagenesis effects, and different features from the core description at some points. Zones A, C, E, and G have high resistivity, high porosity, and low PEF values whereas Zones $\mathrm{B}, \mathrm{D}$, and $\mathrm{H}$ have low resistivity, high porosity, and high PEF values. Zone F has high resistivity, low porosity, and high PEF values.

Table 1 Zone names and depths.

\begin{tabular}{|l|l|}
\hline Zones with Well Names & Depth Intervals (meters) \\
\hline Zone A (Karewa-1) & $1930.9-1932.6$ \\
\hline Zone B (Karewa-1) & $1932.6-1933.2$ \\
\hline Zone C (Karewa-1) & $1933.2-1934.4$ \\
\hline Zone D (Karewa-1) & $1934.4-1935.3$ \\
\hline Zone F (Karewa-1) & $1935.3-1936.6$ \\
\hline Zone G (Karewa-1) & $1936.6-1937.5$ \\
\hline Zone H (Karewa-1) & $1937.5-1940.0$ \\
\hline Zone K (Kahawai-1) & $1940.0-1941.4$ \\
\hline Zone L (Kahawai-1) & $1849.2-1850.9$ \\
\hline Zone M (Kahawai-1) & $1850.9-1852.0$ \\
\hline
\end{tabular}


On the other hand, the Mangaa C-1 gas formation in the Kahawai-1 well was divided into three zones (Zones $\mathrm{K}, \mathrm{L}$, and $\mathrm{M}$ ) by using the deep resistivity $\log$. Zones $\mathrm{K}$, L, and M show high, low, and quite low resistivity values, respectively.

Borehole and invasion corrections were not necessary in the gas formation because these effects were not observed at the Karewa-1 well.

A gas reservoir is seen by the neutron-density crossover at the Karewa-1 well (Figure 2). Zones B, D, and $\mathrm{H}$ at the Karewa-1 well were identified as low resistivity zones within the Mangaa C-1 formation whereas zones A, C, E, F, and G showed consistently high resistivity values, which, at first glance, were thought to have similar lithology and gaswater concentrations. Yet, zone F indicated quite high density and PEF values which result from the high degree of calcite cementation (Figure 2).

Also, density-neutron crossover and high resistivity are seen for the thin Mangaa C-1 formation in the Kahawai-1 well (Figure 3). Zone K at the Kahawai-1 well showed the highest resistivity results in comparison to zones L and M. Neutron-density crossover continues within zone L even though this zone has low resistivity. This low resistivity zone (zone L) shows similar well log responses to zone B, D, and H in the Karewa-1 well in terms of gamma-ray, resistivity, and neutron-density crossover. Dramatic increase of neutron $\log$ and gradual decrease of true resistivity curve are shown within zone $\mathrm{M}$ (Figure 3). 


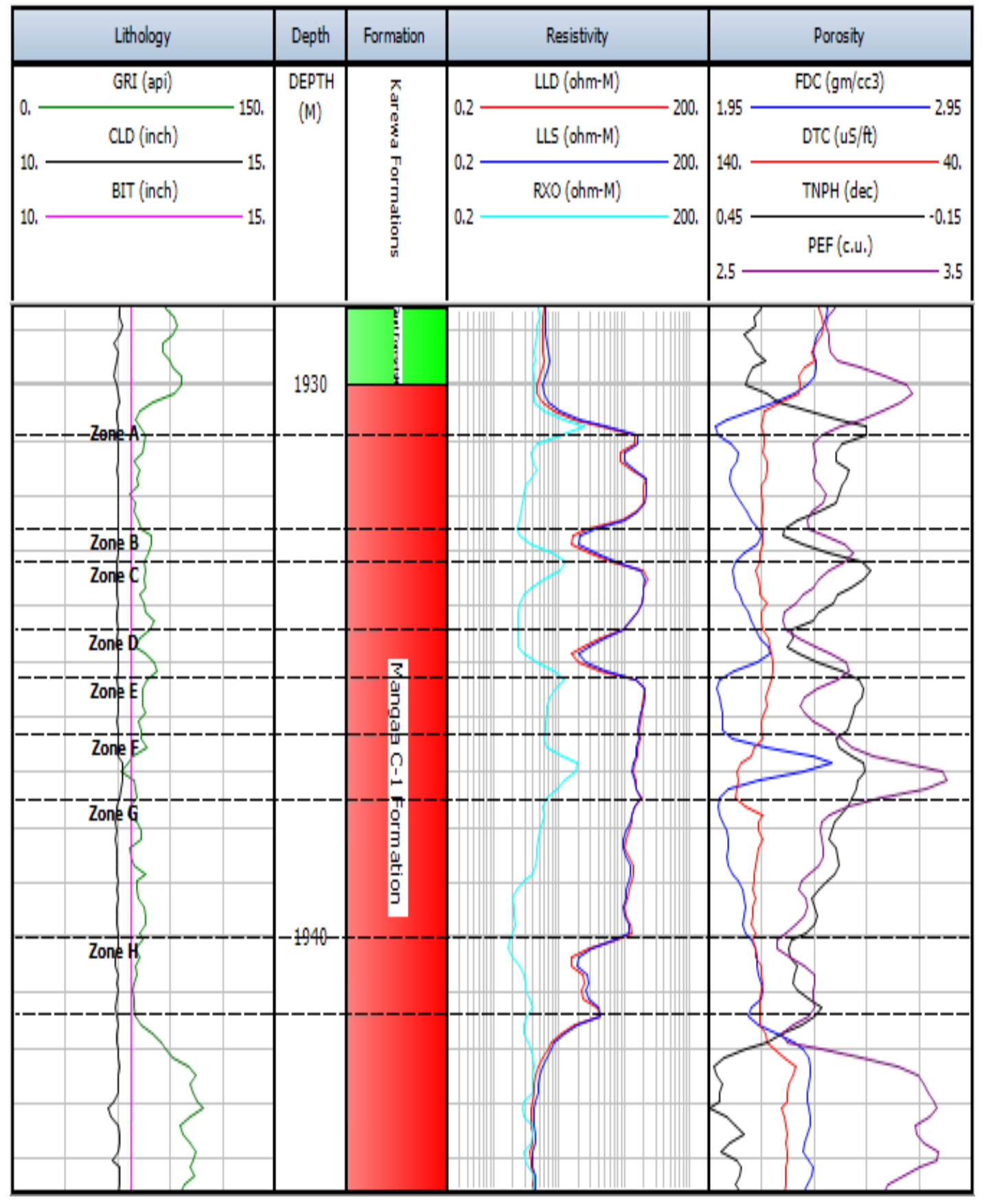

Figure 2 Full log suite of the Karewa-1 well (1930.9-1941m). On the left side, gammaray (GRI), caliper (CLD), and bit size (BIT) curves were shown whereas in the middle, uninvaded deep lateralog (LLD), shallow lateralog (LLS), and invaded zone resistivity (RXO) logs were plotted together. On the right side, bulk density (FDC), sonic compressional (DTC), neutron (TNPH), and photo-electric factor (PEF) logs were indicated. 


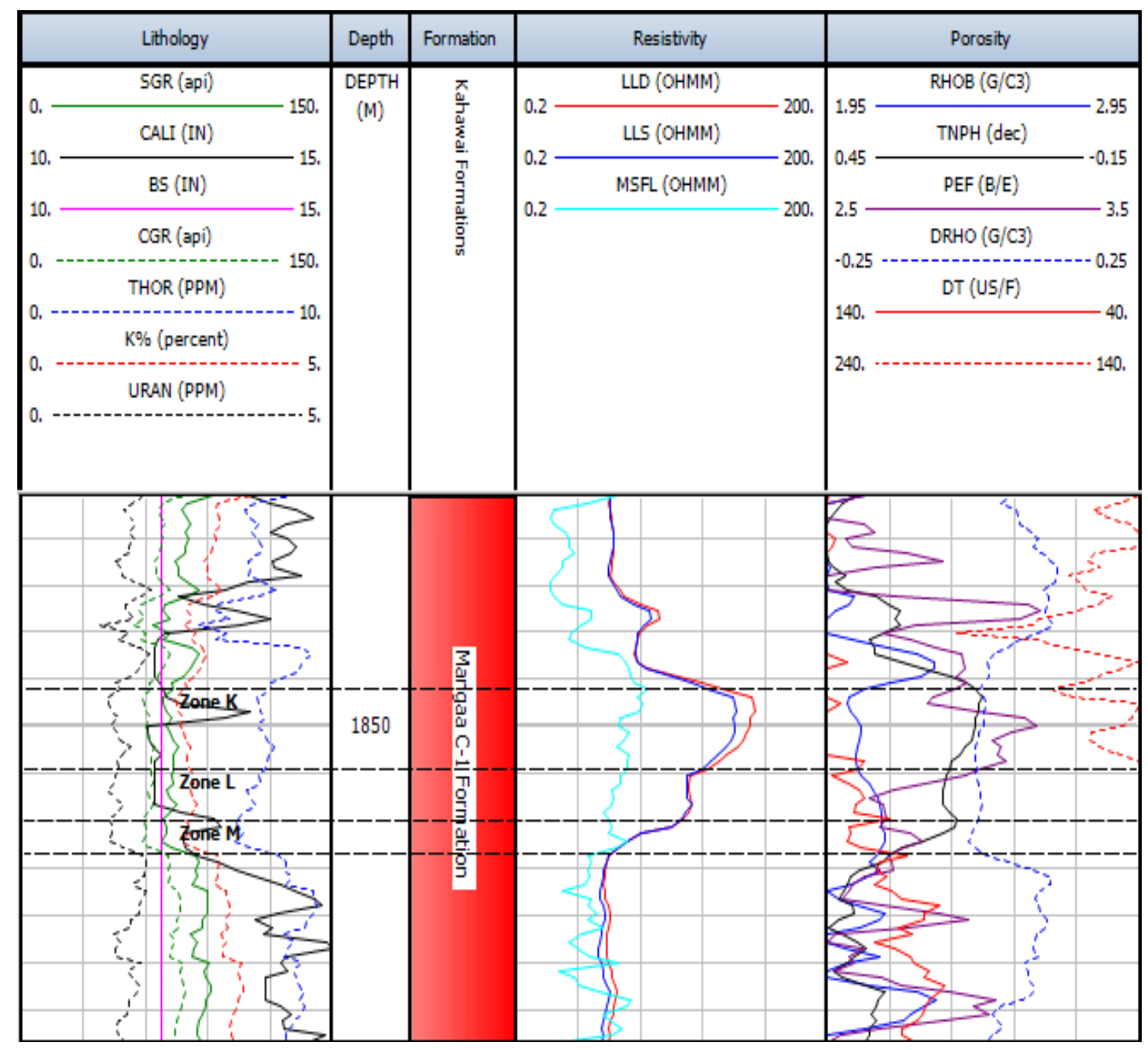

Figure 3 Full log suite of the Kahawai-1 well (1849.2-1852.7m). On the left track, standard gamma-ray (SGR), computed gamma-ray (CGR), caliper (CALI), bit size (BS), and three spectral gamma-ray (thorium (THOR), potassium (K), and uranium (URAN)) curves were displayed, while in the middle track, deep lateralog (LLD), shallow lateralog (LLS), and micro-spherical focused (MSFL) logs were shown. On the right track, bulk density (RHOB), sonic compressional (DT), neutron (TNPH), and photoelectric factor (PEF) logs were demonstrated.

In addition to the standard gamma ray log, the computed and spectral gamma ray logs were measured at the Kahawai-1 well and were useful in identifying the clay minerals and the clay volume more precisely. 
Initial observations indicated that depth-corrections of logs (as provided) were not accurate, and not all logs were properly depth-registered. Mostly, PEF and density logs are linearly correlated to each other, but sharp changes in these two logs were not seen at same depths. These changes in the PEF log have delays in comparison to the changes in the density log. Similarly, sharp changes in the invaded zone resistivity and true resistivity logs were expected to be at the same depths.

According to my observations, at three low resistivity zones (zones B, D, and H), higher invaded zone resistivity values were seen due to the salinity difference between mud filtrate and formation water in isolated dissolution pores (Figure 2). Especially, sharp increases in the invaded zone resistivity values were observed at zones B and D. This proves that the mud filtrate could not push all water from the pores because invaded zone resistivity values in these low resistivity zones are higher than other zones. According to this study, water in the isolated pores is fresher than the mud filtrate. More importantly, this study proves that the invaded zone resistivity log is a powerful tool to identify the ineffective micro pores and secondary pores within the low resistivity hydrocarbon bearing zones.

These two low resistivity zones and high invaded zone resistivity values do not match perfectly and depth-shift of the RXO is needed in addition to the depth-shift of the PEF $\log$. 
Use of density in detail helped to apply depth-correction to PEF $\log$ (Figure 4). Uninvaded zone resistivity $\log (\mathrm{RXO})$ was also depth-shifted with a reference log (Rt) (Figure 6). After the depth-correction of these two logs, all main logs in Karewa-1 well showed consistency with each other.

Zones A, C, E, and G were identical to each other, but were different from the diagenetic zones $(\mathrm{B}, \mathrm{D}, \mathrm{F}$, and $\mathrm{H})$, in terms of well log measurements. Consistent high resistivity, low gamma-ray, low bulk density, low neutron porosity, and low PEF values are attributed to high productive gas saturated zones (Figure 6). Diagenesis effects (dissolution and alteration of the minerals, ineffective microporosity or secondary porosity) were not expected in these zones (A, C, E, and G).

Even though almost the entire gas formation consists of shale (suppressing the resistivity $\log$ ) in both wells, some zones (zone B, D, H, and L) showed even lower resistivity values in the formations. The reasons for low resistivity zones might be ineffective dissolution porosity, authigenic clay cements, small grain size, or transition zone in this formation. Different petrophysical analysis will assist find the reasons of low resistivity values in zones $\mathrm{B}, \mathrm{D}, \mathrm{H}$, and $\mathrm{L}$.

After lithology-correction of neutron log, and depth-shifts of PEF and invaded zone resistivity (RXO) logs in the Karewa-1 well, different characteristics of each zone were shown more precisely (Figure 6). 


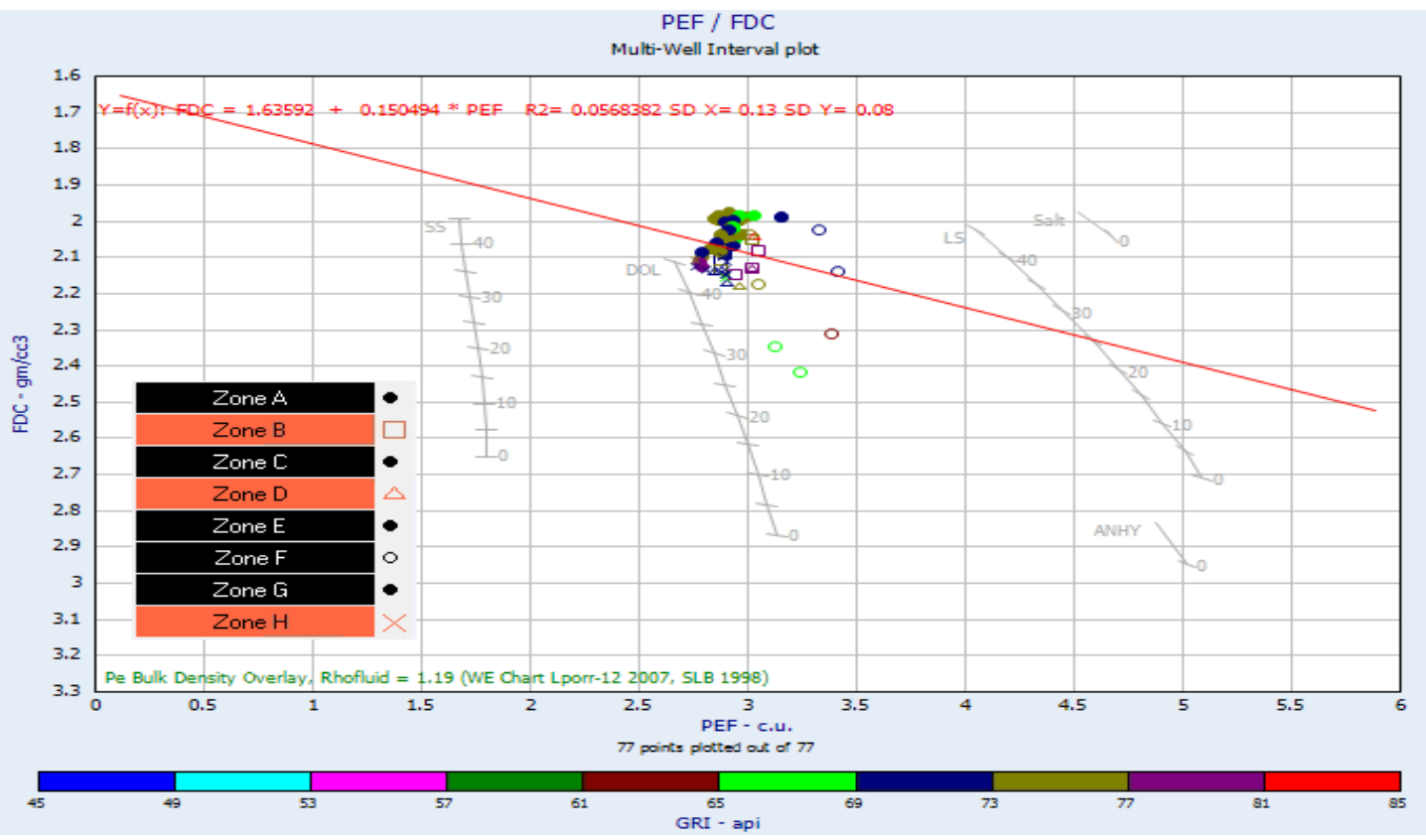

(a)

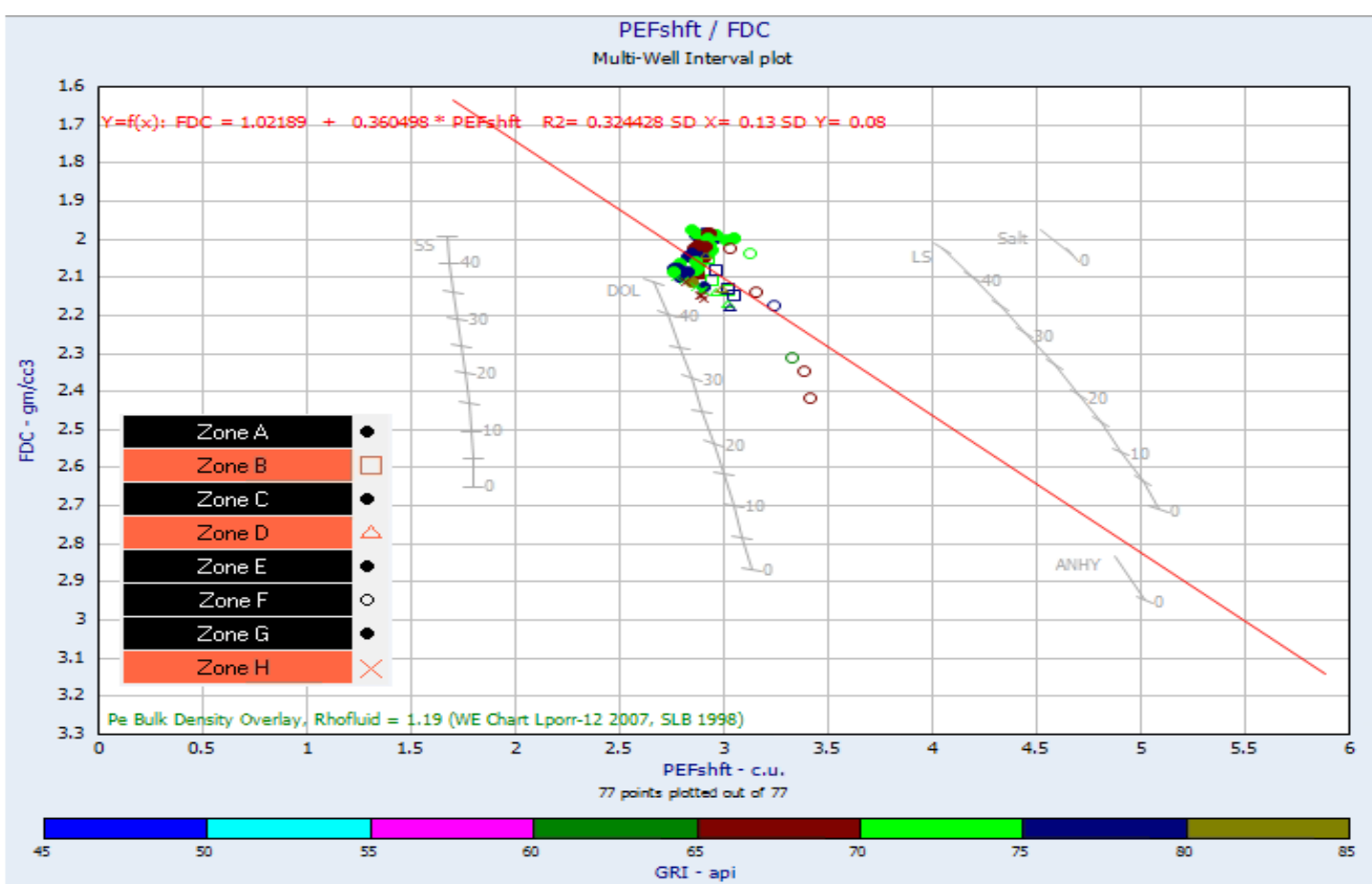

(b)

Figure 4 Karewa-1 well. (a) Original PEF and FDC logs were plotted. (b) After shifting the PEF log, depth shifted PEF log (PEFshft) and FDC logs were plotted. Correlation of these two logs were improved after depth-correction was applied. 


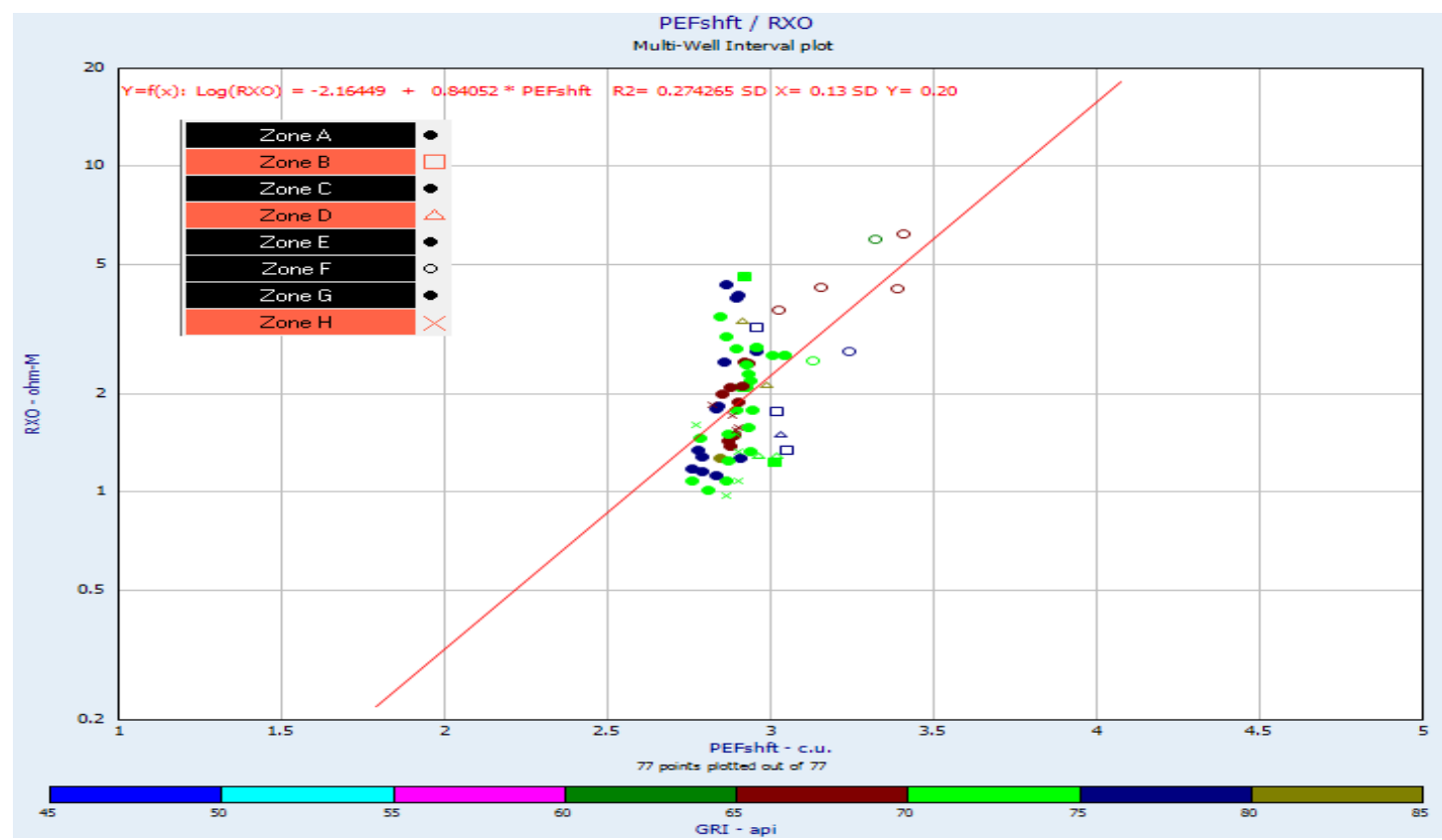

(a)

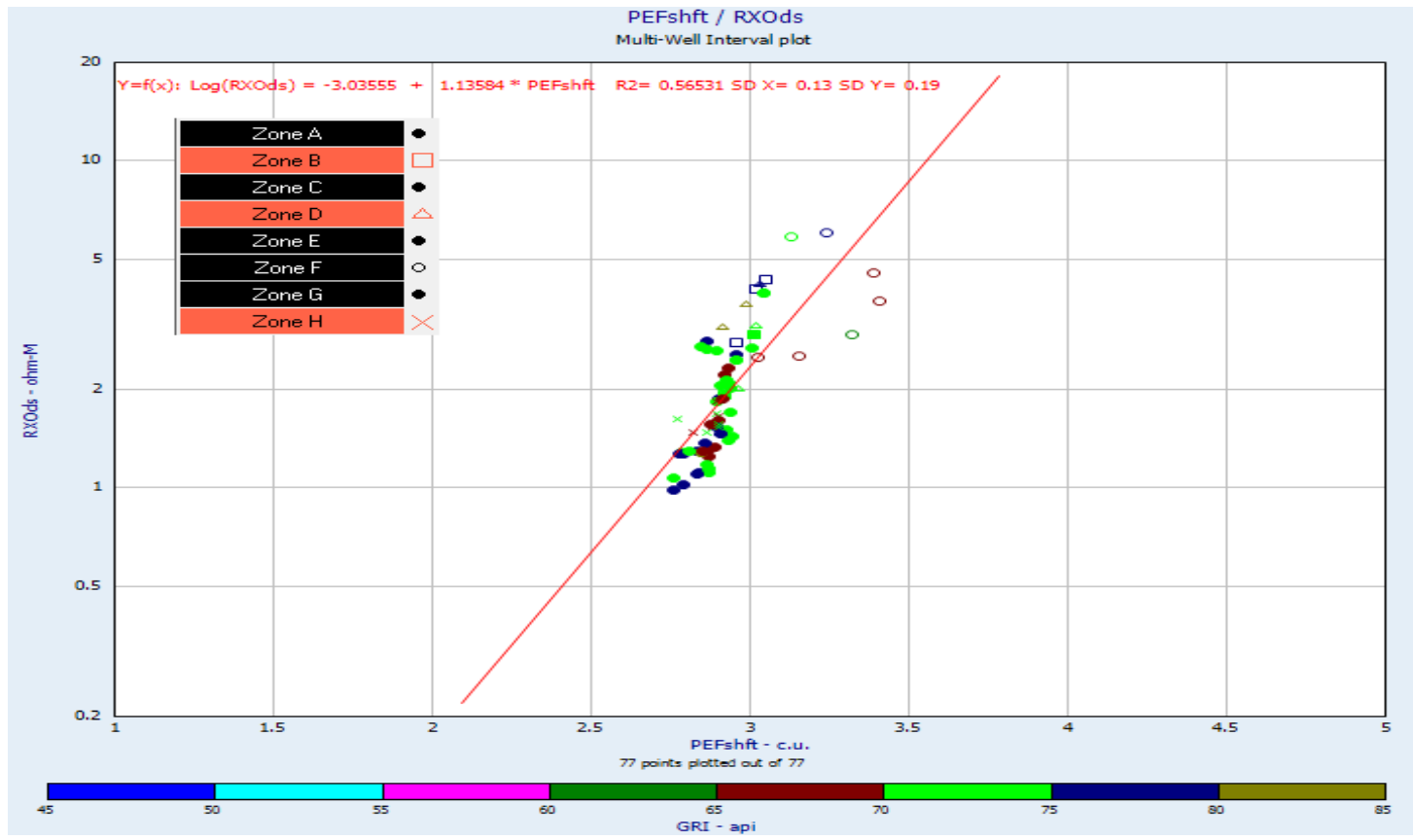

(b)

Figure 5 Karewa-1 well. (a) Depth-shifted PEF (PEFshft) and original invaded zone resistivity (RXO) logs were shown on the crossplot. (b) After shifting the RXO log, PEFshft and depth-shifted invaded resistivity (RXOds) logs were plotted together to show the improvement of the correlation between these two logs. 


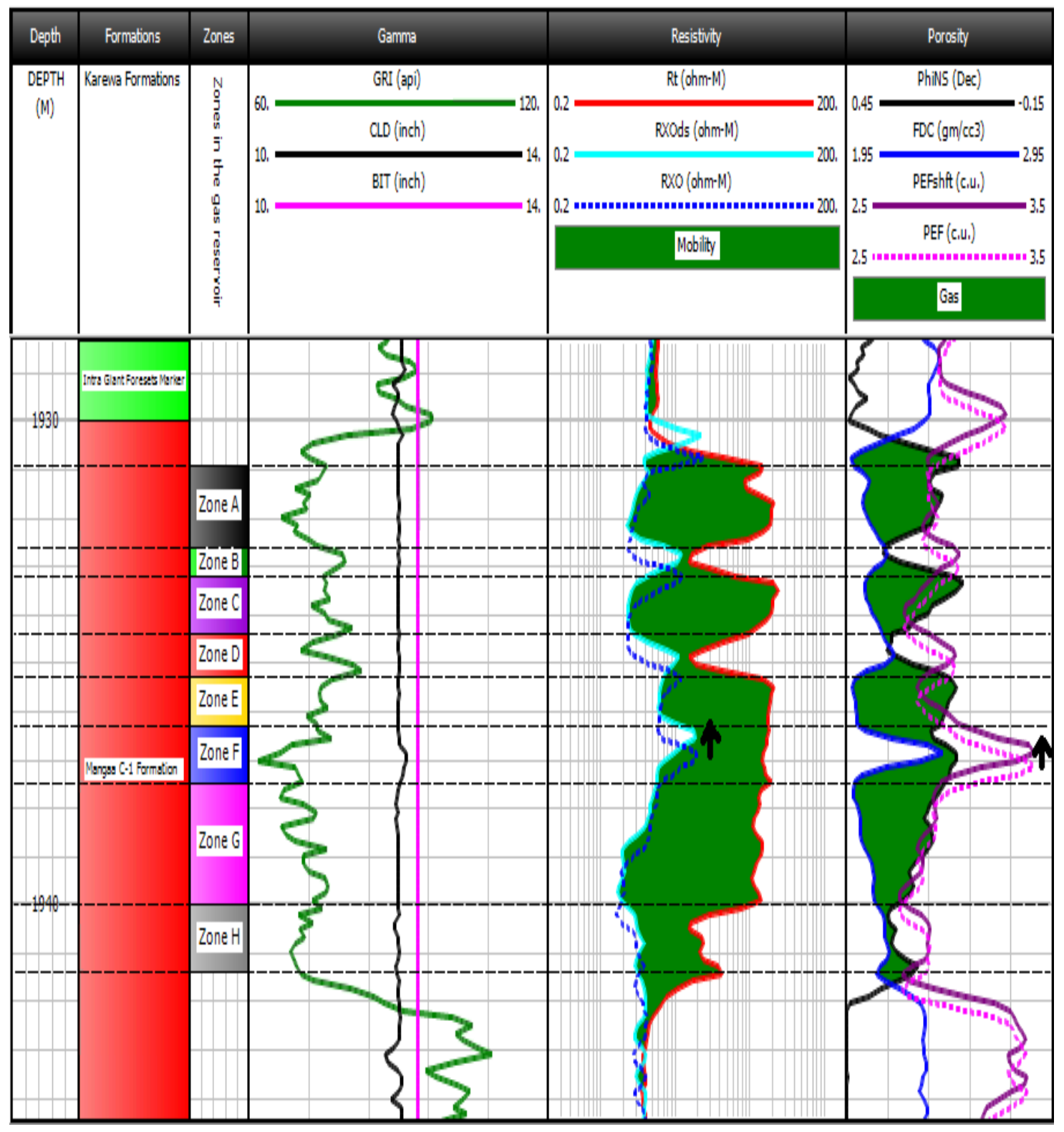

Figure 6 Karewa-1 (Zones A to H) well logs. On the right side, pink dashed line showed the original PEF log. PEFshft log (purple curve) is the depth-shifted PEF log. In the middle, RXOds (aqua solid line) log is the depth-shifted version of the invaded zone resistivity log (RXO log- blue dashed line). Arrows show how much depth-shift applied to the PEF and RXO logs. On the resistivity track, depth-shifted invaded zone resistivity (RXOds) shows better correlation with the true resistivity log (Rt). Similarly, the depthshifted PEF log (PEFshft) displayed better correlation with bulk density (FDC) and lithology-corrected neutron (PHIns) logs on the right side. 


\subsection{Mineral Identification Crossplots}

Different kinds of crossplots can be useful in observing gas and mineralogy effects in the Mangaa C-1 gas sandstone at the Karewa-1 and Kahawai-1 wells.

From the density-neutron crossplot, a gas trend is seen at Karewa-1 well (Figure 7a). Zones B, D, F, and H in Karewa-1 well contained higher water saturation than zones A, $\mathrm{C}, \mathrm{E}$, and $\mathrm{G}$. The points (hollow circles) in zone $\mathrm{F}$ which were interpreted as highly calcite cemented zone approached the sandstone line on the neutron-density crossplot (Figure 7). This is because the calcite cementation narrows the pores by coating the framework grains. By doing that, zone F will have smaller pores, lower porosity and will keep more water because of the higher capillarity in the pores. Hence, the diagenetic points in zone F having almost no clay minerals (observed by low gamma-ray responses) will approach the sandstone line due to having more water and low porosity. The mineralogy templates are designed for a fully water saturated formation; therefore, when water saturation increases highly, points will approach to true places on the mineralogy plots.

M-N plot is a useful mineralogy indicator because gas effects, various minerals, secondary porosity, and shale regions can be identified. The gas effects and calcite cementation (zone F) were seen with trends in opposite directions at the Karewa-1 well (Figure 7b). Zones B, D, and $\mathrm{H}$ gave similar responses on the M-N plot. Zone B (hollow triangle), zone D (hollow perpendicular), and zone H (cross) approached the shale region because of the increased dominancy of the clay minerals (authigenic clay precipitated from the dissolution of feldspar minerals and lithic fragments) on these zones. Also, slight 
increase in "M" number for zone D on the M-N plot displays secondary porosity in the formation (Figure 7b).

The Mangaa C-1 gas sandstone in Kahawai-1 well shows similar results on the neutrondensity crossplot in comparison to the gas formation in the Karewa-1 well. When water saturation increases drastically in zone $\mathrm{M}$, the points moved to the sandstone line (Figure 8a). The highest gas saturation of the Mangaa C-1 formation in the Kahawai-1 well was observed within zone $\mathrm{K}$ (circles), and points in zone L approached closer to the sandstone line due to a higher amount of water in the formation (Figure 8a).

As for the M-N plot, gas trends in Kahawai-1 well were not seen easily because the sonic $\log$ might be affected by the poor quality of well log measurements even though the well $\log$ measurements and borehole quality in the formation of interest were good. Yet, the sonic log values of this thin layered gas reservoir in Kahawai-1 well might be affected by cycle-skipping effects. Higher water saturations in zone 


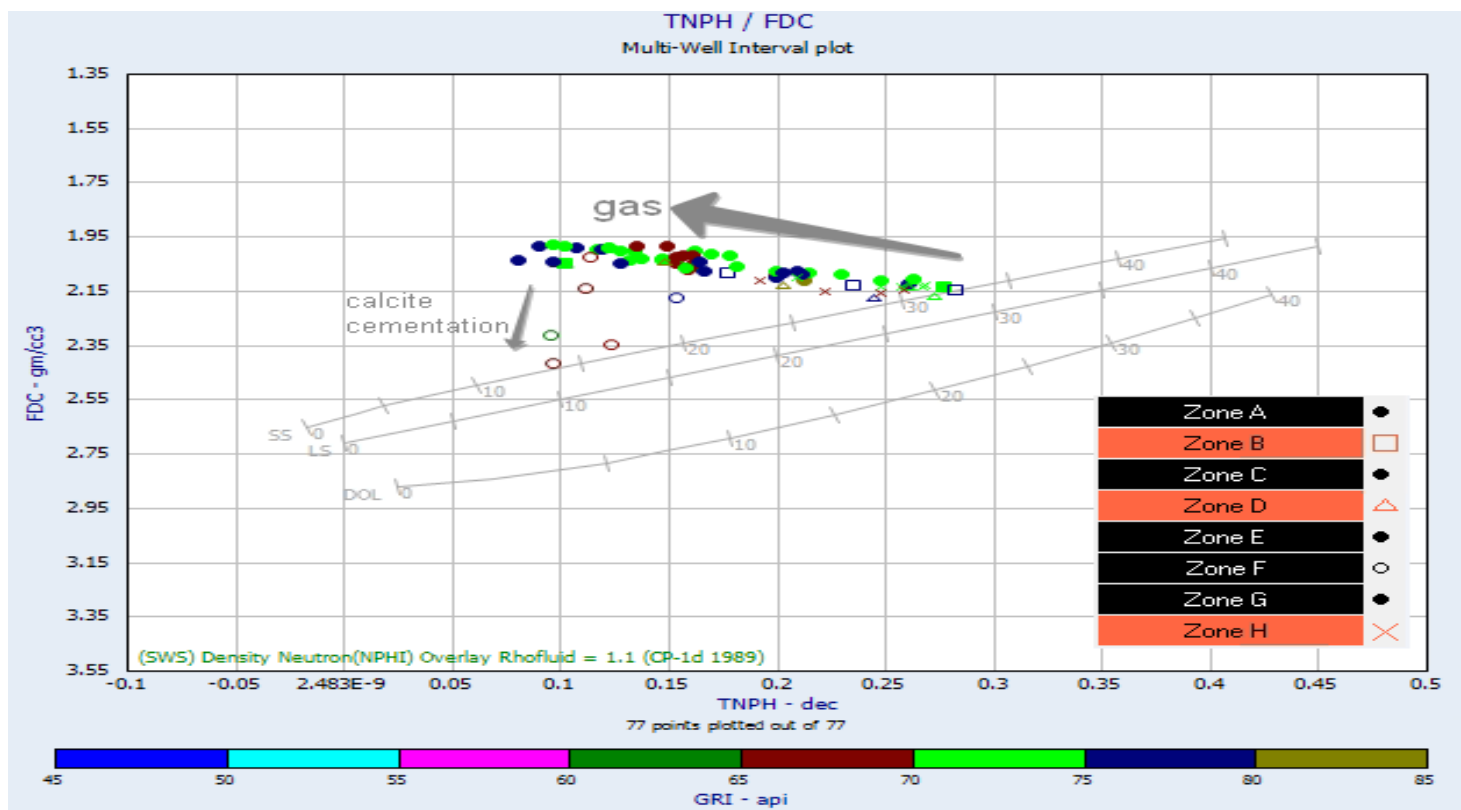

(a)

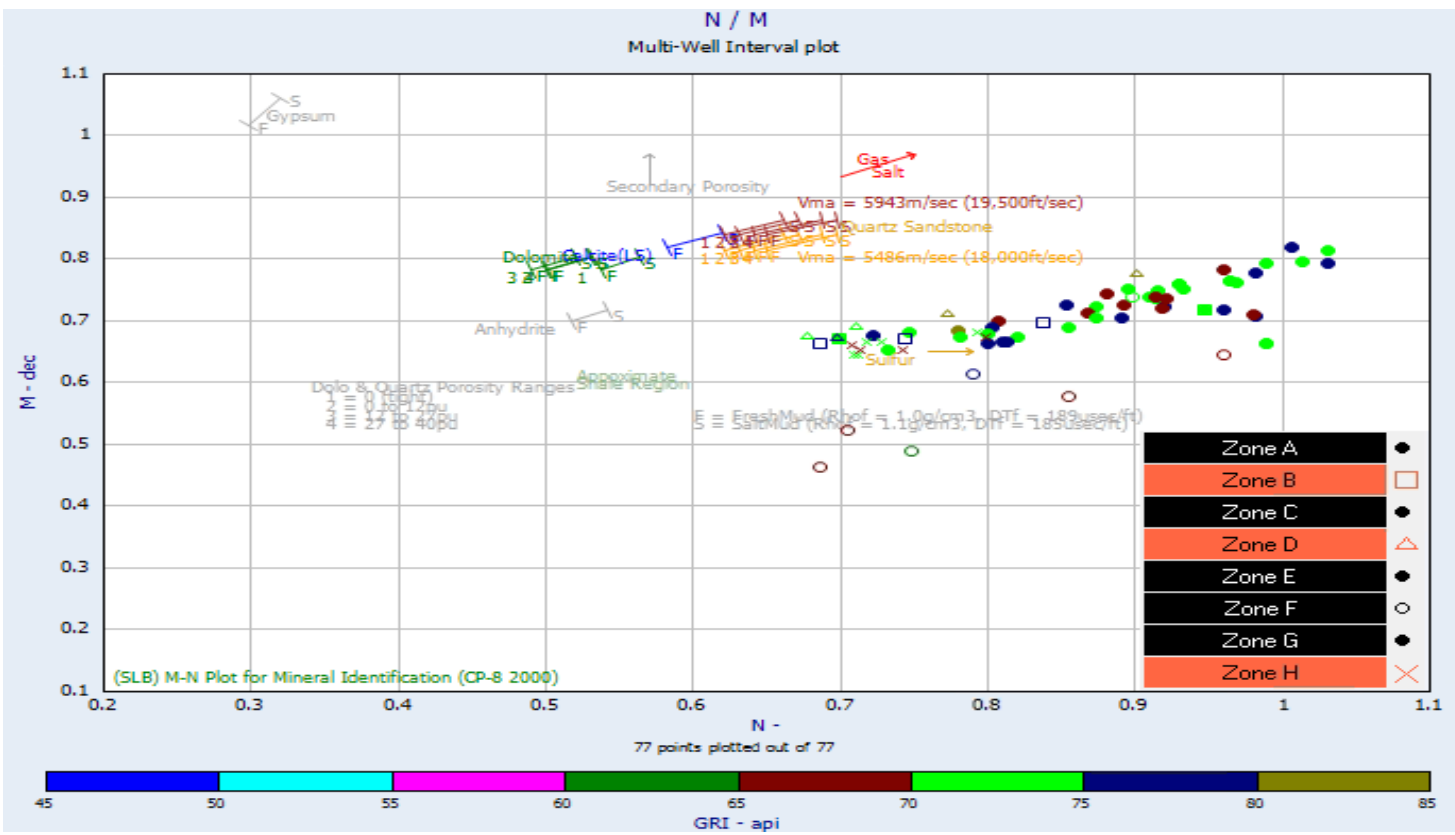

(b)

Figure 7 Karewa-1 well (Zones A to H). (a) The crossplot of the neutron (TNPH)-density (FDC) logs displays the gas trend (solid circles) and high calcite cemented zone (zone Fhollow circles). (b) M-N crossplot shows the gas trend (solid circles), high calcite cemented zone (zone F-hollow circles), and secondary porosity (hollow triangles and cross signs). 


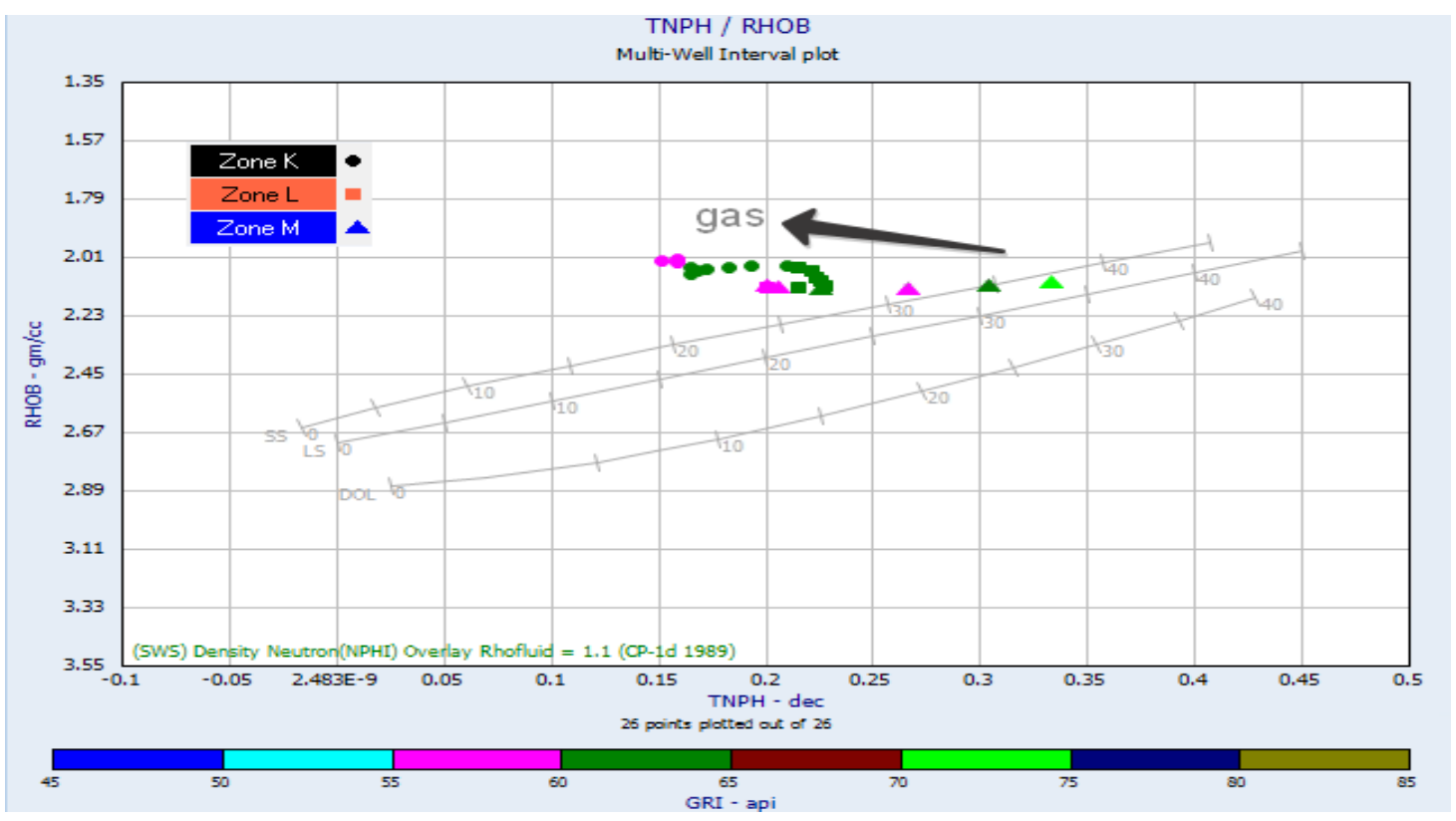

(a)

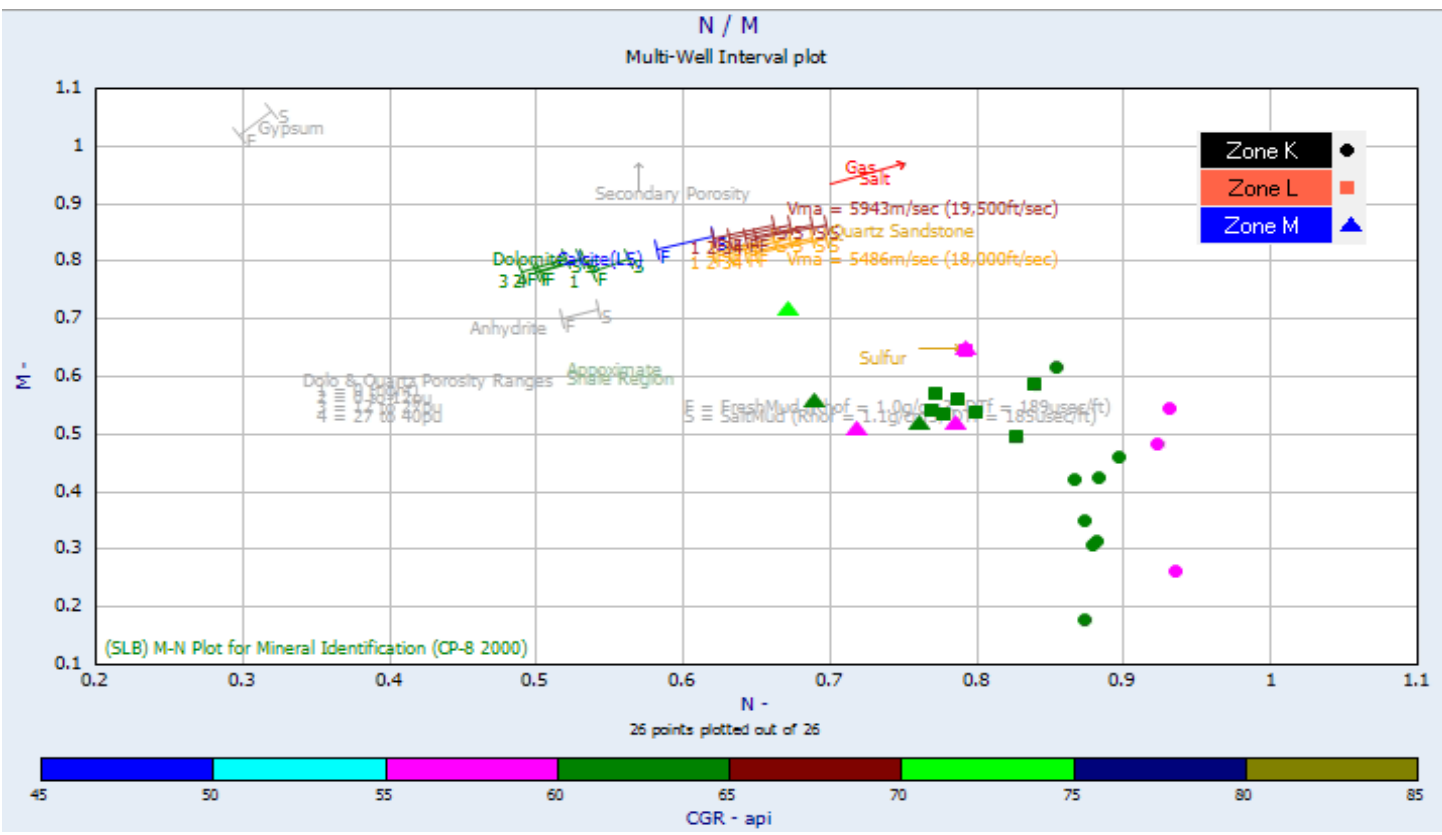

(b)

Figure 8 Kahawai-1 well (Zone K, L, and M). (a) Neutron (TNPH)-density (FDC) logs crossplot shows the increasing gas saturation trend (solid circles). (b) M-N crossplot did not display the gas trend clearly because sonic log used to calculate "M" might be affected by cycle-skipping effects. Zone $\mathrm{M}$ (triangle signs) includes higher water saturation and approaches to the mineral points. 


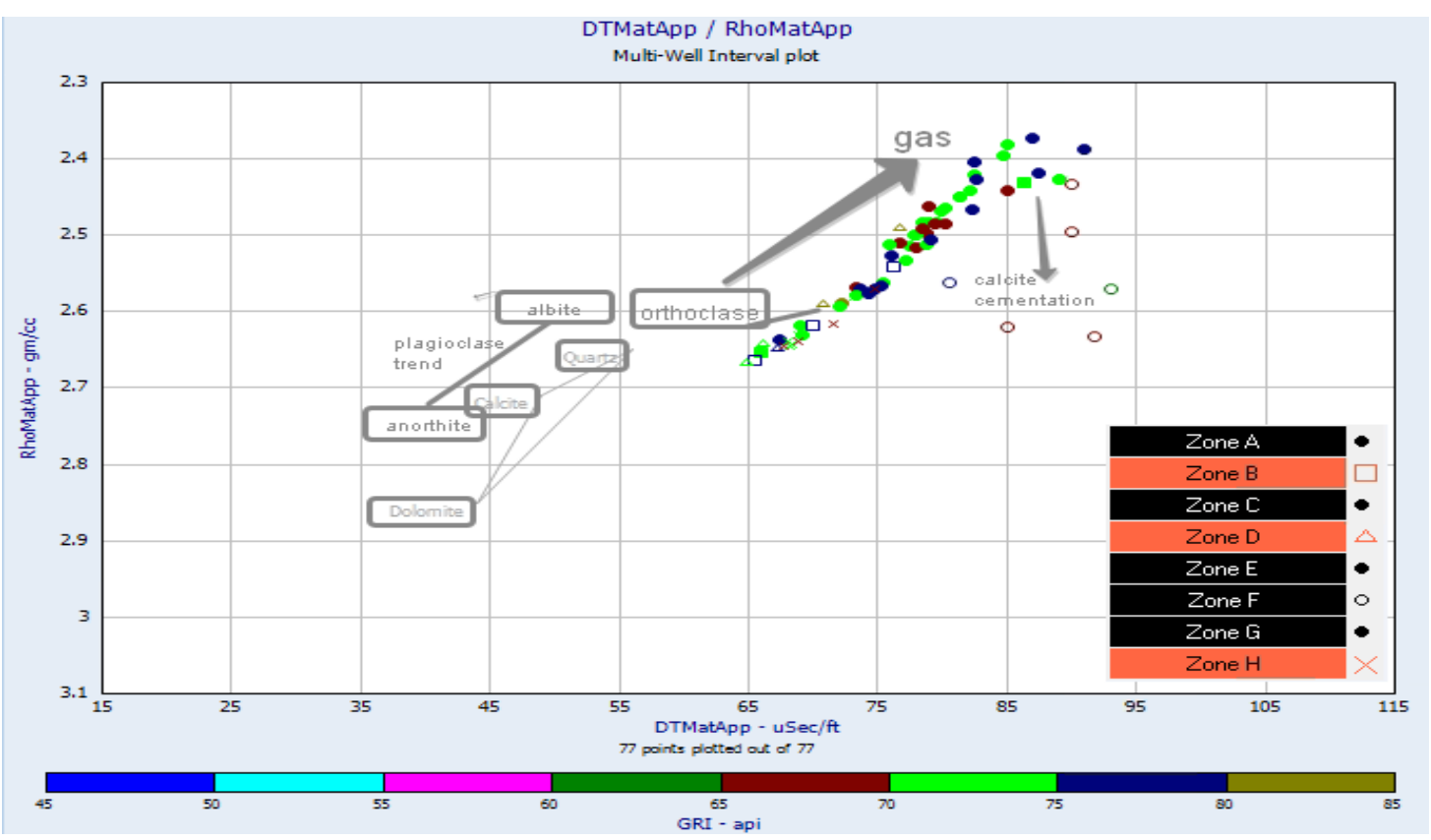

(a)

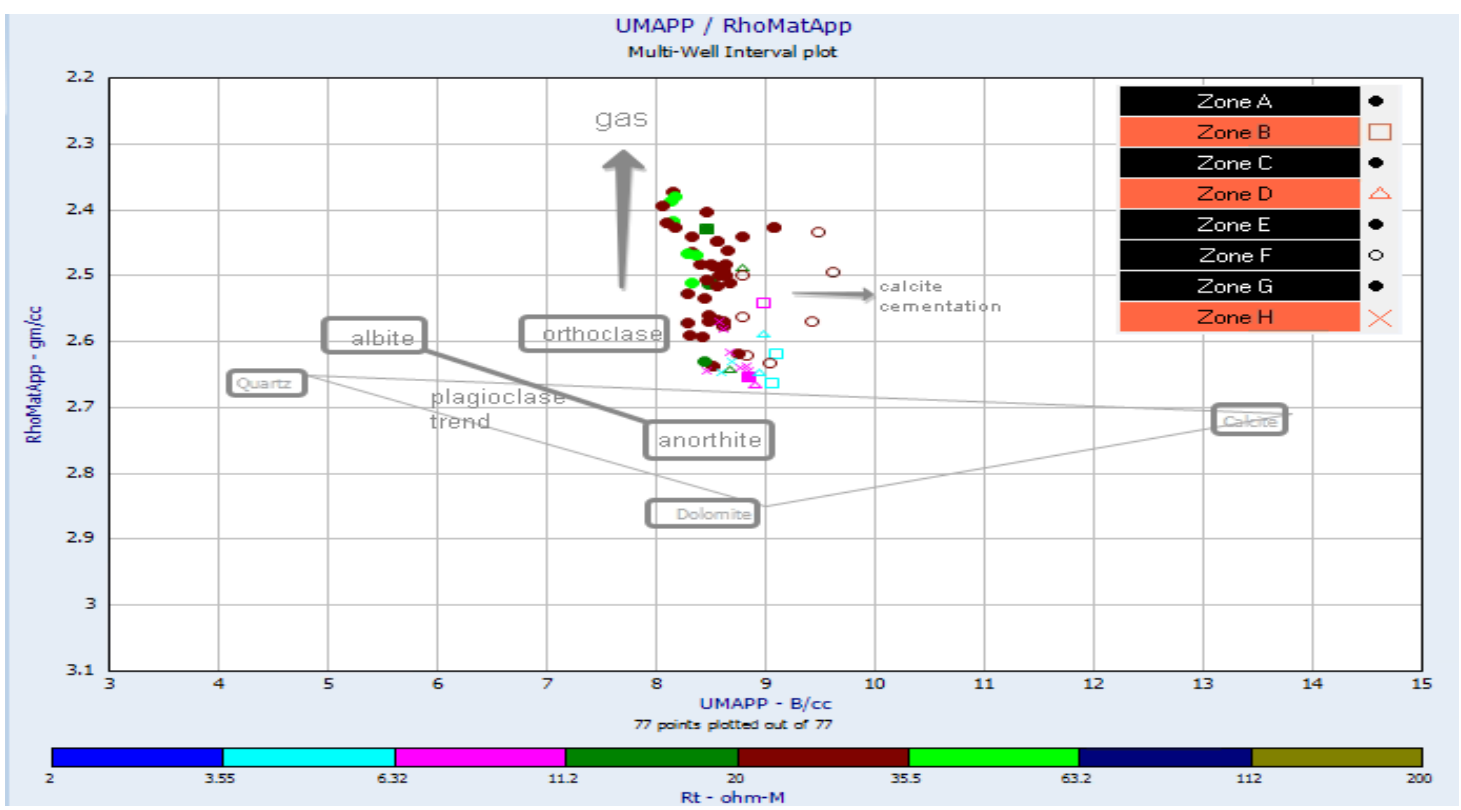

(b)

Figure 9 Karewa-1 well (Zones A to H). (a) Apparent matrix grain density (Qmaa) and apparent matrix transit time $\left(\Delta \mathrm{t}_{\text {maa }}\right)$ MID crossplot displays the gas trend and calcite cemented zone (hollow circles). (b) Apparent matrix grain density (@maa) and apparent matrix volumetric cross section $\left(\mathrm{U}_{\text {maa }}\right)$ MID crossplot indicates the gas effects and calcite cementation. 
$\mathrm{M}$ (triangle) resulted in moving the points to the mineral points (sandstone line) (Figure 8b). Apparent matrix density and apparent matrix transit time parameters were calculated and plotted in order to define different fluid and mineral concentrations of the Mangaa C1 gas zone at two wells. Zone B (hollow triangle), zone D (hollow perpendicular), and zone $\mathrm{H}$ (cross) were interpreted to have fewer gas saturation effects on the crossplot (Figure 9a). Moreover, data points were observed around the orthoclase mineral point and removing the gas effects will place the points somewhere between quartz, plagioclase, and the K-feldspar mineral points at the Karewa-1 well.

As to the @maa vs. $U_{\text {maa }}$ MID crossplot (Figure 9b), gas trends were seen with increasing apparent matrix density and similar apparent matrix volumetric cross section. Zone $\mathrm{F}$ (highly calcite cemented sandstone) is seen with hollow circle signs and points are closer to the calcite mineral point shown with the horizontal arrow (Figure 9b). Diagenetic zones (zones B, D, and $\mathrm{H}$ ) showed slightly higher apparent matrix volumetric cross section values $\left(\mathrm{U}_{\mathrm{maa}}\right)$. On the other, increasing gas saturation results in decrease in apparent matrix density (Figure 9b).

Apparent matrix density and apparent matrix transit time were also plotted for the thin gas formation in the Kahawai-1 well (Figure 10a). The increase in apparent matrix transit time and a decrease in apparent matrix density correspond to increasing amount of gas saturation in the formation. On the other hand, the Qmaa vs. U maa MID crossplot (Figure 10b) shows higher gas saturation for zone K (solid circles). 
Using the PEF log for the mineral identification had the limitation in the existence of the feldspar minerals and illite minerals which have similar PEF as dolomite (Figures 11 and 12). The core descriptions of the gas reservoir at some depths show that there are no calcite or dolomite minerals within the formation. Rather, the formation consists of mainly quartz with abundant feldspar and clay minerals. The core descriptions at a few depths which were combined with the PEF-density crossplot helped us understand the mineralogy of the gas formation at all depths within the gas formation.

The crossplot of the PEF and density logs shows that the density log is affected not only by minerals but also by fluids. Nevertheless, the PEF-density crossplot will be the best mineral identification option because points on the crossplot would be seen between the K-feldspar, plagioclase feldspar, and illite mineral points if the density log was not affected by gas (Figures 11 and 12). The mineralogy crossplots cite the best results of mineralogy for fully-water filled zones, and gas zones will be seen with different trends on the various mineralogy crossplots. 


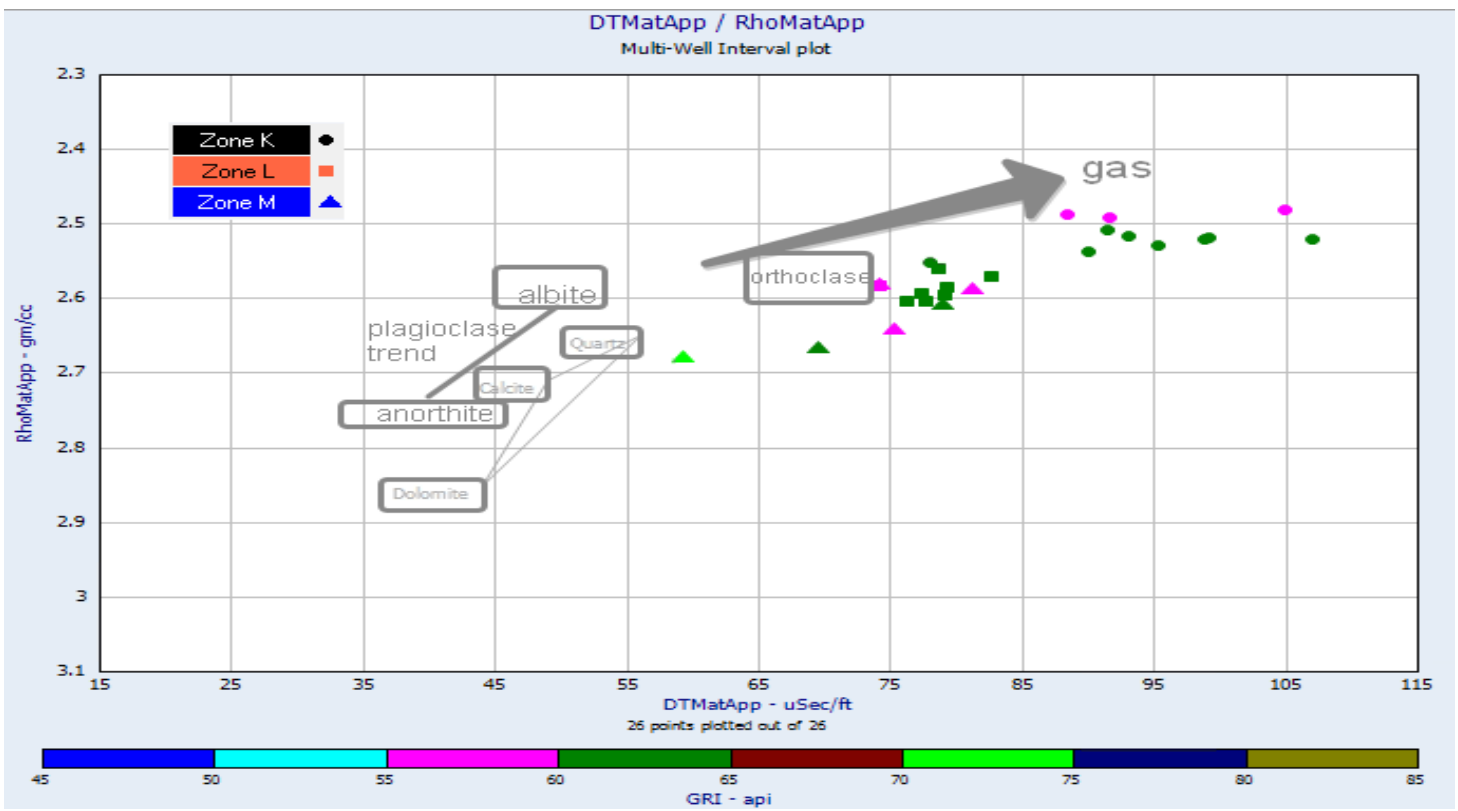

(a)

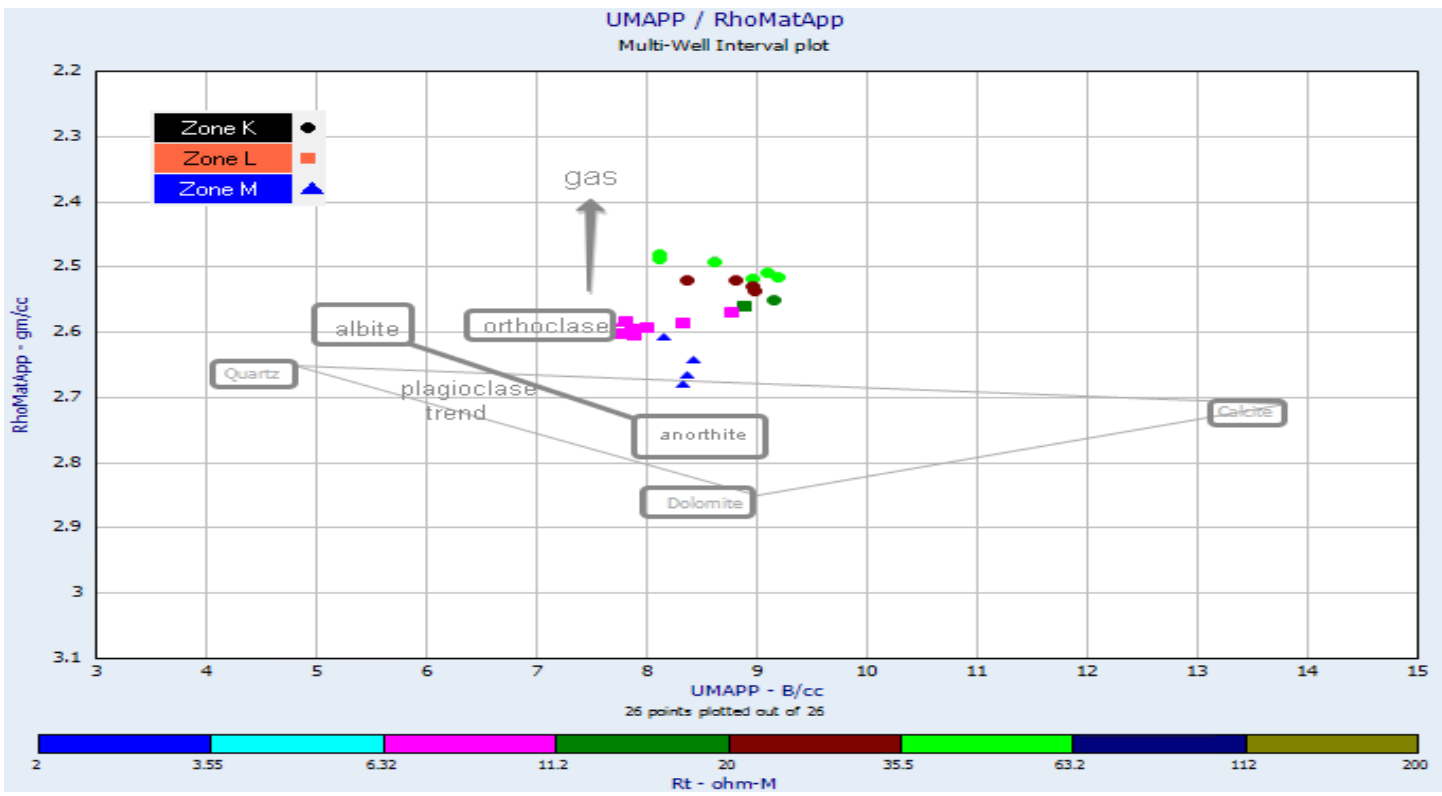

(b)

Figure 10 Kahawai-1 well (Zones K, L, and M). (a) Apparent matrix grain density (@maa) and apparent matrix transit time $\left(\Delta \mathrm{t}_{\mathrm{maa}}\right)$ MID crossplot shows the gas trend. Zone $\mathrm{M}$ has less gas effects and approaches to the mineral points. (b) Apparent matrix grain density (Qmaa) and apparent matrix volumetric cross section $\left(\mathrm{U}_{\text {maa }}\right)$ MID crossplot exhibits increasing gas saturation points (solid circles) and increasing water saturation points (solid triangles). 


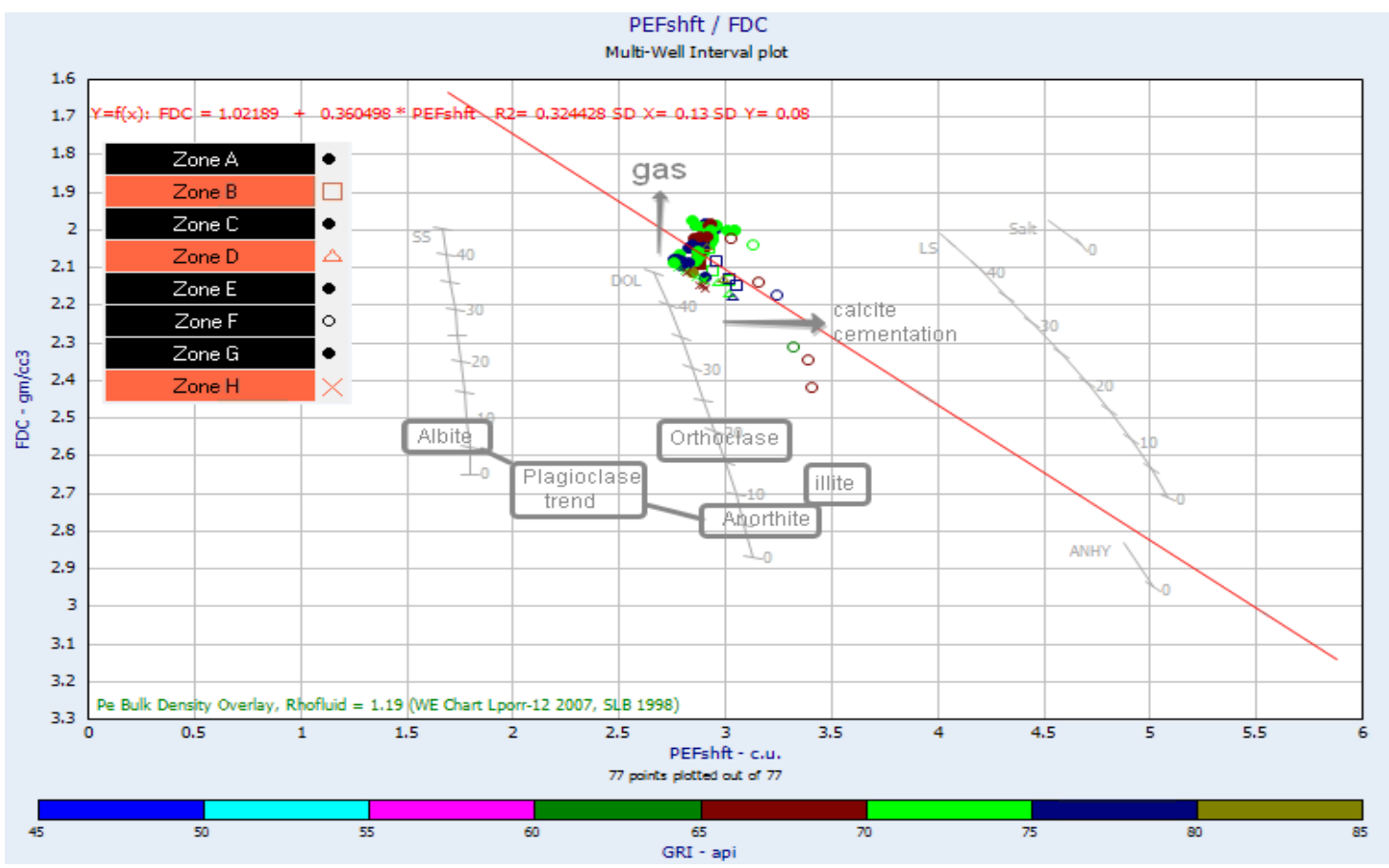

Figure 11 Karewa-1 well (Zones A to H). PEF-FDC crossplot. Increasing density and PEF log values showed the calcite cementation zones (hollow circles). Higher gas saturation is seen with lower density values on the upper side.

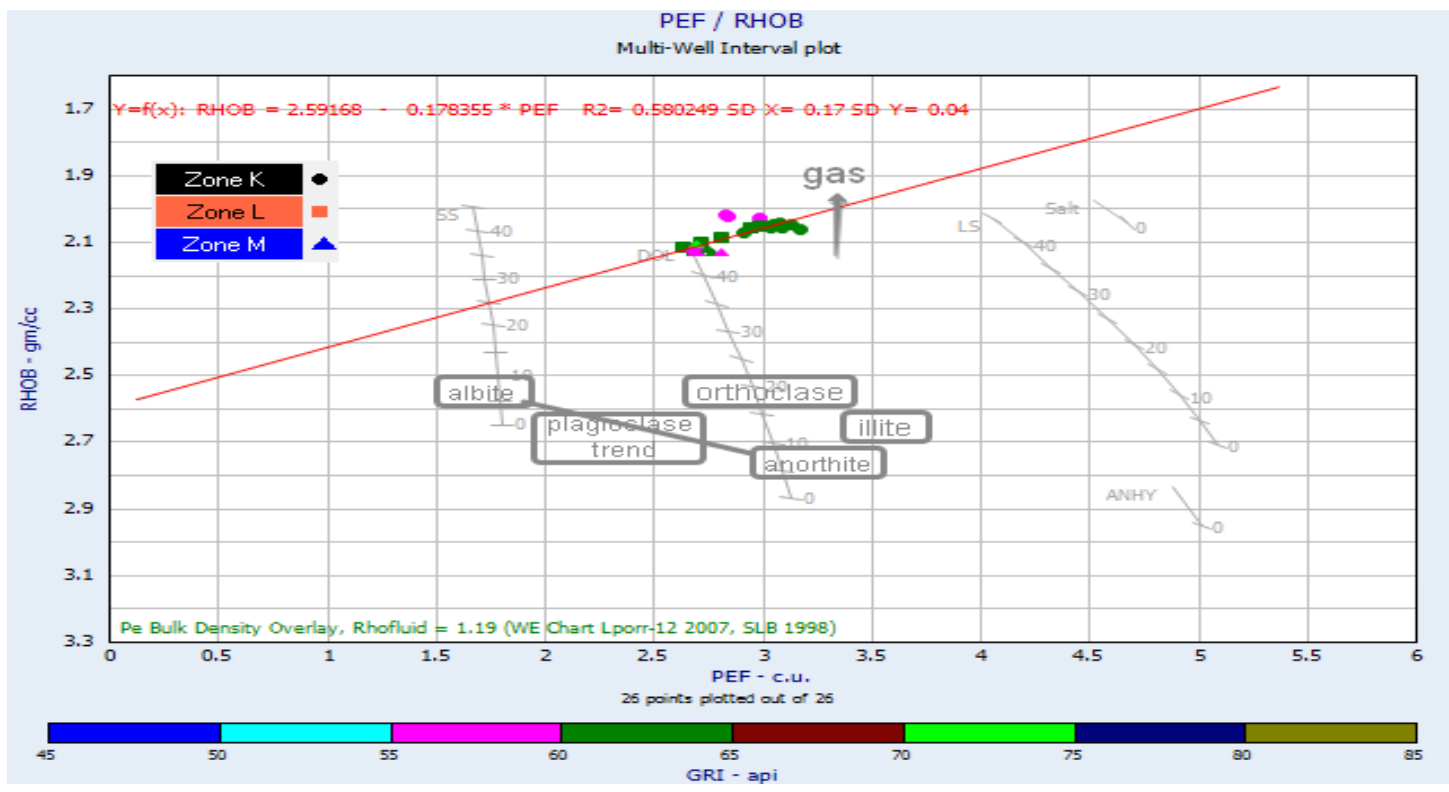

Figure 12 Kahawai-1 well (Zone K, L, and M). PEF-FDC logs crossplot displays slightly higher gas saturation points with solid circles. 
The PEF log and spectral gamma-ray logs are plotted to determine different kinds of clay minerals in the gas sandstone. These crossplots showed that the gas formation in the Kahawai-1 well is illite-rich sandstone (Figures 13 and 14). Thorium-potassium crossplot gave more precise results than PEF-Potassium and PEF-Potassium/Thorium ratio crossplots to identify the clay minerals in the sandstone (Figure 13b). This is because PEF values are not only affected by clay minerals, but also feldspar and quartz minerals change the PEF values. On the other hand, potassium and thorium elements tend to occur within the clay minerals and are more useful to identify the dominant clay minerals from the plot. Illite minerals might suppress the resistivity $\log$ and affect water saturation calculations. Therefore, shaly sand water saturation equations will be used in this study to predict the effective water saturation. 


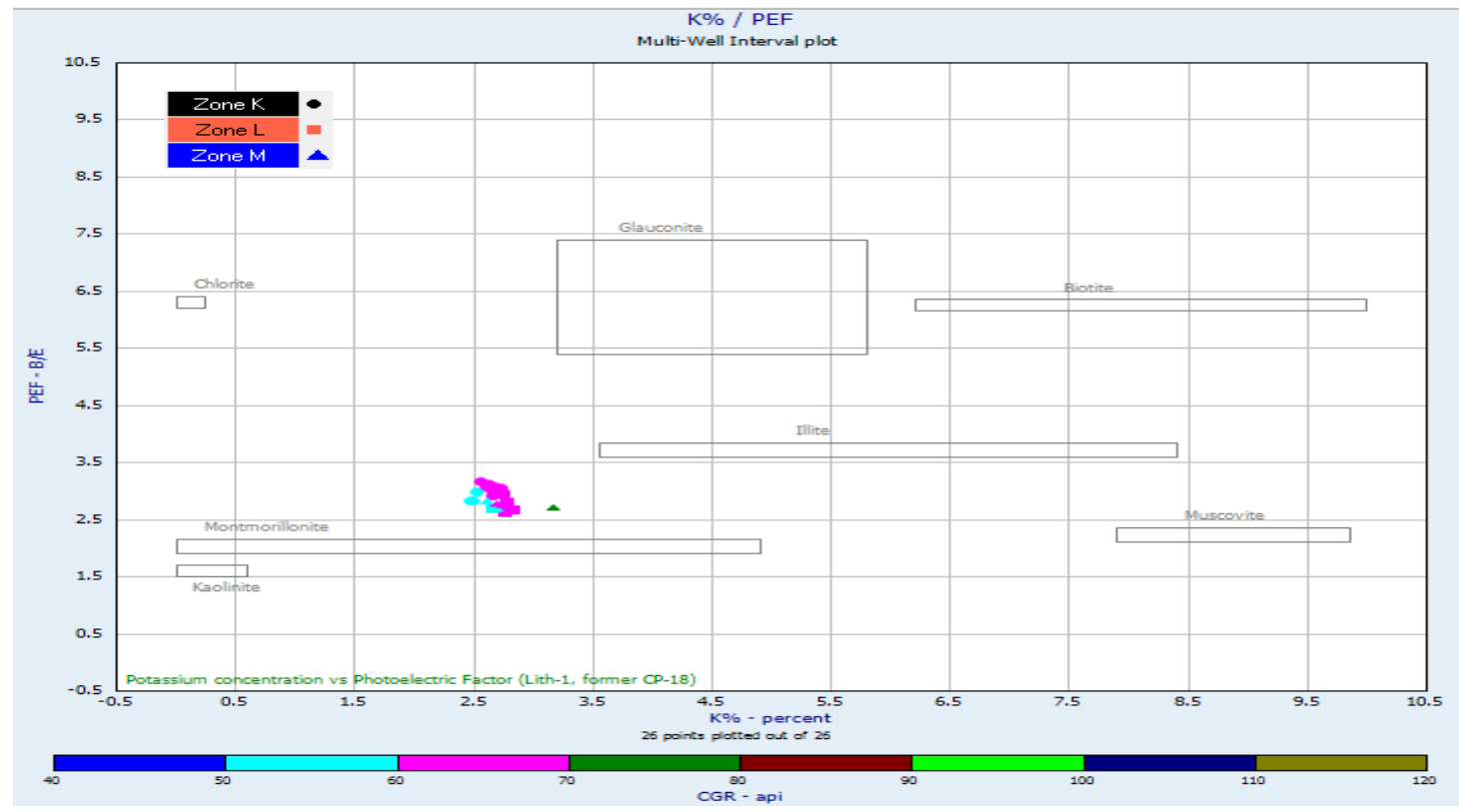

(a)

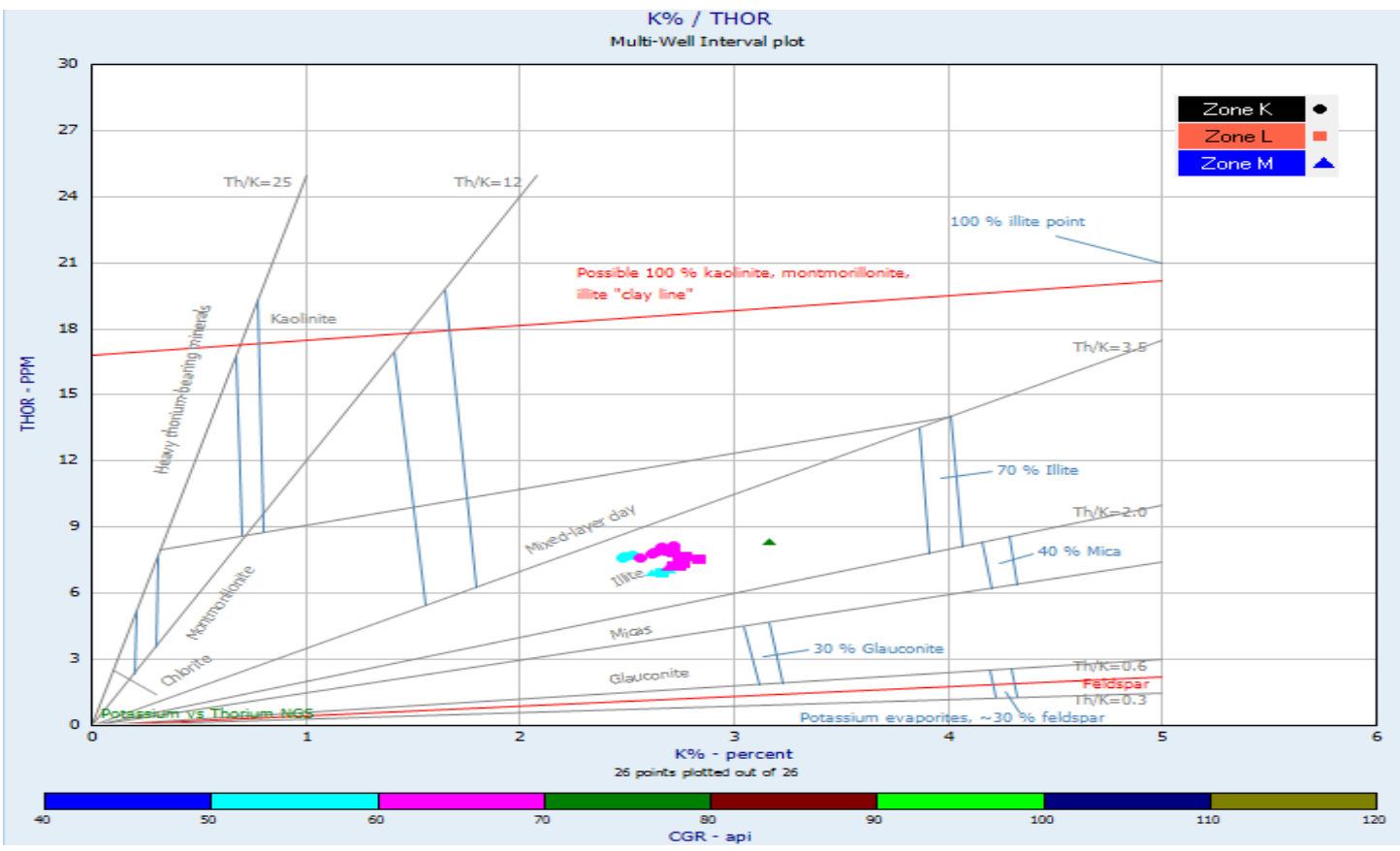

(b)

Figure 13 Kahawai-1 well (Zone K, L, and M). (a) Potassium (K)-PEF logs crossplot shows clay mineral type as illite and montmorillonite. (b) Potassium-thorium logs crossplot clearly proves that the clay minerals in thin gas formation are illite, primarily. 


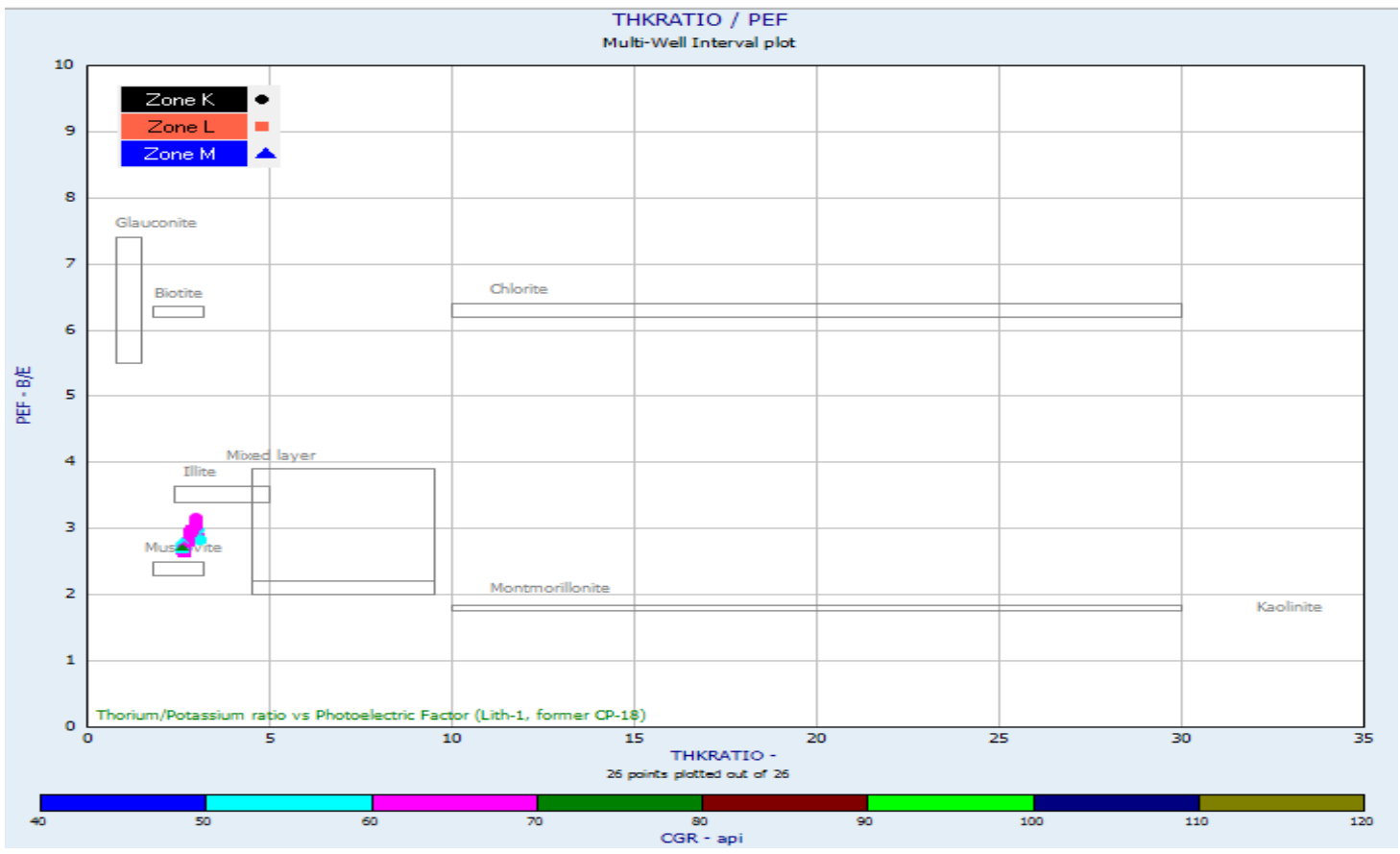

Figure 14 Kahawai-1 well (Zone K, L, and M). Thorium-potassium ratio and the PEF log crossplot shows the points among illite, muscovite, and mixed layer (illite/montmorillonite) minerals.

\subsection{Petrophysical Properties}

In this section, shale volume, effective and total porosity, and total and effective water saturation of the Mangaa C-1 gas reservoir at Karewa-1 and Kahawai-1 wells were predicted. Then, with these estimated parameters, the lithology logs were created to understand the different geological features in the gas reservoir.

Reasonable shale volume and effective porosity must be determined by the well logs for the shaly sand formation to estimate other petrophysical parameters such as effective water saturation and the productivity of the gas reservoir, properly. To find the shale volume in the gas reservoir, I used the non-linear Larianov equation for Tertiary-aged rocks since potassium feldspar minerals, which show high radioactivity, complicate shale 
volume estimations (Larianov, 1969). The results of the Larianov shale volume compared to the thin section clay volume at four depths were very consistent in the Karewa-1 well (Figure 15). The reflection of the coefficient between these two clay volume results was 0.431152 which was acceptable for using few data points for linear regression.

Secondly, the effective porosity was estimated for this gas formation in two wells. Effective porosity does not include the pores in shale since these pores are too small for gas or oil to flow through. Correlation of the coefficient between thin section porosity and porosity calculated from well logs was 0.501317 , which was adequate for this study (Figure 16).

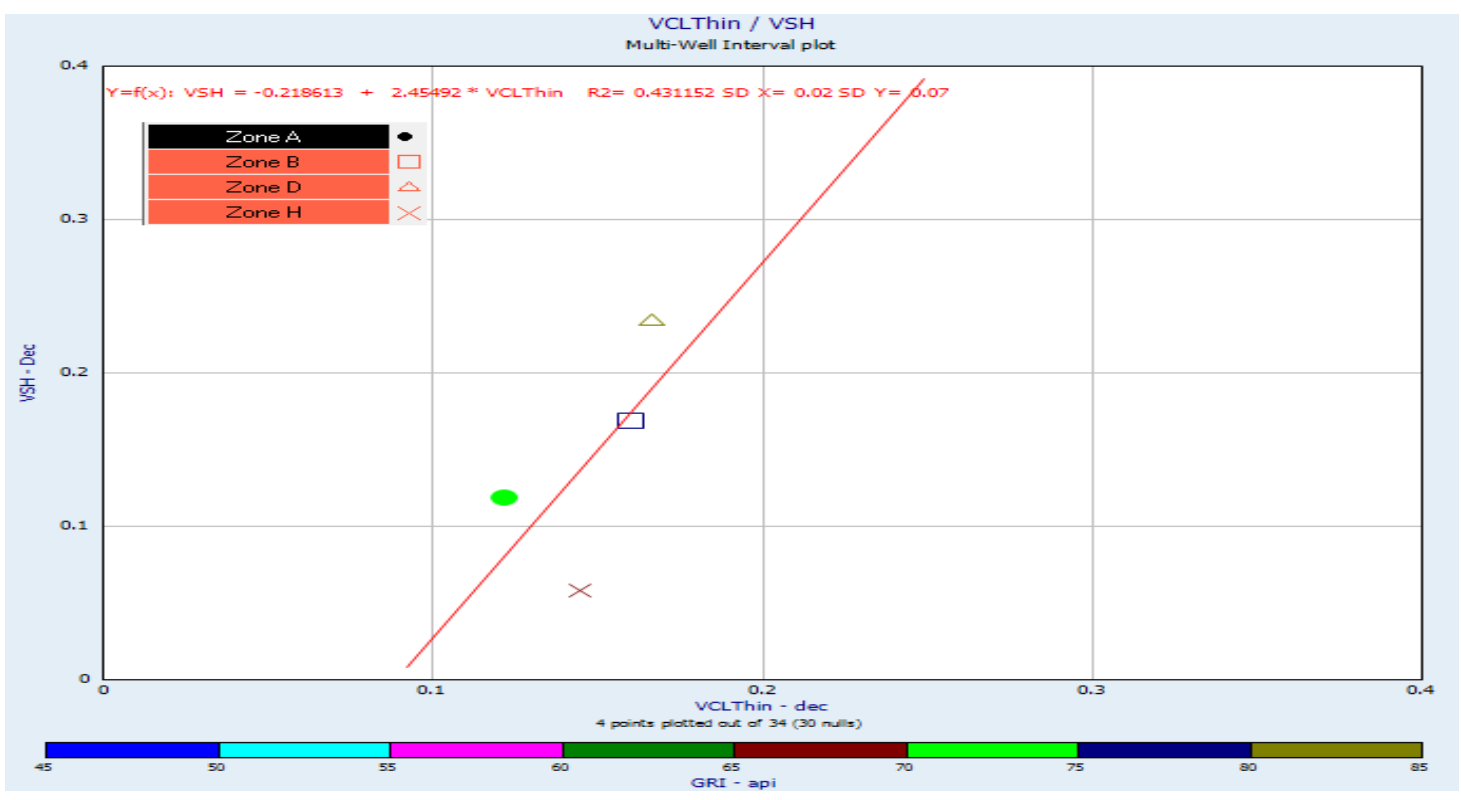

Figure 15 Karewa-1 well (Zones A to H). Comparison of the clay volumes from thin sections (VCLThin) and well logs (Vsh). 


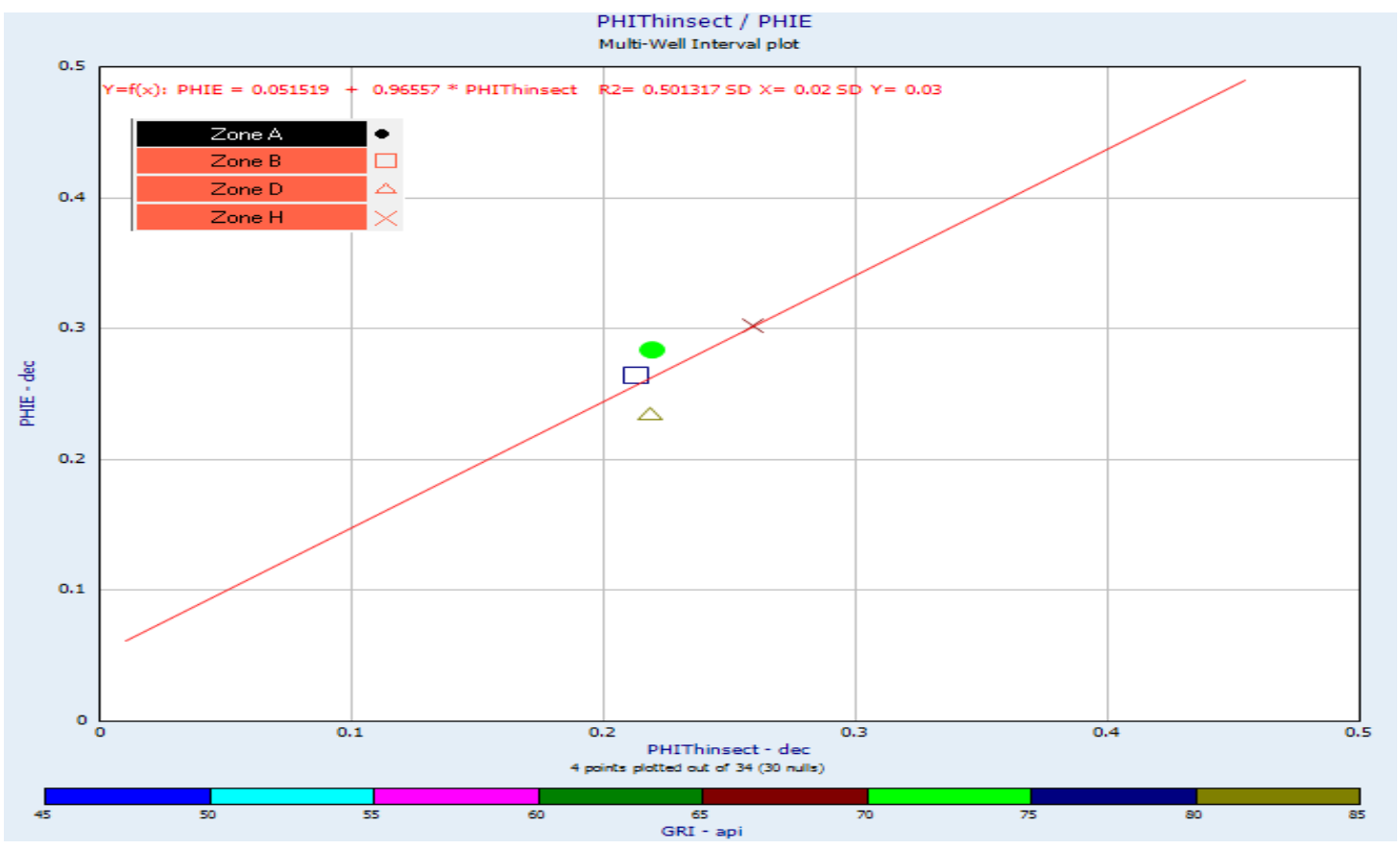

Figure 16 Karewa-1 well (Zones A to H). Comparison of effective porosity from thin sections (PHIThinsect) and well logs (PHIe).

Effective water saturation is then calculated by different equations for a shaly sand formation with $15 \%$ shale volume. The Archie equation (1942) assumes that rock minerals have zero conductivity; only water is conductive in formations; hydrocarbons are non-conductive fluids; formations are shale-free clean sand.

In reality, in some heavy minerals such as pyrite, glauconite, or magnetite, clay minerals (montmorillonite and illite), ineffective microporosity and secondary porosity created by dissolution of minerals will create extra conductivity pathways in addition to free water and will suppress the resistivity logs. 
The gas formation in two wells is illite-rich sandstone. Illite minerals have high conductivity due to high cation exchange capacity and high specific surface area. These minerals will hold more bound water on their surfaces.

More importantly, abundant dissolution porosity (microporosity and secondary porosity) in the gas formation suppress the resistivity logs and cause the overestimations of the effective water saturation results calculated by the Archie equation. At three depths, microporosity and secondary porosity values were known from the thin section data (Karewa-1 well completion reports, 2002-2003).

The Pickett plot (1966) is applied to estimate the water resistivity (Rw) on the formation and cementation component $(\mathrm{m})$ (Figure 17). Also, shale resistivity, shale density and neutron porosity, and shale total porosity were read from the nearby shale formation (1925.3m), assuming that petrophysical properties of shale in the gas formation and in the nearby shale formation are similar. 


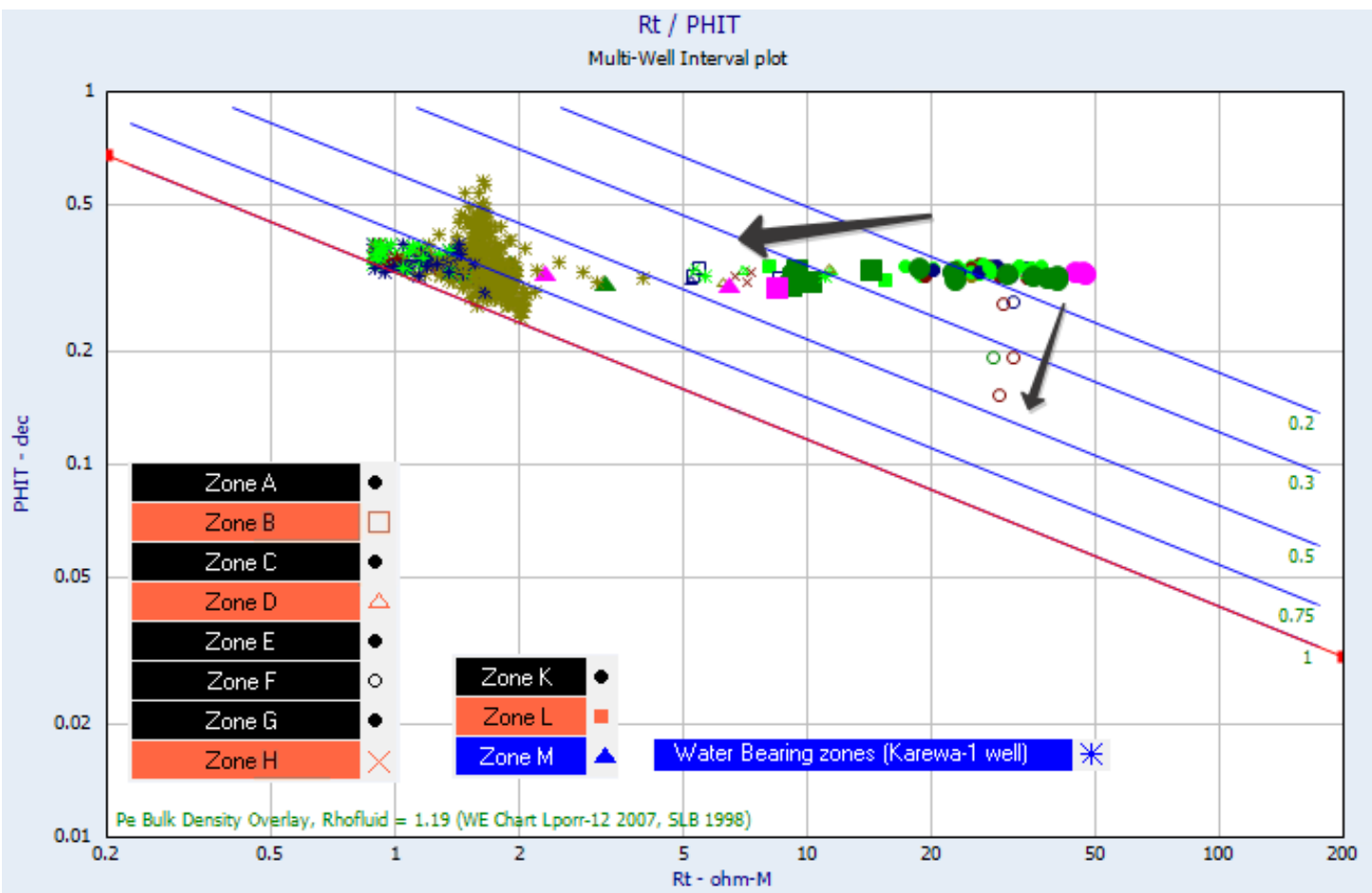

Figure 17 Karewa-1 (1930.9-2020m) and Kahawai-1 (1849.2-1852m) wells. Pickett plot to find the water resistivity ( $\mathrm{Rw}$ ) and cementation component (m). Arrows show the higher water saturation zones with different trends. More or less constant true resistivity and decreasing total porosity are attributed to a high calcite cementation zone. On the other hand, constant total porosity and dramatic decrease of true resistivity are thought to be the zones having ineffective dissolution porosity and some authigenic clay minerals.

Table 2 Estimated water saturation parameters.

\begin{tabular}{|l|l|l|l|l|}
\hline Formation & $\mathrm{R}_{\mathrm{w}}$ & $\mathrm{a}$ & $\mathrm{m}$ & $\mathrm{n}$ \\
\hline Mangaa & 0.0827 & 1 & 2.23 & 2 \\
C-1 & & & & \\
\hline
\end{tabular}




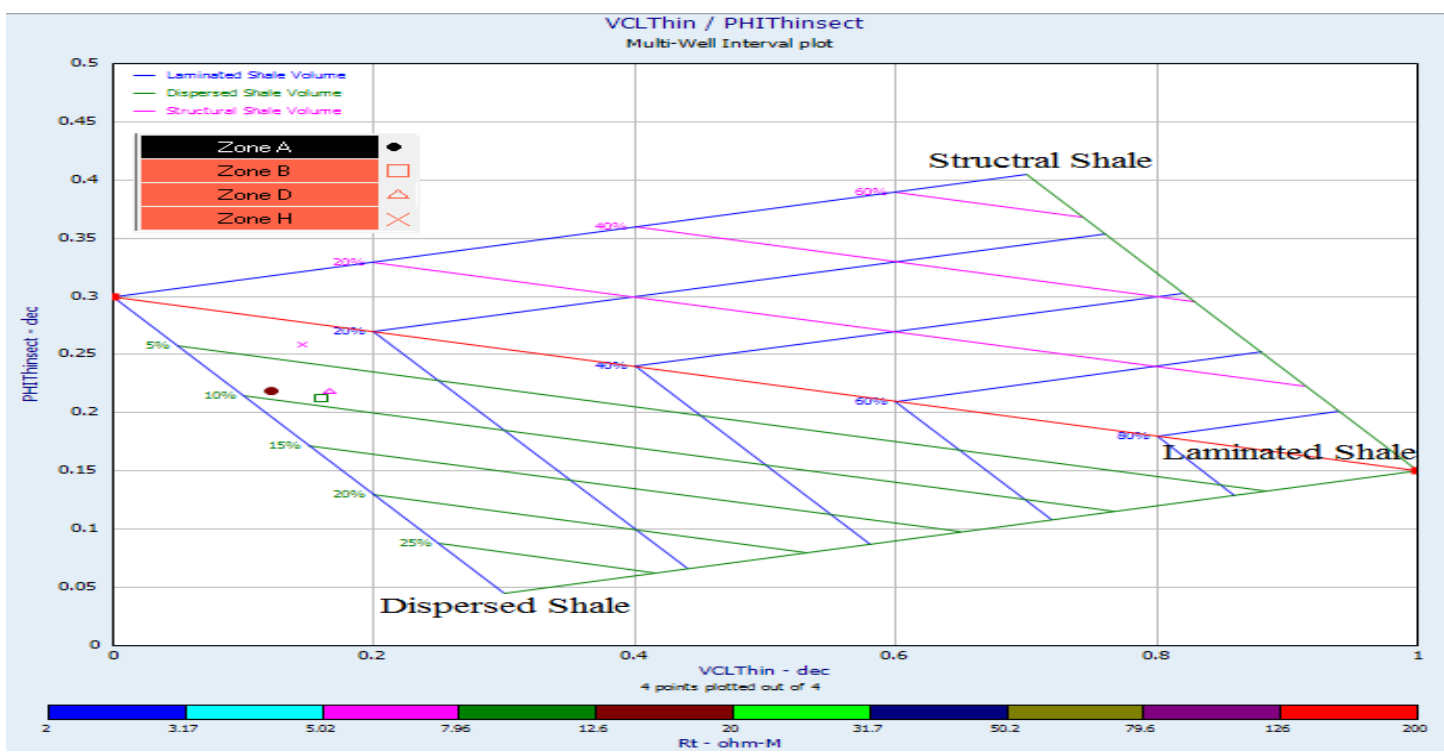

(a)

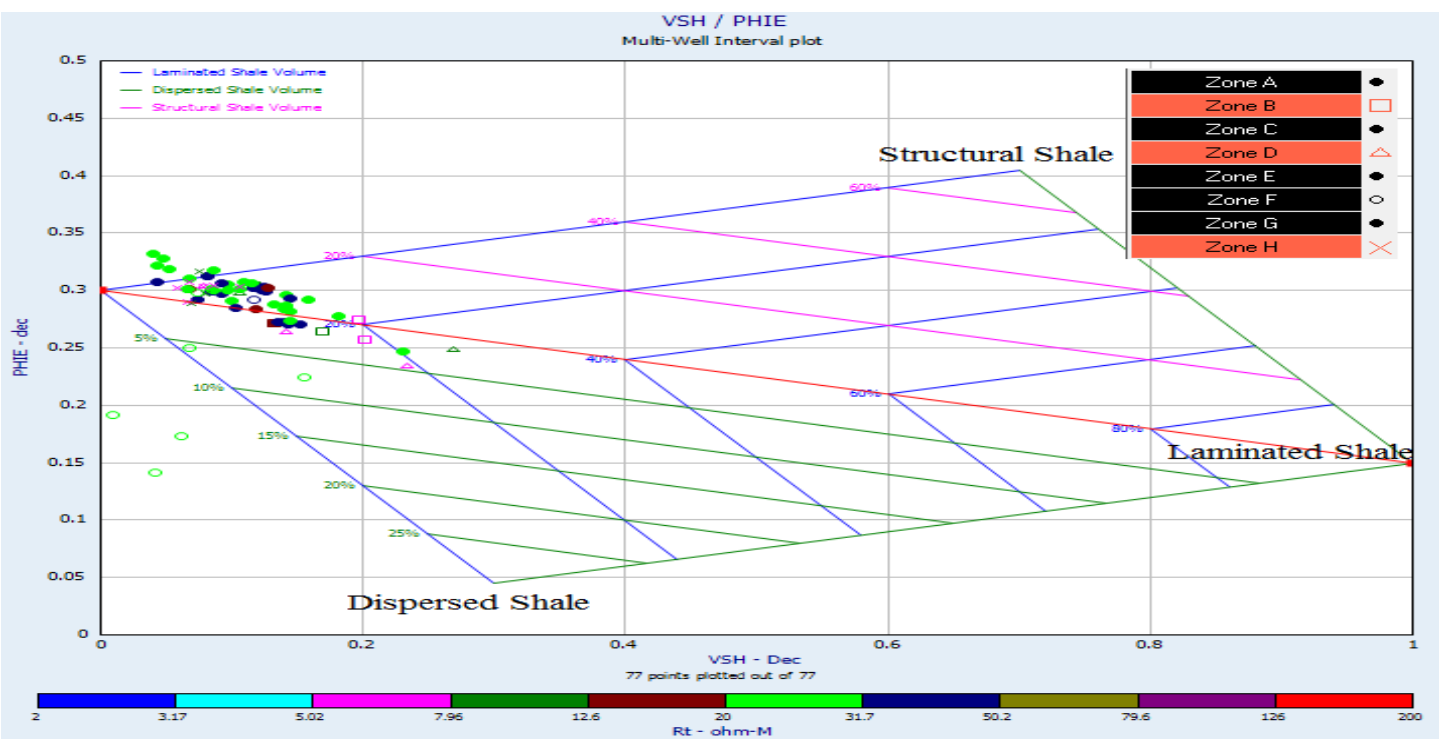

(b)

Figure 18 Karewa-1 well (Zones A to H). (a) The Thomas-Stieber crossplot for the clay type in the gas sand reservoir by thin section porosity (PHIThinsect) and clay volume (VCLThin). At four depths, the plot shows some dispersed and laminated shale. (b) The Thomas-Stieber crossplot for the clay type in the gas sand reservoir by well log porosity (PHIe) and clay volume (Vsh). The plots displays laminated shale in the formation. The Thomas-Stieber method is accurate when porosity is only decreased by shale. In zone $\mathrm{F}$ (hollow circles), calcite cementation decreased the porosity. There is no dispersed shale in zone $\mathrm{F}$ even though there seems to be some dispersed shale on the plot. 


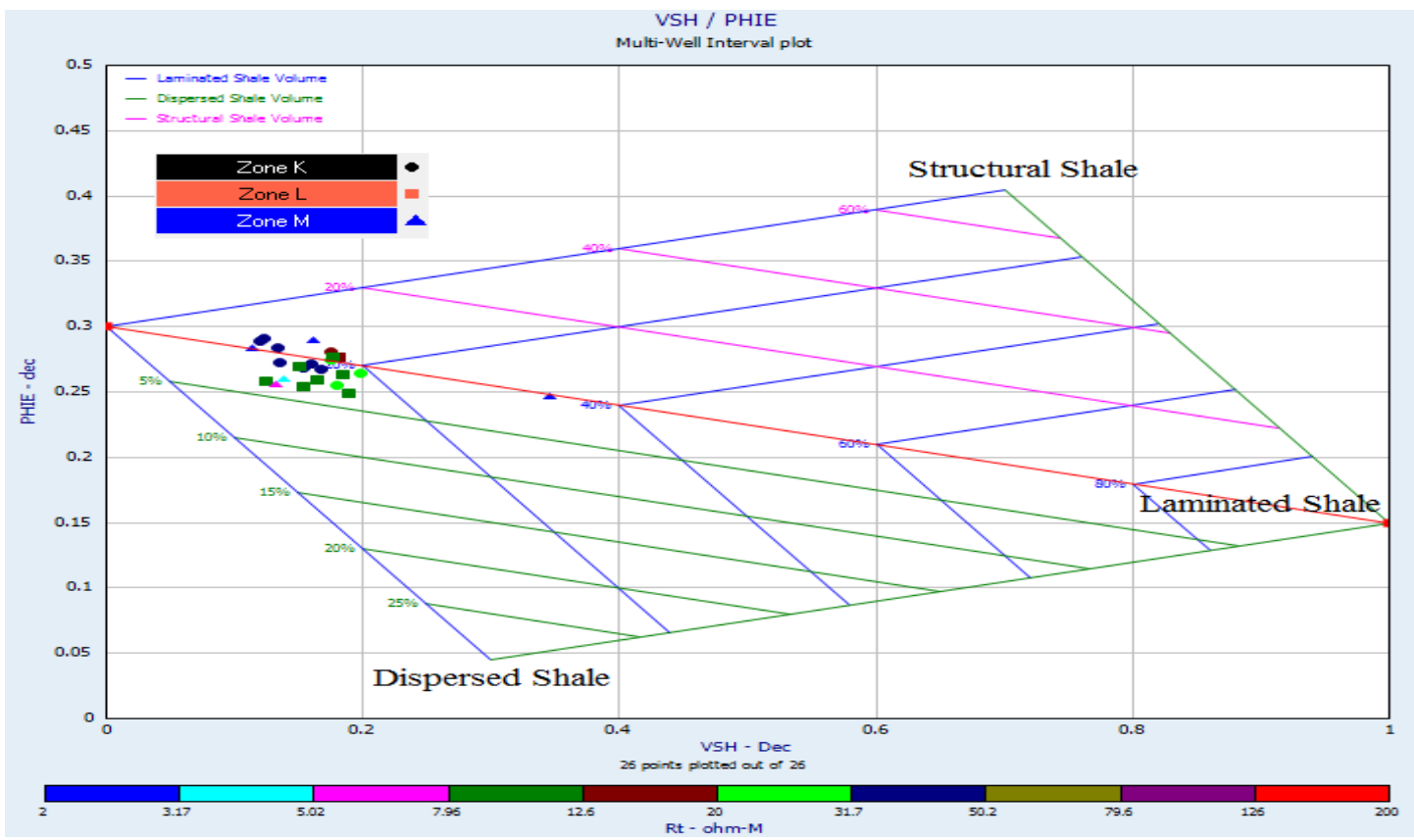

Figure 19 Kahawai-1 well (Zone K, L, and M). The Thomas-Stieber crossplot by well log porosity (PHIe) and clay volume (Vsh) presents that shale in the gas formation is laminated. Zone L shows some dispersed shale which might result from the alteration of unstable minerals (feldspar minerals).

Table 3 Estimated shale properties from nearby shale formation.

\begin{tabular}{|l|l|l|l|l|l|}
\hline Formation & Depth & Rsh & $\Phi_{d s h}$ & $\Phi_{n s h}$ & $\Phi_{\text {tsh }}$ \\
& & & & & \\
\hline Mangaa C-1 & $1925.3 \mathrm{~m}$ & 1.92 & 0.231 & 0.495 & 0.31 \\
\hline
\end{tabular}

The Thomas-Stieber plot (1975) is used to identify clay minerals in formations. The method assumes that the porosity is only decreased by clay minerals. Plots in two wells showed that shale in the gas formations is laminated with some dispersed shale (Figure 18 and 19). This dispersed shale was probably generated after the dissolution and alteration of feldspar minerals and lithic fragments. The Thomas-Stieber crossplot with 
thin section porosity and shale volume at four depths (Karewa-1 well) showed that there are some dispersed shale which is interpreted as authigenic shale generated by dissolution and alteration of feldspar minerals in this formation (Figure 18a). Unlike the ThomasStieber method with well log porosity and clay volume, the Thomas Stieber plot with four thin section porosity and clay volume (Figure 18a) showed some dispersed shale in the low resistivity zones. The Thomas-Stieber plot is so sensitive to slight overestimations or underestimations of porosity. Therefore, dispersed shale was not seen clearly on the Thomas-Stieber plot using well log data (Figure 18b). For the same formation in the Kahawai-1 well, some dispersed shale, which might result from the dissolution and the alteration of diagenetic minerals was seen within zone L (solid perpendicular signs) and the rest of the formation has mostly laminated shale (Figure19).

Archie (1942) and non-Archie shale models (Simandoux (1963), Schlumberger (1972), Indonesia (Poupon and Leveaux, 1971), and Dual Water (Dewan, 1983)) were used to estimate the effective water saturation results. The Archie ( $\left.\mathrm{Sw}_{\text {archie}}\right)$, Indonesia (Swe $\left.\mathrm{Sind}\right)$, and total water saturation $\left(\mathrm{Sw}_{\text {dual }}\right)$ from Dual Water model gave similar results (Figure 20). The similarity of total water saturation from Dual Water and Archie water saturation proves that the Archie equation estimates total water saturation in this formation. At some zones, Archie gave even higher water saturation estimations than total water saturation estimation calculated by the Dual Water model. On the other hand, effective water saturation $\left(\mathrm{Swe}_{\text {dual }}\right)$ from the Dual Water model gave quite low water saturation results in some zones (Figure 20). 


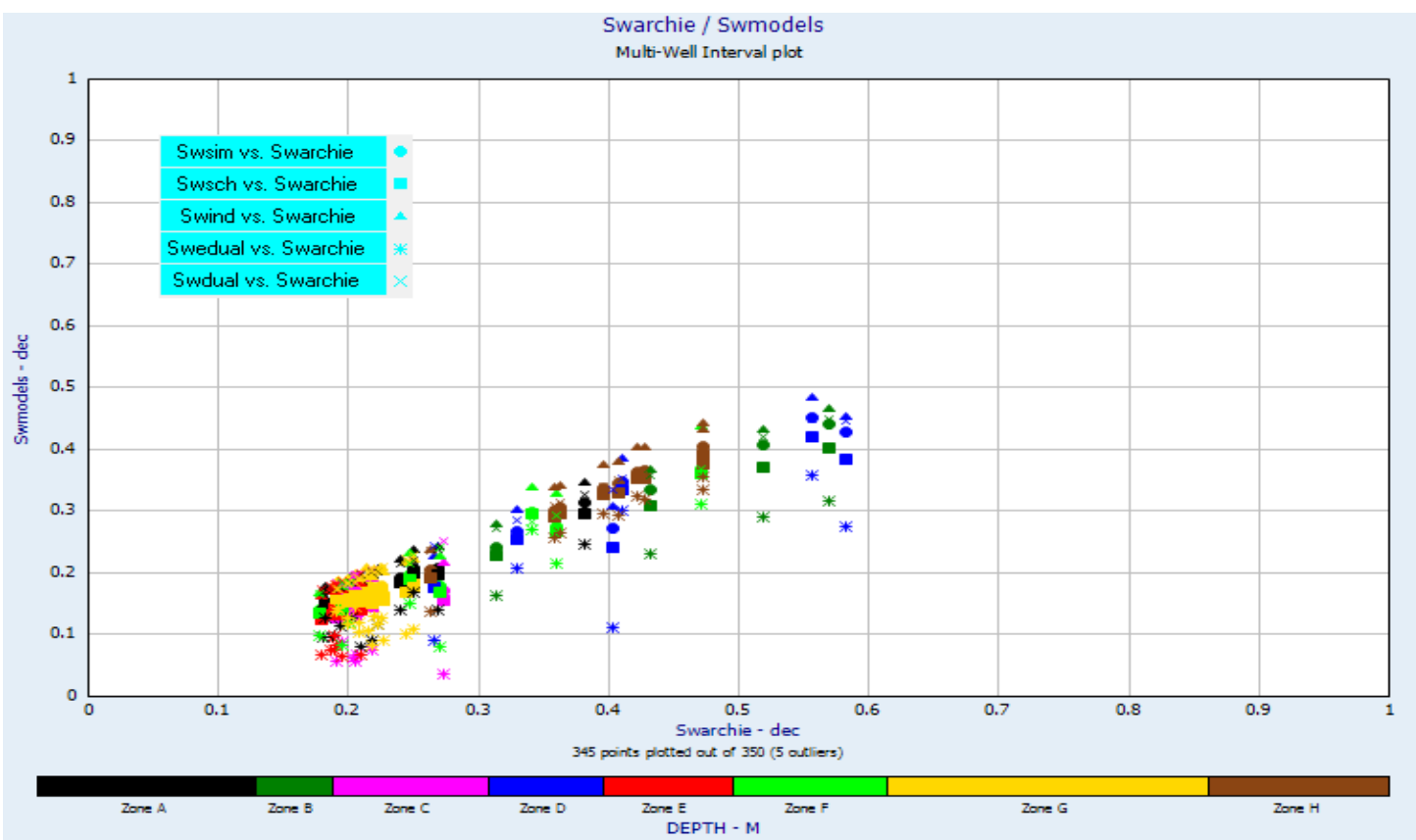

(a)

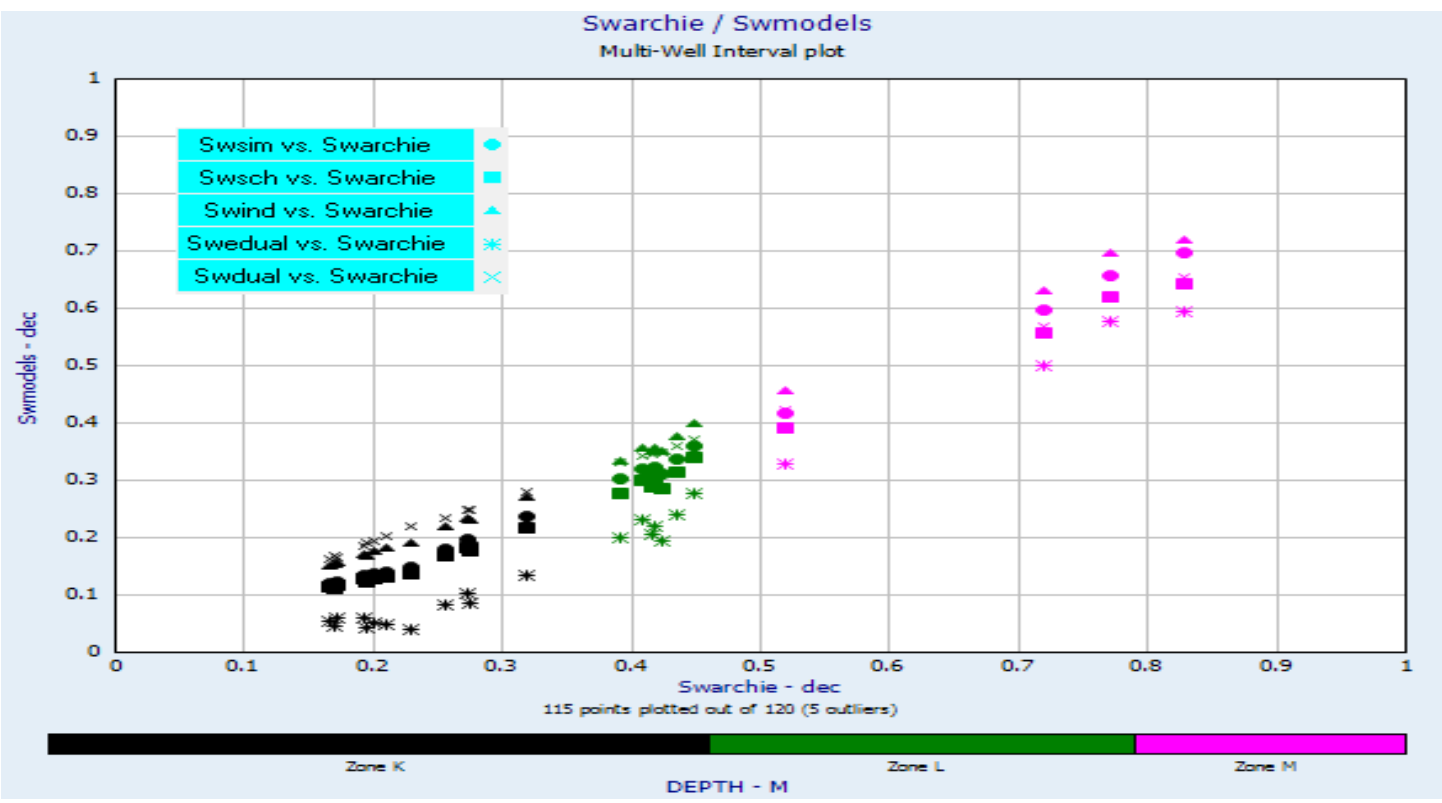

(b)

Figure 20 Comparison of the non-Archie models with the Archie equation. (a) Karewa-1 well (Zones A to $\mathrm{H}$ ) water saturation models. (b) Kahawai-1 well (Zones K, L, and M) water saturation models. In both wells, the water saturation models gave similar results. The Dual Water model (asterisk signs) shows the lowest water saturation results in low irreducible water saturation zones (zones A, C, E, G, and K). The results of Indonesia and Archie models are similar. Simandoux and Schlumberger models give similar results, but differ from other three models. 


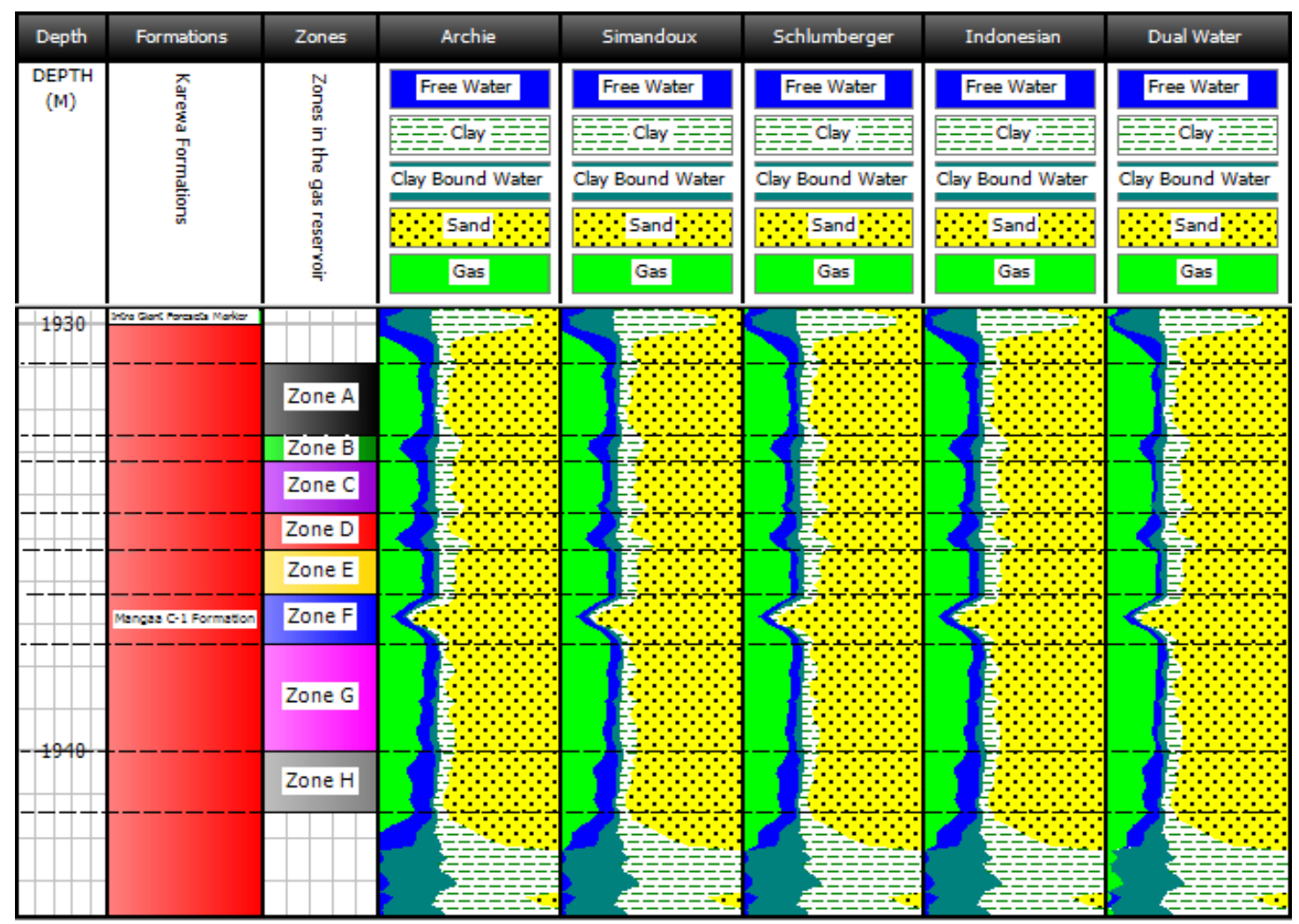

Figure 21 Karewa-1 well (Zones A to H). Lithology logs from different water saturation models show that zone B, D, and $\mathrm{H}$ are high water saturated zones. Other zones showed low water saturation results. Zone F exhibits higher rock volume which is interpreted as high degree of calcite cements.

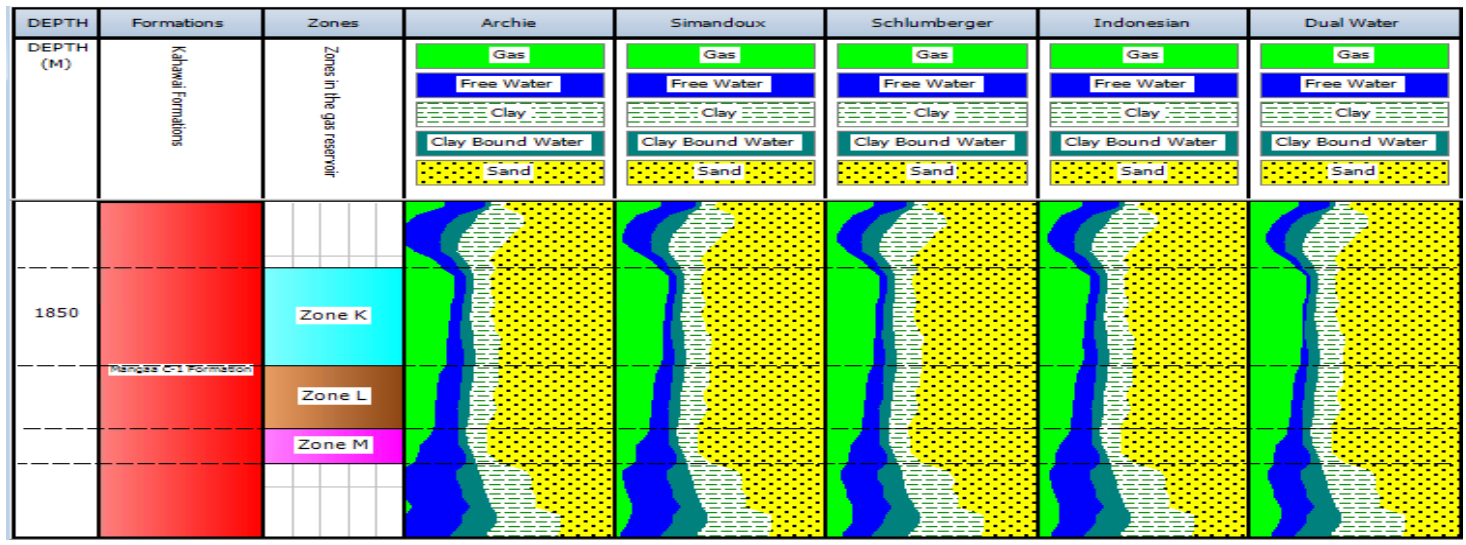

Figure 22 Kahawai-1 well (Zone K, L, and M). Lithology logs from different water saturation models. Zone L shows higher water saturation. Dramatic increase in water saturation is observed for zone $\mathrm{M}$ which is likely to be gas-water transition zone. Zone $\mathrm{K}$ showed minimum water saturation. Gas showings are misleading above zone $\mathrm{K}$ and below zone $\mathrm{M}$ due to the poor quality of well log measurements at those depths. 
Simandoux $\left(\mathrm{Swe}_{\mathrm{sim}}\right)$ and Schlumberger $\left(\mathrm{Swe}_{\mathrm{sch}}\right)$ gave best results for effective water saturation in comparison to other models.

After finding shale and sand volume, effective and total porosity, and effective, bound, and total water saturation, lithology logs were created to combine with the bulk volume water plot in further steps (Figures 21 and 22). Lithology logs help us determine the transition zone and irreducible water saturation zones.

\subsection{Bulk Volume Water (BVW)}

The challenge remaining is to determine whether the Mangaa C-1 shaly sand formation is at irreducible water saturation or not. Bulk volume water will be used here; it is the multiplication of the effective water saturation and the effective porosity.

Buckles (1965) and Asquith and Krygowski (2004) showed that bulk volume of water is constant or nearly constant at irreducible water saturation for the same lithology and grain

size. Swe-Фe parameters were plotted (bulk volume water plot) and the distribution of the bulk volume water values on the plot was observed. Increasing grain size will result in increasing bulk volume water and in the transition zone, the bulk volume water will drastically increase, regardless of the porosity (Asquith and Krygowski, 2004). Furthermore, if the hydrocarbon bearing reservoirs have mobile water in the pores, the points get randomly scattered (Asquith and Krygowski, 2004). 
In the bulk volume water plot, I used the effective porosity and the effective water saturation estimated by the Schlumberger water saturation model. When I used the bulk volume water plot (different water saturation results vs. the effective porosity), I classified the points in terms of the mean grain size found by the bulk volume water (Asquith, 1985). The Mangaa C-1 gas saturated formation contained very fine to fine grained rocks (Karewa-1 well completion report, 2002-2003). After classifying the mean grain size of the zones by the bulk volume water, I decided to use the effective water saturation results calculated by the Schlumberger model which gave the best mean grain size classification on the bulk volume water plot, and hence the best effective water saturation results (Figure 23). For the Mangaa $\mathrm{C}-1$ gas zones (Zones A to $\mathrm{H}$ ) in the Karewa-1 well, most of the zones showed the same bulk volume water values on the plot. Zones A, C, E, and G (circles) and zone F (hollow circles) showed similar bulk volume water values (Figure 23). Slight changes in the bulk volume water for zones A, C, E, G and $\mathrm{F}$ corresponded to the changes in the grain size of the formation. 

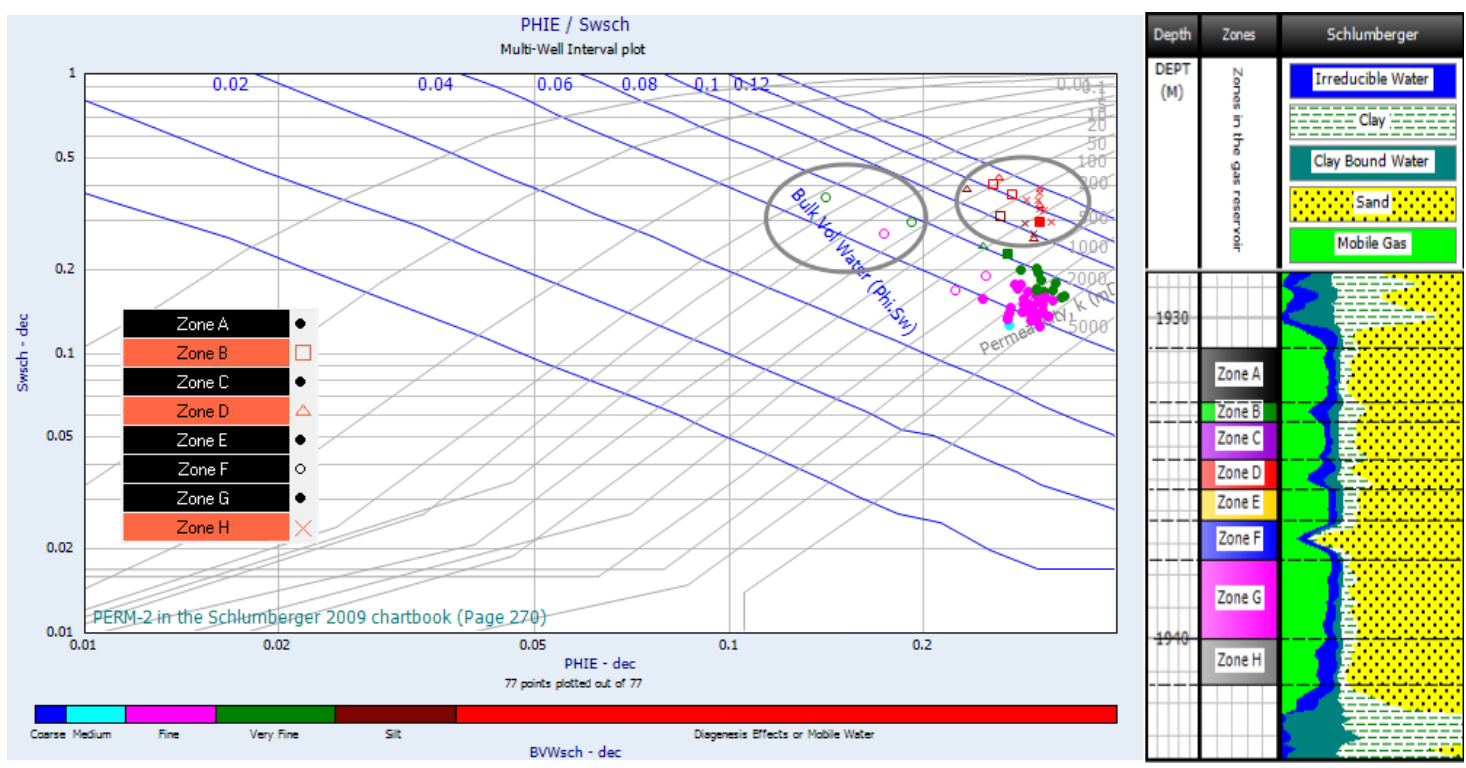

(a)
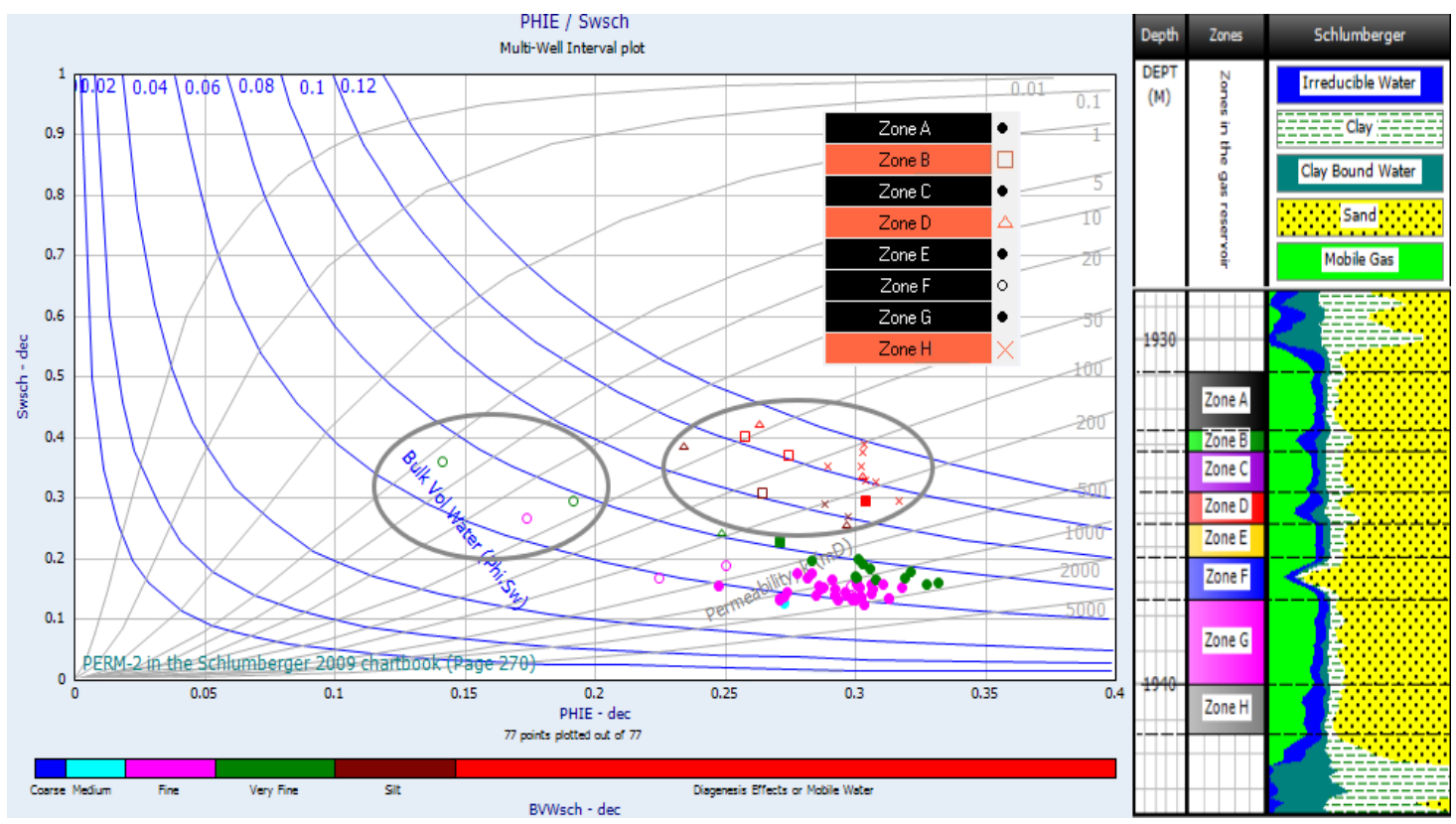

(b)

Figure 23 Karewa-1 well (Zones A to H). Bulk volume water (BVW) plots (Swe from Schlumberger model) with lithology logs to observe the transition zone and irreducible water saturation levels. Big circle covering hollow circle points on the left shows high calcite cemented zone (zone F). Zone F (hollow circles) has minimum bulk volume water and shows similar bulk volume water values with other low irreducible water saturation zones (zones A, C, E, and G) symbolized with solid circles. On the other hand, another large circle on the left shows zones $\mathrm{B}, \mathrm{D}$, and $\mathrm{H}$ (hollow perpendicular, hollow triangle, and cross signs). These scattered points are caused by ineffective dissolution porosity (microporosity and secondary porosity). (a) Logarithmic scale. (b) Linear scale. 
I interpreted that the calcite cemented zone F (hollow circle) displayed the same grain size with zones A, C, E, and G (circles), even though the porosity of zone F was too low (Figure 23). This is true because porosity is independent of grain size changes. Calcite cementation coated the sand grains without changing the grain size. The high degree of calcite cementation might completely close micro pores and secondary pores generated by feldspar dissolution, and this high degree of calcite cementation probably occurred after dissolution and alteration of feldspar minerals and lithic fragments, resulting in really low porosity in this zone. It means that if some mineral grains in zone $\mathrm{F}$ were partially or completely dissolved and created extra pore spaces, high calcite cementation which resulted from the chemical interactions of the minerals with water would fill these secondary pores and decrease the porosity drastically. Consequently, the high degree of the calcite cementation of zone F occurred after minerals were dissolved; otherwise, the porosity of zone F would not be so low.

There are several zones (zones B, D, and $\mathrm{H}$ ) which have higher bulk volume water and which are scattered on the upper parts of the bulk volume water plot (Figure 23). They were caused by neither the transition zone nor the mobile water; rather, microporosity and secondary porosity created by unstable diagenetic feldspar minerals (plagioclase or potassium feldspar minerals) and lithic fragments caused the increase of the bulk volume water as a result of higher irreducible water in the pores. 


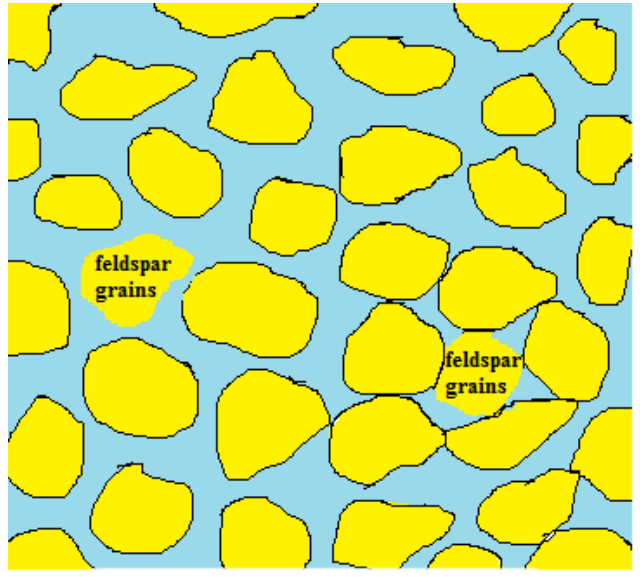

Before dissolution of feldspar minerals (no dissolution porosity)

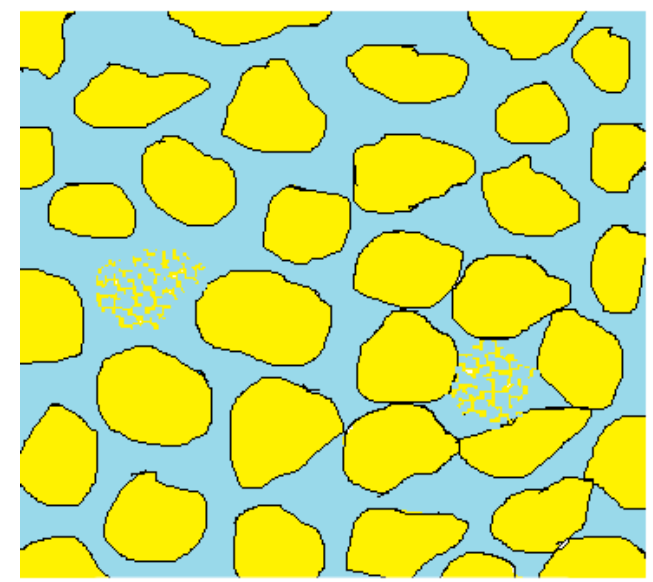

Dissolution of feldspar minerals continues (increasing amount of micro pores)

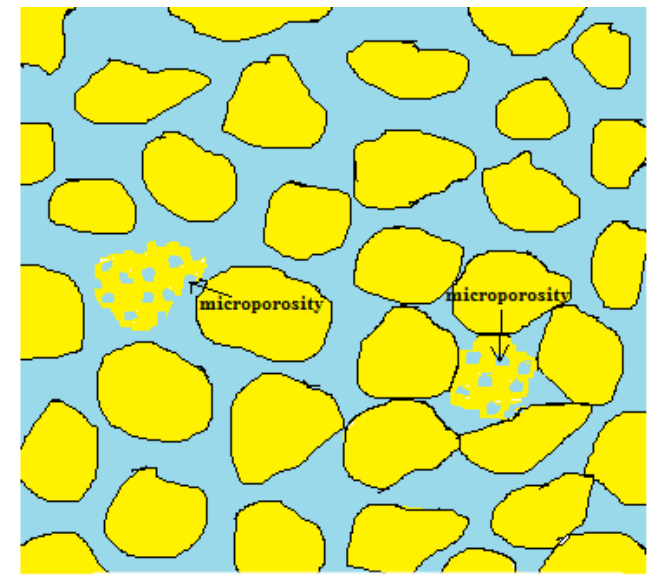

After partially dissolution of feldspar minerals (micro pores)

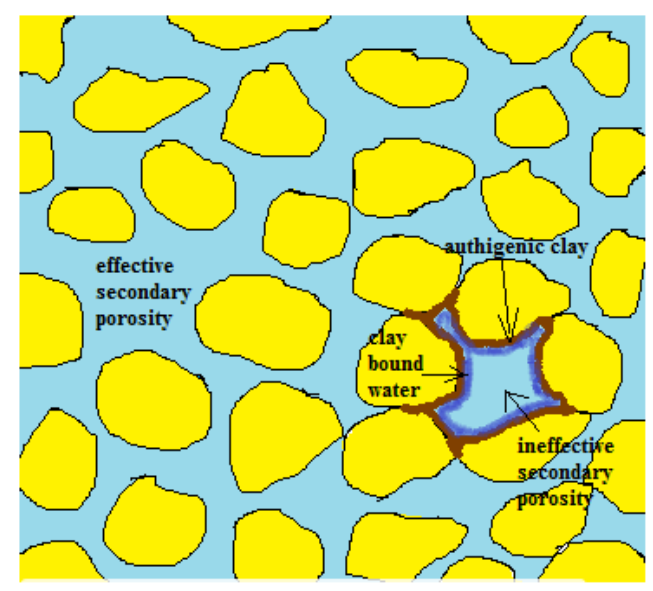

After fully dissolution of feldspar minerals (effective and ineffective second pores with authigenic clay cements)

Figure 24 Dissolution of feldspar minerals (diagenesis) and forming of micro pores, secondary pores, and authigenic clay cements within pores.

Partially or fully dissolved feldspar minerals and lithic fragments created micro pores and secondary pores within the formation (Karewa-1 well completion reports, 2002-2003) (Figure 24). If the micro pores and the secondary pores were connected to the effective pore systems in the formation, the bulk volume water values for zones B, D, and $\mathrm{H}$ calculated from the effective porosity would be similar to other zones (low irreducible water zones) for the same grain size. On the other hand, bulk volume water values in 
zones $\mathrm{B}, \mathrm{D}$, and $\mathrm{H}$ were higher than irreducible water saturation zones (zones A, C, E, F, and G) (Figure 23). The reason is not expected to be the existence of mobile water because the PEF log increases in zones B, D, and $\mathrm{H}$.

PEF log was not affected by water and the increase of the PEF log was due to the abundancy of the plagioclase and potassium feldspar minerals which were prone to be subjected to diagenesis effects at low pressure and temperature conditions (Ali Sa, 2010) and due to the some precipitating clay minerals (authigenic) which might form as byproducts of altering feldspar minerals and lithic fragments (Huang W. L., 1986).

Core descriptions (thin sections) showed that there were some microporosity and secondary porosity (formed after diagenesis) in addition to intergranular porosity in zones B, D, and H (Karewa-1 well completion report, 2002-2003). Removing dissolution porosity will help us identify the true bulk volume water values in the effective pore systems in which gas flows. 

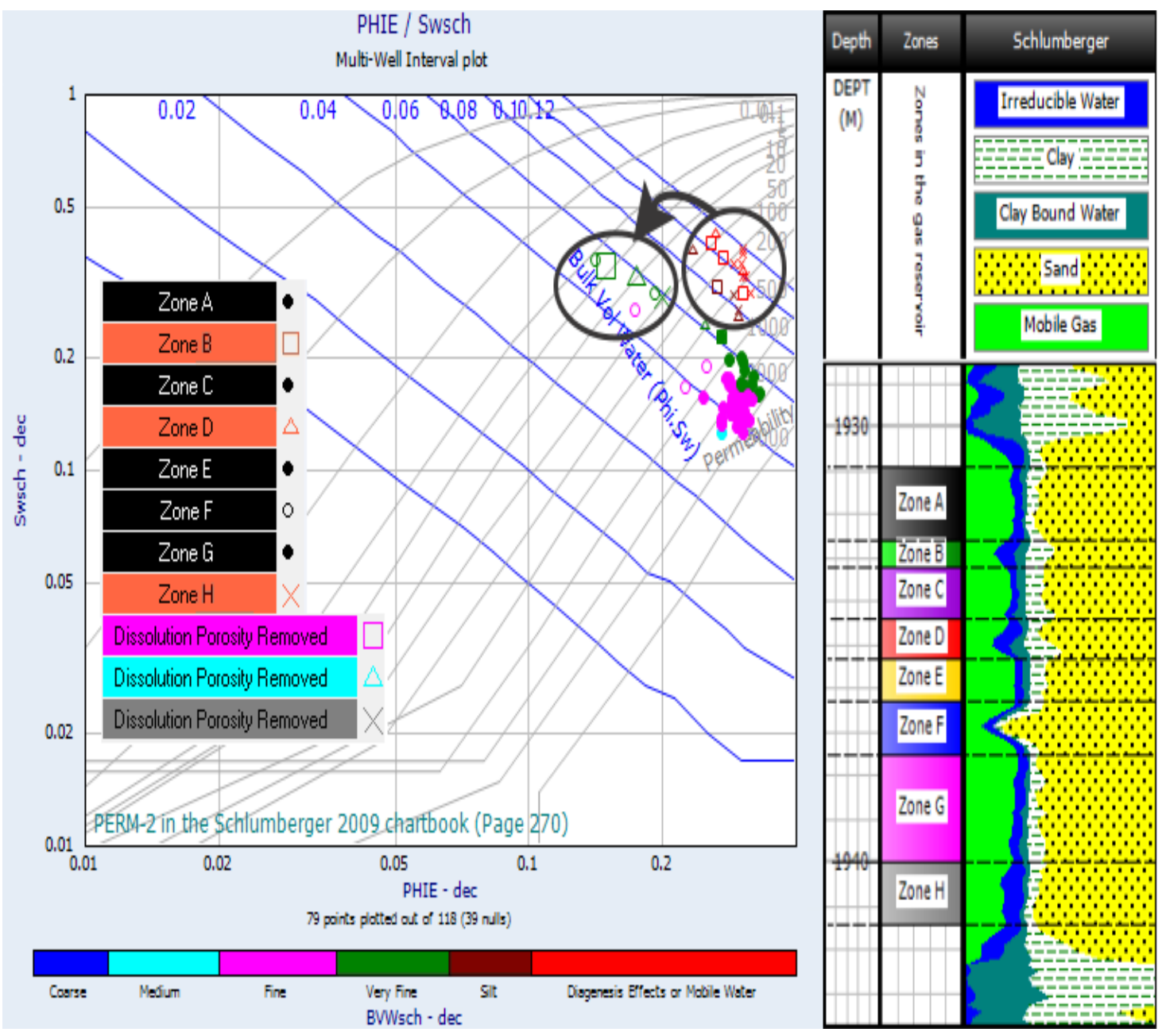

Figure 25 Karewa-1 well (Zones A to H). Three thin section intergranular porosity (removed for secondary and micro pores in zones B, D, and $\mathrm{H}$ ) and water saturation from the Schlumberger equation adjusting the Rt log and effective porosity (dissolution porosity removed) were added to the bulk volume water plot to show the true places of the diagenetic zones (zones B, D, and $\mathrm{H}$ ). Before removing the dissolution porosity, these diagenetic zones (triangle, perpendicular, and cross signs) marked with a large circle on the right misleadingly correspond to mobile water or transition zone. Yet, after removing the dissolution porosity (known from thin sections at three depths), the true bulk volume water values of these zones marked with a large circle on the left are seen to be similar to low irreducible water saturation zones (solid circles and hollow circles). Removing ineffective dissolution porosity moved the points to lower bulk volume water values shown with an arrow. Logarithmic scale. 

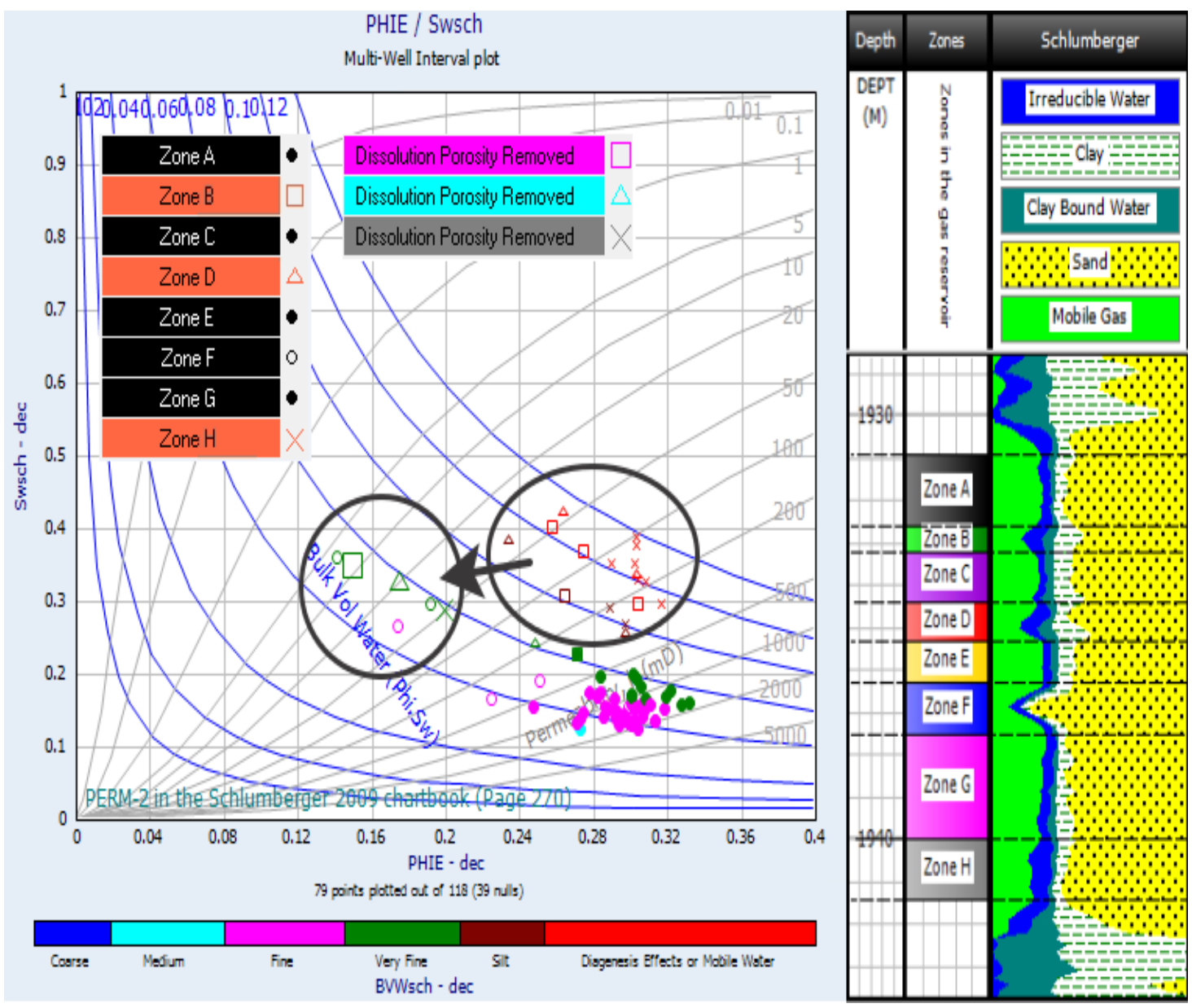

Figure 26 Karewa-1 well (Zones A to H). Three thin section intergranular porosity (removed for secondary and micro pores in zones B, D, and $\mathrm{H}$ ) and water saturation from the Schlumberger equation adjusting the Rt $\log$ and effective porosity (dissolution porosity removed) were added to the bulk volume water plot to show the true places of the diagenetic zones (zones B, D, and H). Linear scale.

Thin section microporosity and secondary porosity at three depths for zones B, D, and $\mathrm{H}$ were removed from the effective porosity. To find the true irreducible water saturation at these three depths, the deep resistivity log must be adjusted on the Schlumberger equation. This is because the deep resistivity log results at three diagenetic zones were not only suppressed by the clay minerals, but also water in the ineffective dissolution pores will create extra conductivity pathways and will suppress the resistivity log even 
more. Schlumberger equation attempts to eliminate only the effects of the clay minerals on the conductivity, but ineffective dissolution porosity must be removed, as well.

Grain size classification within the diagenetic zones $(\mathrm{B}, \mathrm{D}$, and $\mathrm{H})$ is very fine. Knowing the effective porosity and grain size classification at these zones, I adjusted the true resistivity values to find the effective water saturation (Figures 25 and 26). The bulk volume water irreducible was then calculated for each. Results show that true predictions of effective porosity (in addition to microporosity in shale, microporosity and secondary porosity in diagenetic minerals were removed) and irreducible water saturation assist in finding true bulk volume water values of these zones $(\mathrm{B}, \mathrm{D}$, and $\mathrm{H})$ within the effective pore systems.

The transition zone can be recognized on bulk volume water plots with increasing bulk volume water values (scattered points). At first glance, zone $\mathrm{H}$ might be thought to be the transition zone because bulk volume water values are variously increasing within this zone, but removing dissolution porosity showed that the reason for increasing bulk volume water values in the zone is ineffective dissolution porosity (microporosity and secondary porosity) rather than mobile water. Also, under zone $\mathrm{H}$, there is a shale interval rather than water saturated sandstone; thus, there is no transition zone or free water level identified under the gas formation in the Karewa-1 well.

As for the thin gas formation in the Kahawai-1 well, the same process is applied. Bulk volume water results showed that zone $\mathrm{K}$ has minimum and constant bulk volume water 
which corresponds to irreducible water saturation (Figure 27). On the other hand, the consistency of the bulk volume water values within zone $\mathrm{L}$ is seen on the plot, but rather than minimum bulk volume water, higher bulk volume water values were seen in zone $\mathrm{L}$ (Figure 27). The grain size decrease in zone L corresponds to higher capillarity in the pores. This silt-size grains within zone L will hold more water in the pores. Additionally, there might be some other reasons such as microporosity and secondary porosity which increase bulk volume water values, but within zone L, bulk volume water is consistent (big circle) which corresponds to changes in the grain size (Figure 27). Lastly, combining with lithology logs, the bulk volume water plot displayed that zone $\mathrm{M}$ is the transition zone due to the dramatic increase of the bulk volume water (shown with the arrow) (Figure 27). 

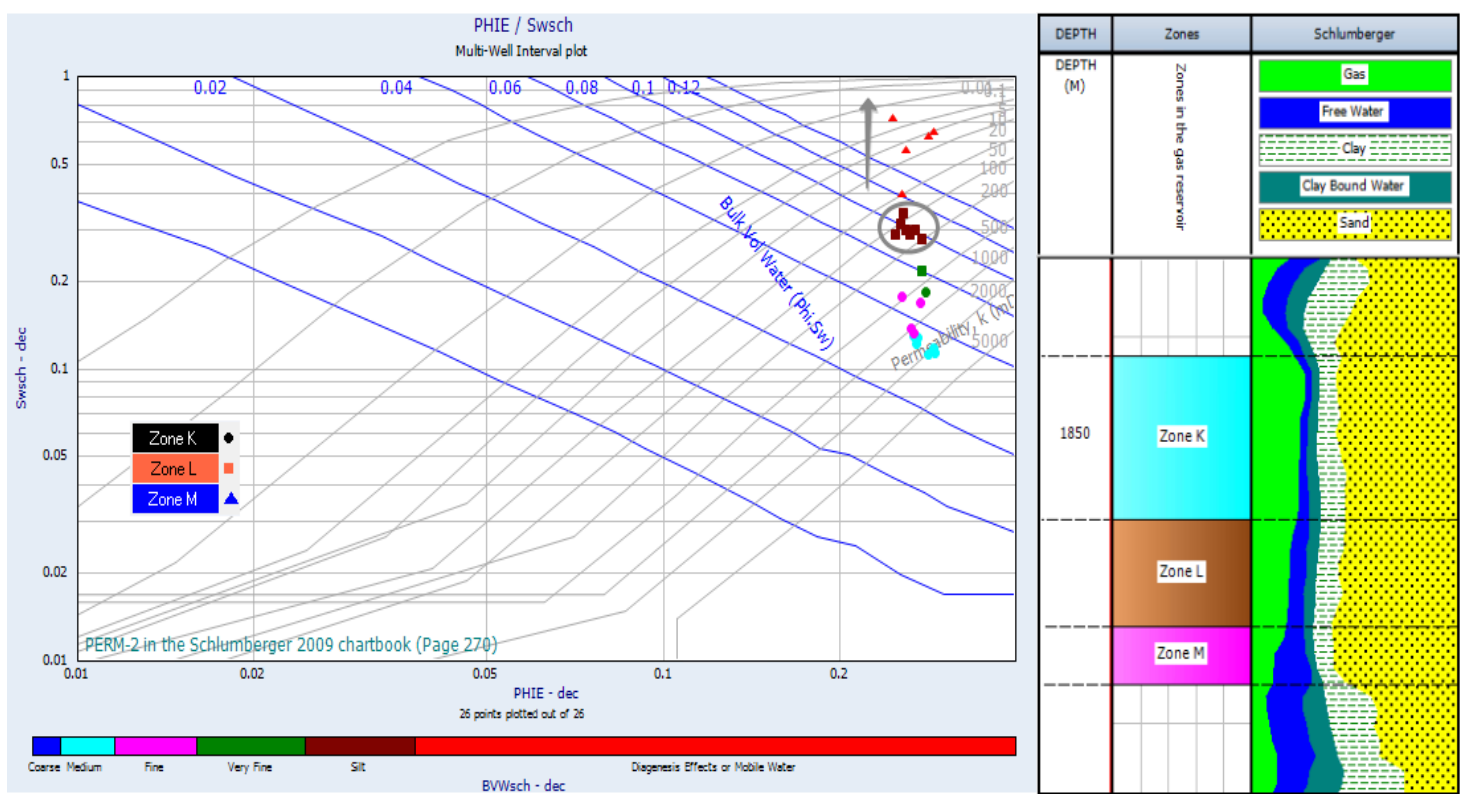

(a)

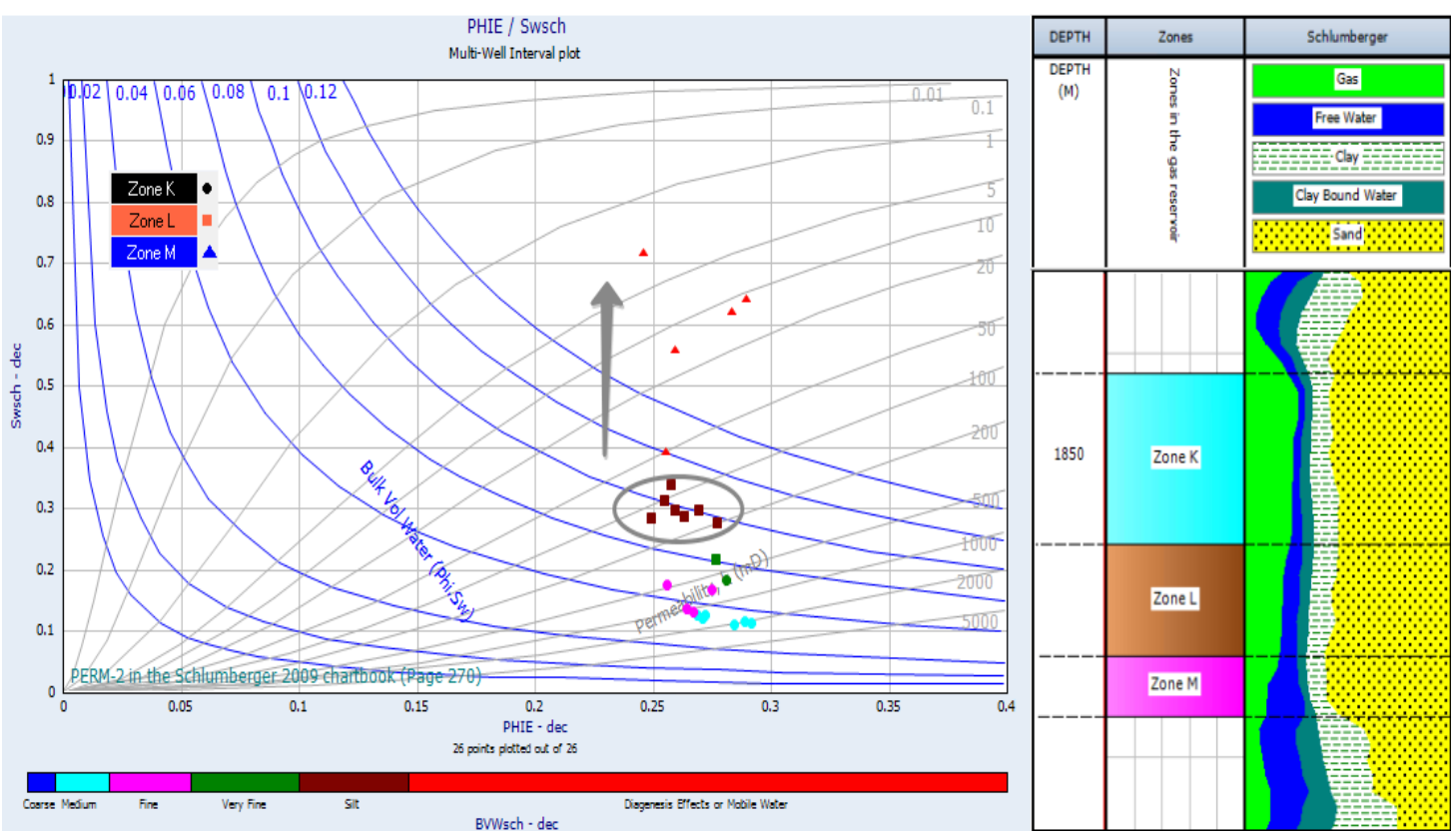

(b)

Figure 27 Kahawai-1 well (Zone K, L, and M). Bulk volume water (BVW) plots (Swe from Schlumberger model) with lithology logs to observe the transition zone and irreducible water saturation levels. Zone L (perpendicular signs) marked with a large circle shows constant bulk volume water values, affected by grain size. Smaller grain size (higher capillarity in the pores) caused high irreducible water saturation. On the other hand, drastic increase of bulk volume water shown with the arrow in zone $M$ (triangle signs) indicates a typical transition zone. (a) Logarithmic scale. (b) Linear scale. 
All information mentioned above proved that the bulk volume water plot combined with the lithology logs and core descriptions can be used to determine detrimental diagenesis effects (ineffective microporosity and ineffective secondary porosity). Also, the bulk volume water plot demonstrated that the diagenesis effects caused higher irreducible water saturation in zones $\mathrm{B}, \mathrm{D}$, and $\mathrm{H}$ whereas in zone $\mathrm{L}$, abundant-silt sized grains kept higher irreducible water in the pores. This information will be useful in estimating the permeability of the zones at irreducible water saturation.

\subsection{Log-derived Permeability}

In this section, permeability will be calculated for zones at irreducible water saturations and results will be discussed. Moreover, air permeability to be used in the Winland correlation for pore type characterization of the reservoir was estimated from the gas absolute permeability of the formation, using an empirical relationship (Swanson, 1981).

Permeability might be estimated from irreducible water saturation and effective porosity by using some empirical models (Timur, Morris-Biggs, Coates-Denoo, and CoatesDumanoir). All these formulas were created from the Wyllie-Rose (1950) equation. Except Morris-Biggs equation, other three empirical models are suitable for medium gravity oil fields. Morris-Biggs permeability equation used in this study is already suitable for gas fields.

Permeability of the gas formation cannot be estimated from the empirical permeability equations (Timur, Coates-Denoo, and Coates-Dumanoir) which are suitable for medium 
gravity oil fields because these three equations were used for laminar flow (Dewan, 1983). On the other hand, around the borehole, gas flow might be turbulent (Dewan, 1983). For gas reservoirs, these three equations must be modified.

With respect to Dewan's suggestion (1983), gas density must be added to the permeability equation to better predict the absolute permeability for gas fields. Therefore, I modified the permeability Timur, Coates-Denoo, and Coates-Dumanoir equations by adding the gas density (Assumed to be $0.1 \mathrm{~g} / \mathrm{cm} 3$ ).

To approximate air permeability (laboratory permeability) which is used in Winland's equation, I assumed that the gas absolute permeability found by empirical models in this study is equal to the liquid permeability (no Klinkenberg effect). I used Swanson's empirical relationship (1981) which converts liquid permeability to air permeability.

Also, multi-linear regression analysis is used to create a permeability equation from well logs, using Timur permeability results and the gamma ray, density and deep resistivity $\log$.

Lastly, Timur permeability $(\mathrm{Kt})$ is calculated from the irreducible water saturation and effective porosity (dissolution porosity removed) for zones $\mathrm{B}, \mathrm{D}$, and $\mathrm{H}$, at three depths. This is because dissolution porosity was isolated in zones $\mathrm{B}, \mathrm{D}$, and $\mathrm{H}$ and must be removed from effective porosity for true judgement of permeability within these zones. 
Removing dissolution porosity in three zones assisted to find more reliable permeability results shown with red points (Figure 25a).

As I showed on the bulk volume water plot, except for in zone M (transition zone), the gas formation in two wells is at irreducible water saturation (no water cut). Therefore, the permeability estimations are invalid for zone $\mathrm{M}$ which has mobile water, and pore type characterization of zone $\mathrm{M}$ will not be included in this study.

The Timur and Coates-Denoo permeability results were similar in both wells. The MorrisBiggs gas permeability values were lower than other three permeability equations. The Coates-Dumanoir gave higher values than other equations.

Permeability estimations display high productive and low quality (diagenetic) rocks in the gas formation in the Karewa-1 well (Figure 25a). Even though calcite cementation might mostly contribute permeability of rocks, in this gas formation, the high degree of calcite cementation (zone F) showed quite detrimental effects to reservoir quality and decreased the permeability and the porosity in the gas formation. Even though grain size (related to permeability) was not changed in zone 


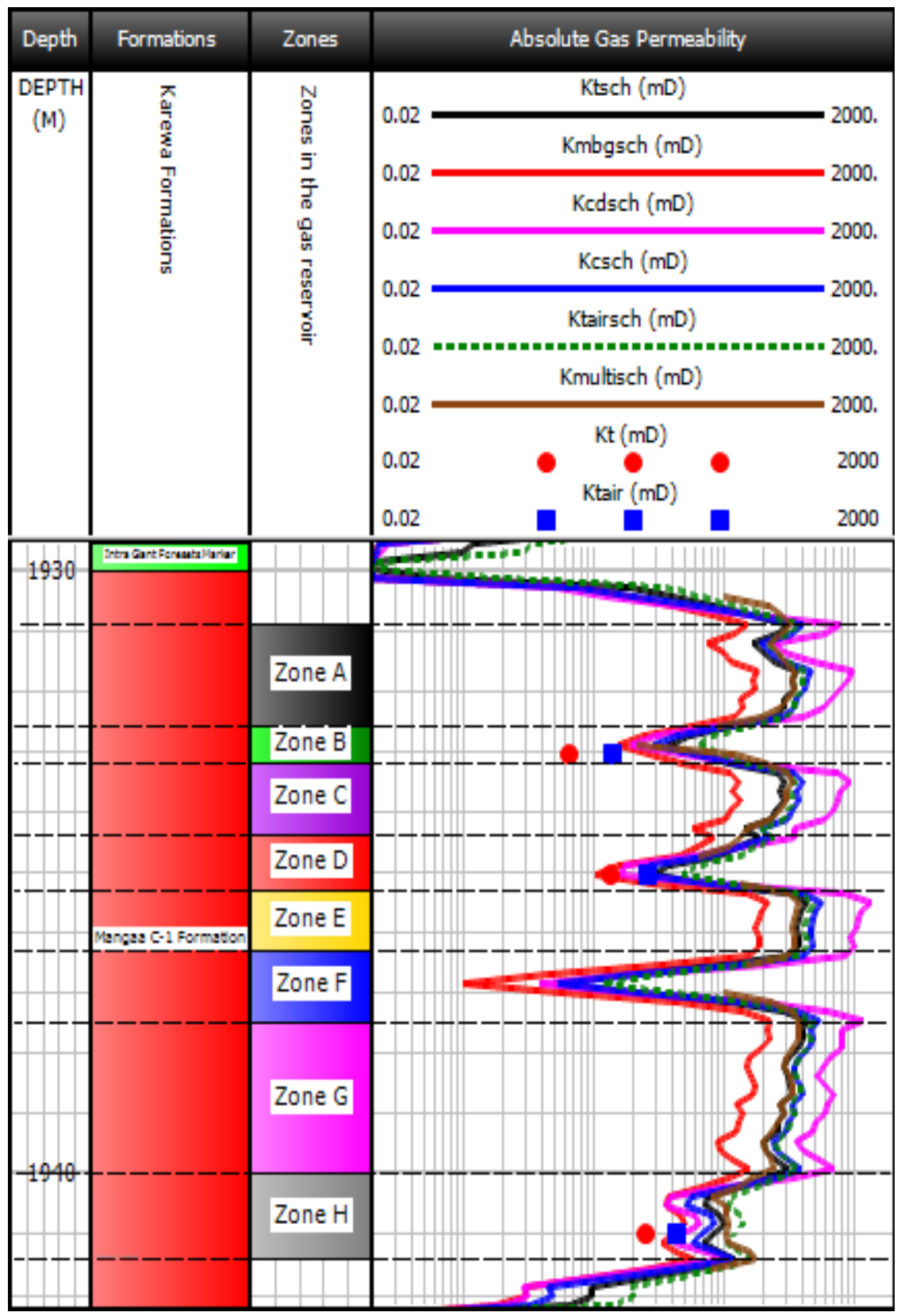

Figure 28 Permeability results. Karewa-1 well for zones A to H. Permeability estimations from empirical models. Ktsch, Kmbgsch, Kcsch, Kcdsch, Ktairsch, Kmultisch, Kt, and Ktair are Timur, Morris-Biggs, Coates-Denoo, Coates-Dumanoir, air (converted from Timur permeability), multi-linear regression, Timur absolute (dissolution porosity removed), Air (dissolution porosity removed) permeability results calculated from the effective porosity and the irreducible water saturation of the Schlumberger model, respectively. Permeability results are high in zones A, C, E, and G whereas permeability results are too low in diagenetic zones (zones $\mathrm{B}, \mathrm{D}, \mathrm{F}$, and $\mathrm{H}$ ). 


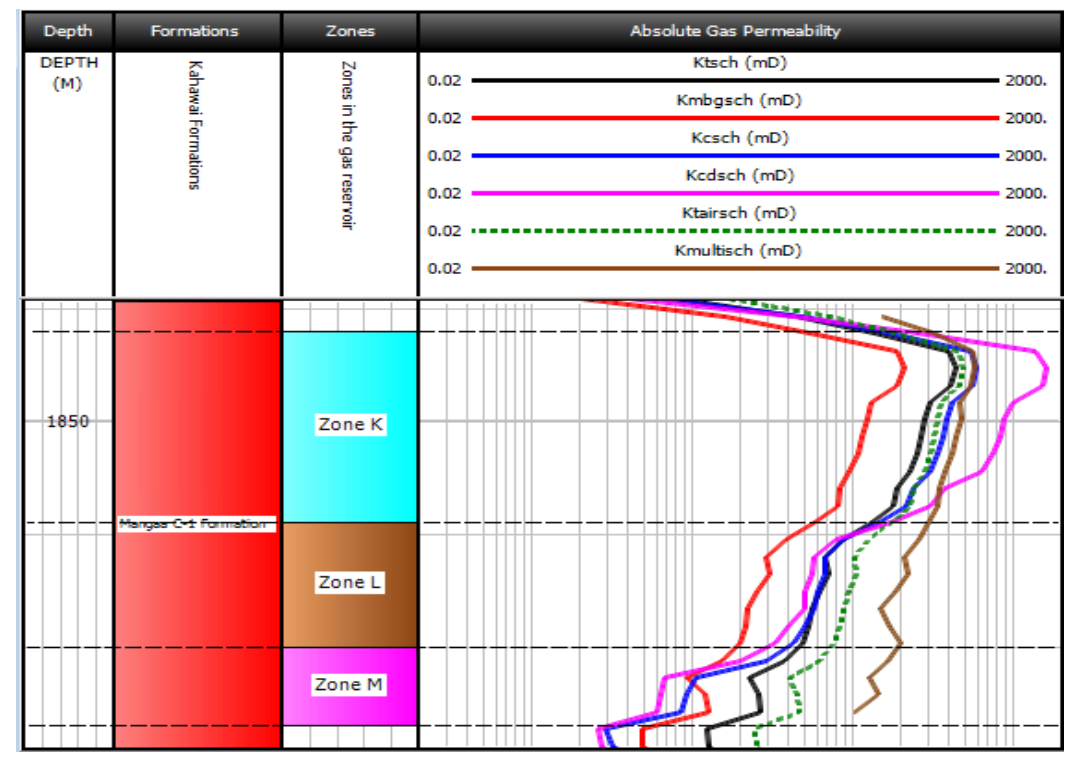

Figure 29 Permeability results. Kahawai-1 well for zones K and L. Permeability estimations from empirical models. Ktsch, Kmbgsch, Kcsch, Kcdsch, Ktairsch, and Kmultisch are Timur, Morris-Biggs, Coates-Denoo, Coates-Dumanoir, air (converted from Timur permeability), and multi-linear regression permeability results calculated from the effective porosity and the irreducible water saturation of the Schlumberger model, respectively. Within zone $\mathrm{M}$ (transition zone), permeability results are not reliable. Permeability results are high in zone K.

F (calcite cemented), permeability was decreased due to low porosity, small intergranular pores and high irreducible water saturation.

As for zones $\mathrm{B}, \mathrm{D}$, and $\mathrm{H}$, diagenesis effects such as dissolution, alteration and precipitation of minerals decreased the absolute permeability due to the poor connectivity of micro pores and secondary pores (dissolution porosity) to effective pore systems. Rest of the formation (zones A, C, E, and G) are recognized as highly permeable zones (low irreducible water saturation zones) (Figure 25a). The main controls of permeability for the gas formation in Karewa-1 well are isolated micro pores, secondary pores, and shale in sandstone. 
For the thin gas formation in Kahawai-1 well, high permeability was observed in zone K. On the other hand, zone L showed lower permeability due to smaller grain size (abundant silt grains) and high irreducible water saturation (Figure 25b).

\subsection{Flow Unit Characterization}

\subsubsection{Flow Zone Indicator (FZI)}

The Flow zone indicator or the hydraulic flow unit characterize different flow units in formations. High productive zones, low-quality rocks, and diagenesis effects can be identified by a flow zone indicator (FZI). Soto et al. (2010) created an equation to estimate reservoir quality index from permeability and effective porosity. Amaefule (1993) identified the flow zone indicator from the ratio of the reservoir quality index to the normalized porosity. Normalized porosity is the ratio of pore volume to rock volume. A Log-log plot of the reservoir quality index and the normalized porosity was used to observe the different flow zone units (high productive, low quality, or diagenetic zones). I used Timur permeability results estimated by effective porosity and Schlumberger effective water saturation to find the reservoir quality index (RQI), normalized porosity, and flow zone indicator (FZI) values in different zones. Higher flow zone indicator values were attributed higher reservoir quality rocks on the plot.

Flow zone indicator plot distinguished the diagenetic rocks, silt-size grained rocks, and highly gas productive zones from each other (Figures 30a and 30b). Diagenetic rocks (zones $\mathrm{B}, \mathrm{D}, \mathrm{F}$, and $\mathrm{H}$ ) gave the lowest flow zone indicator values whereas the silt-size grained zone (zone L) showed slightly higher flow units. Zones A, C, E, G, and K showed 


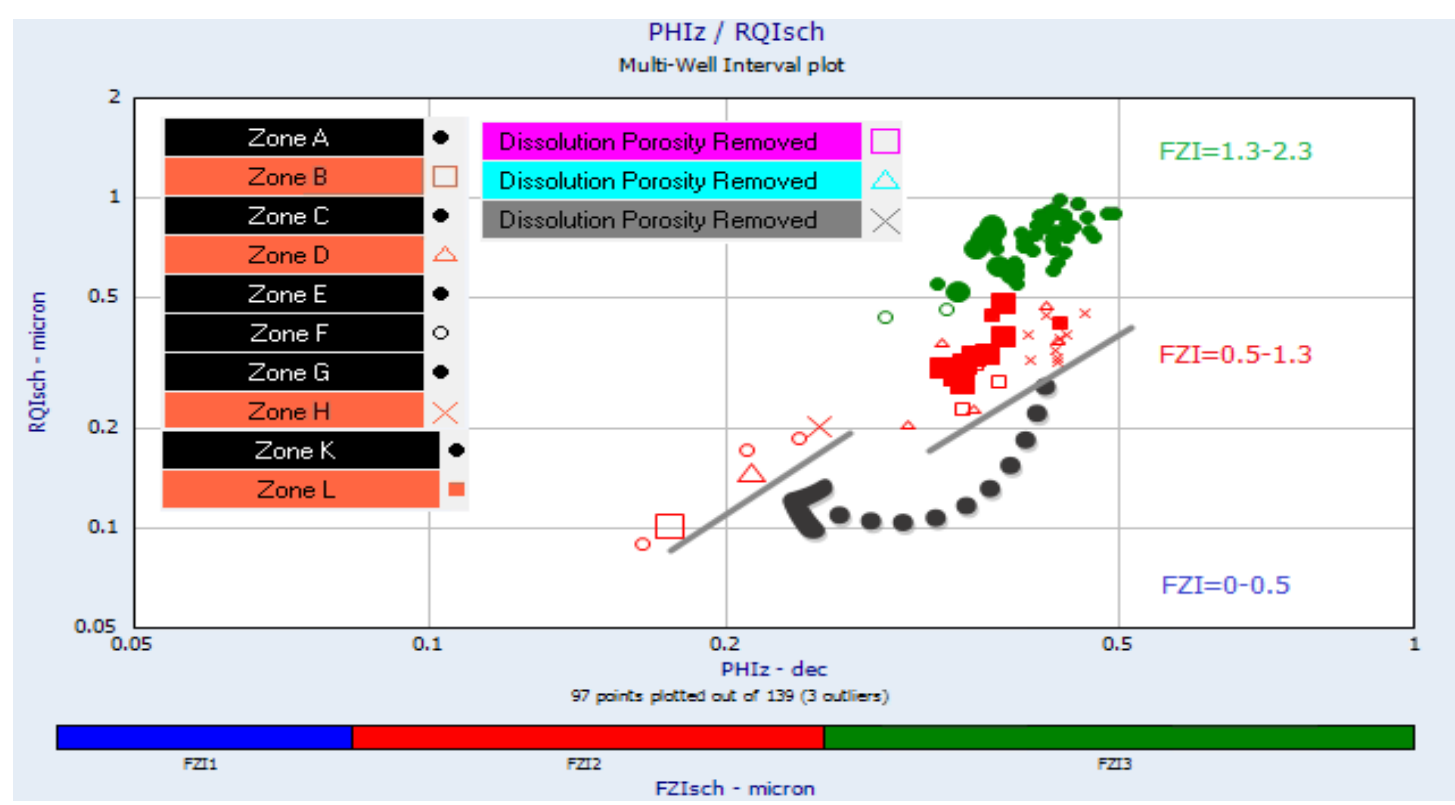

(a)

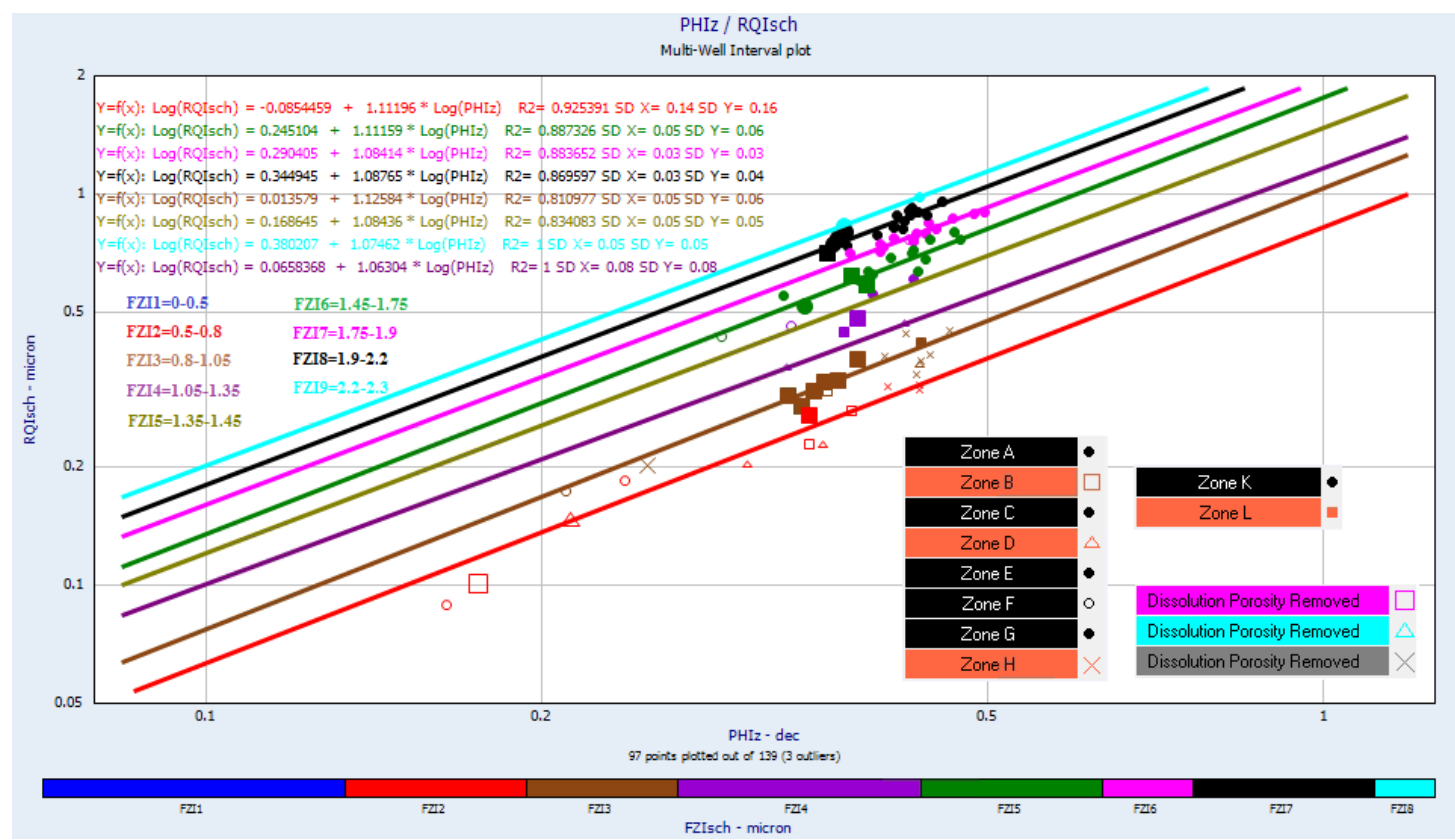

(b)

Figure 30 Flow zone indicator (FZI) plot. Karewa-1 (Zones A to H) and Kahawai-1 (Zones K and L) wells. FZI from Timur absolute permeability (Ktsch) found by Schlumberger water saturation equation. (a) Red color symbols show the low flow zone indicator values (diagenetic and smaller grain size rocks) whereas green color points display the high flow zone indicator values (high permeable and low irreducible water saturation zones). (b) It shows detailed version of the flow zone indicator plot. 
higher flow zone indicator values. Depending on the similar flow zone indicator values, points were colored on the plot (Figure 30b).

As a result of the flow zone indicator plot, diagenesis was interpreted more detrimental to the reservoir quality than the effects of smaller grain size (silt size grains) within the gas formation.

\subsubsection{Winland (R35) Empirical Correlation}

H. D. Winland (Amoco Production Company) created empirical equations by correlating the air permeability, the porosity and the pore throat size with different mercury saturation values from mercury injection capillary tests (Kolodzie, 1980). Winland concluded that pore throat radii at $35 \%$ mercury saturation give the best results for the dominant pore throat size of the rocks (Kolodzie, 1980). Winland used 82 (56 sandstone and 26 carbonate) samples with Klinkenberg-corrected permeabilities and 240 sandstone and carbonate samples with uncorrected air permeabilities. Kolodzie (1980) published the equation that Winland created. 


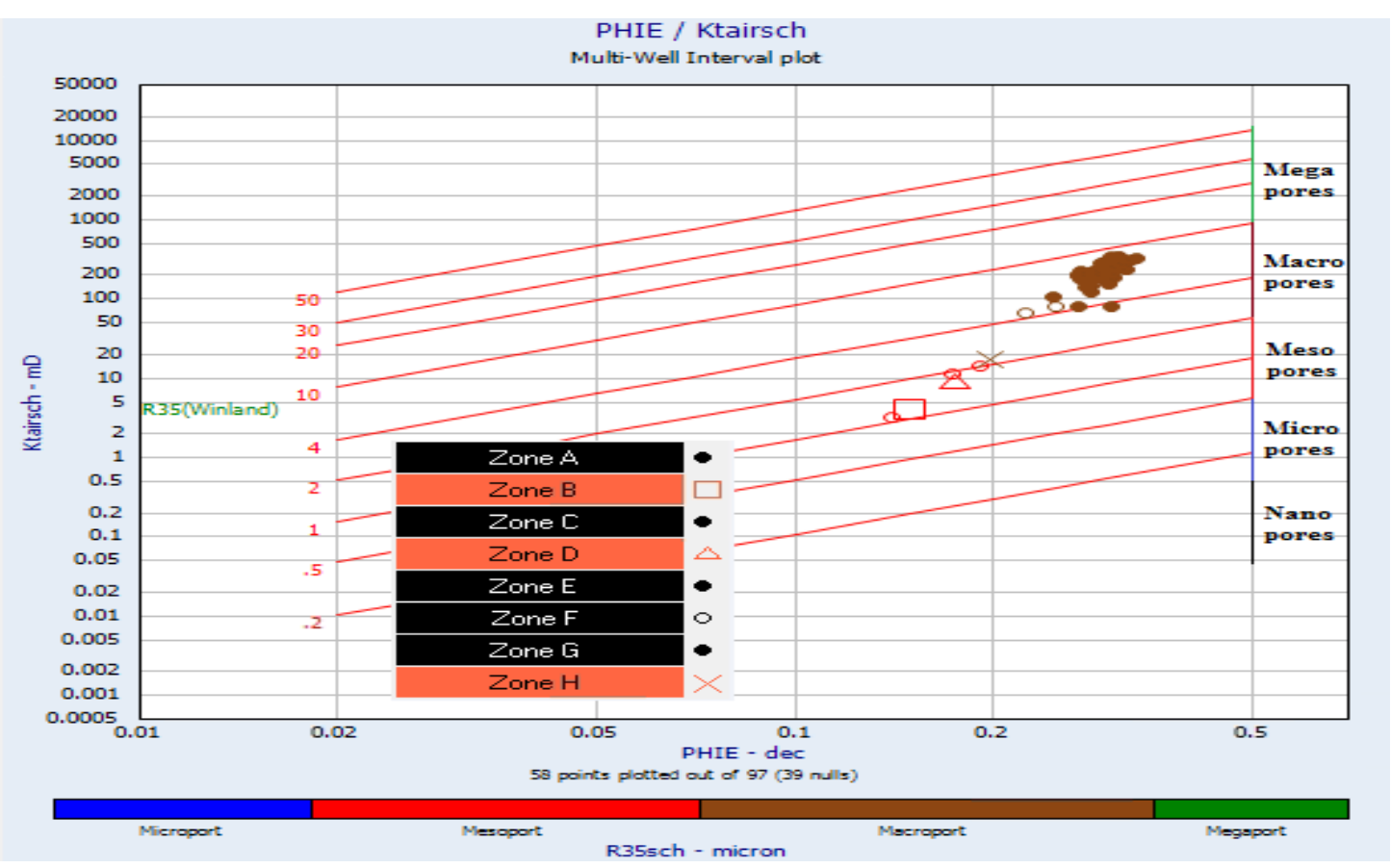

Figure 31 Karewa-1 well (Zones A to H). Winland (R35) plot. Pore throat size at 35\% mercury saturation (R35) from Timur air permeability (Ktairsch) (Logarithmic scale).

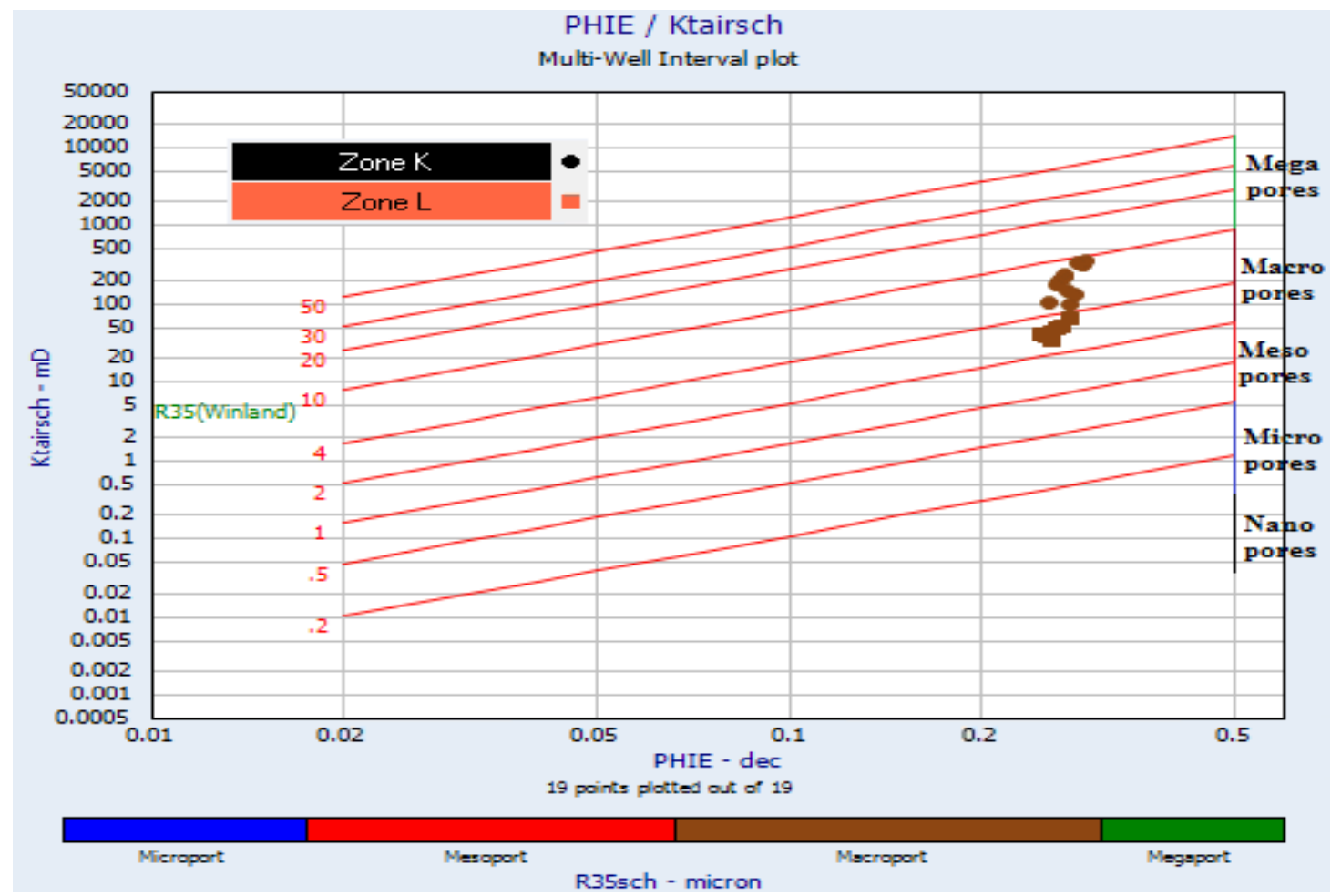

Figure 32 Kahawai-1 well (Zone K and M). Winland (R35) plot. Pore throat size at 35\% mercury saturation (R35) from Timur air permeability (Ktairsch) (Logarithmic scale). 
To use Winland's empirical correlation for pore size and pore type classification, I converted the gas absolute permeability to the uncorrected air permeability by using the Swanson's empirical relationship (1981) between the liquid permeability and the air permeability. My assumption was that the liquid permeability which does not have gas slippage effects was accepted to be equal to the gas absolute permeability that I found from the Timur, Morris-Biggs, Coates-Denoo, and Coates-Dumanoir models.

The results for the Mangaa C-1 gas formation in the Karewa-1 well showed that the pore throat radius at $35 \%$ mercury saturation (port size or R35) was decreased by the diagenesis effects (calcite cementation, dissolution and alteration of feldspar minerals and lithic fragments, and precipitation of authigenic clay cements) in zones B, D, F, and $\mathrm{H}$. In zone $\mathrm{F}$, the high degree of calcite cementation which might fill the pores created by the diagenesis effects narrowed the pore throats greatly without decreasing the grain size of the formation at these depths. Lower pore throats correspond to higher capillarity within the pores by keeping a greater amount of irreducible water among the grains.

After removing the ineffective dissolution porosity in zones $\mathrm{B}, \mathrm{D}$, and $\mathrm{H}$, I estimated the dominant port size (R35) more reasonably in the diagenetic zones $(\mathrm{B}, \mathrm{D}$, and $\mathrm{H})$. Before correction, port size of zones B, D, and $\mathrm{H}$ (hollow perpendicular, hollow triangle, and times signs, respectively) was higher and classified as "macroport" on Winland's plot. After the diagenesis correction (shown with the arrow), port size of the diagenetic zones was lowered and classified as "mesoport" similar to zone F (Figure 31). 
On the other hand, the high productive zones (A, C, E, and G) showed higher port sizes and were classified as "macroport". Zones A, C, E, and G were interpreted as intergranular porous zones.

In the Kahawai-1 well, the Mangaa C-1 gas formation showed macro port size on Winland's plot (Figure 32). Pore throat size of zone K was interpreted as macroport and is similar to high productive zones (zones A, C, E, and G) in the Karewa-1 well. On the other hand, zone L showed decreasing pore throat size, but the dominant pore throat type in the zone is classified as macroport.

Zone $\mathrm{M}$ was not considered in the pore type characterizations because all pore type characterization methods in this study necessitated effective porosity and absolute permeability parameters, but zone $\mathrm{M}$ was recognized as the transition zone which the permeability models were invalid. Therefore, zone $\mathrm{M}$ was not involved for flow unit methods.

\subsection{3 $\mathrm{K} / \Phi$ ratio}

The permeability-porosity ratio was used to characterize different flow units (pore size) in the gas reservoir for the Karewa-1 and Kahawai-1 wells (Figure 33). Rather than interpreting porosity or permeability alone, I used the permeability-porosity ratio to better understand different hydraulic flow units in the gas reservoir. I plotted the gas absolute permeability calculated from Timur's model, the effective porosity, and the ratio of these 


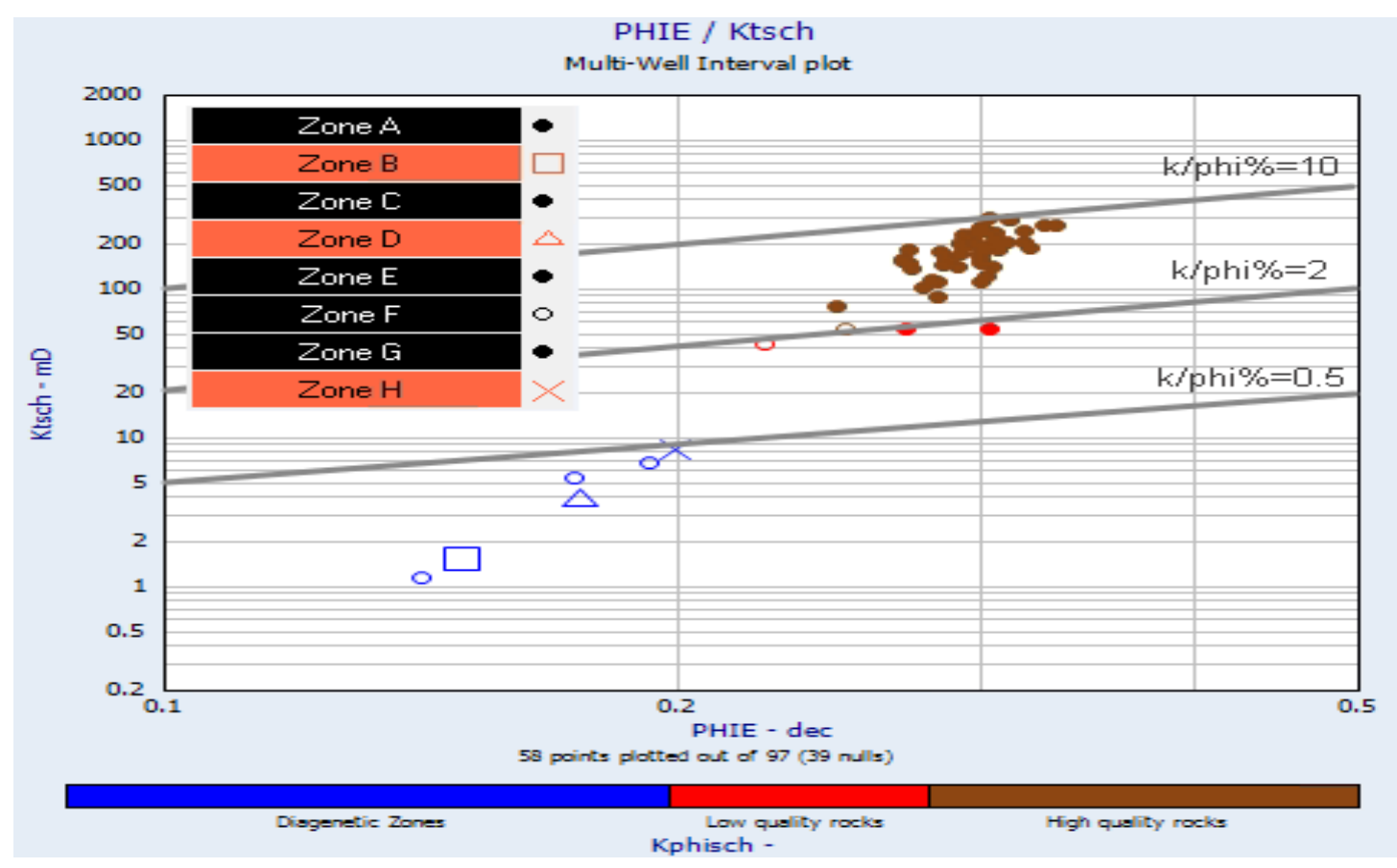

(a)

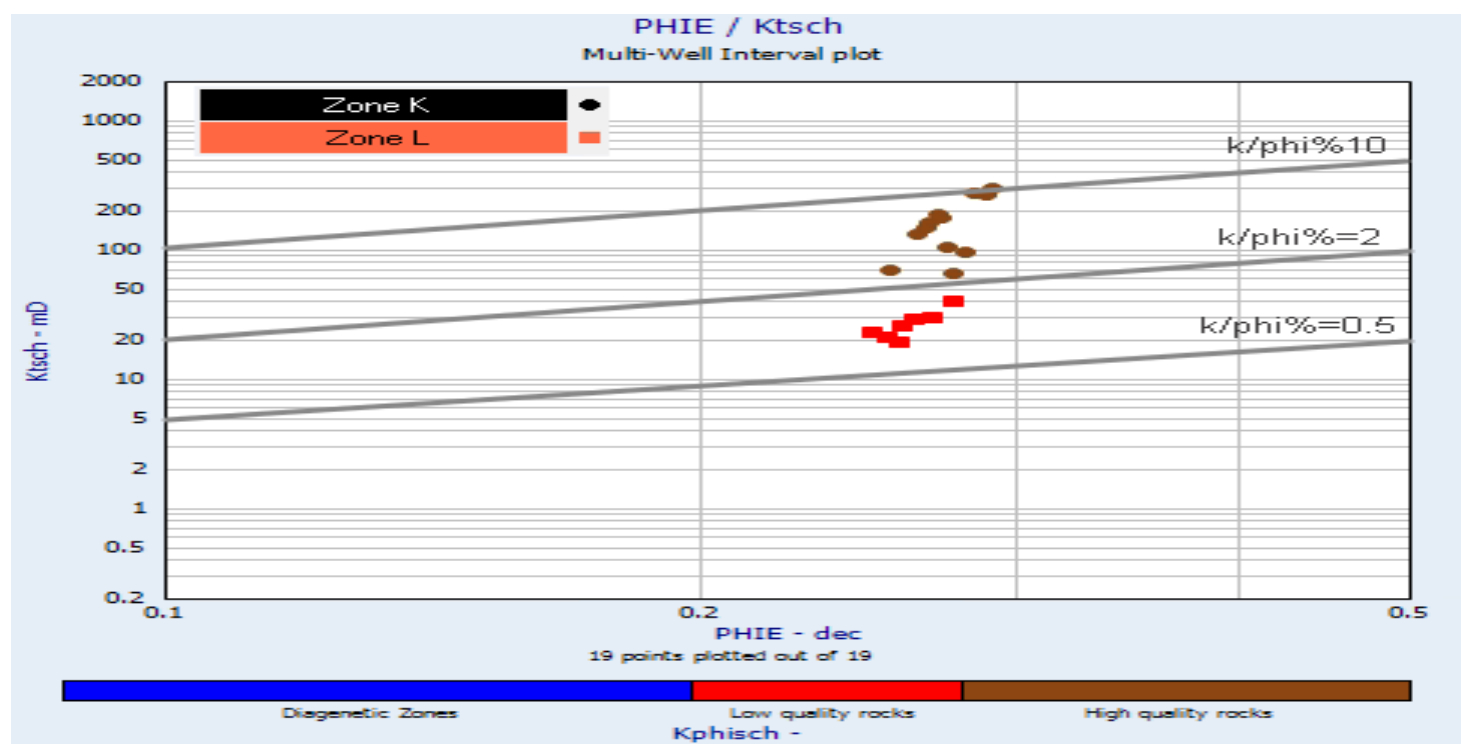

(b)

Figure 33 (a) Karewa-1 well-permeability (K)-porosity $(\Phi)$ plot from Timur absolute permeability (Ktsch). Porosity-permeability ratio was dramatically reduced by diagenesis effects in zones B, D, F, and $\mathrm{H}$. After removing the dissolution porosity from the effective porosity, true places of the diagenetic zones (zone B, D, and $\mathrm{H}$ ) were indicated by an arrow. (b) Kahawai-1 well (Zone $\mathrm{K}$ and $\mathrm{M}$ ) permeability (K)-porosity $(\Phi)$ plot from Timur absolute permeability (Ktsch). Zone L has a lower permeability-porosity ratio due to abundant smaller grain size and pore throat size. 
parameters. In this plot, I observed three different flow unit types in terms of the permeability-porosity ratio. Zones A, C, E, and G in the Karewa-1 well and zone $\mathrm{K}$ in the Kahawai-1 well showed a high permeability-porosity ratio $(\mathrm{K} / \mathrm{phi} \%>2)()$. Conversely, zones $\mathrm{B}, \mathrm{D}, \mathrm{F}$, and $\mathrm{H}$ in the Karewa-1 well showed a low permeability-porosity ratio $(\mathrm{K} /$ phi $\%<0.5)$ (diagenetic zones). Lastly, zone L in the Kahawai-1 well displayed a permeability-porosity ratio between 0.5 and 2 which corresponds to lower quality rocks (abundant silt-sized grains).

\section{Results and Discussion}

Using conventional well logs, the petrophysical study of the Mangaa C-1 shaly sand gas formation was conducted. The log-derived permeability values of the Mangaa C-1 gas saturated shaly sand formation and pore type characterization of the formation were made at the Karewa-1 and Kahawai-1 wells, in the Taranaki Basin. Shale existence and diagenesis effects (dissolution, cementation, and precipitation of the minerals) complicate pore type and grain size distributions and hence predictions of permeability. However, mineralogy crossplots helped us understand fluid, mineralogy, and diagenesis effects on the rocks to proceed in this study.

Different diagenesis effects on the mineralogy crossplots were seen with different trends.

On the neutron-density crossplot, M-N crossplot, @maa $-t_{\text {maa }}$ MID plot, and @maa -Umaa MID plot, gas and diagenesis effects were observed more readily whereas the PEFdensity crossplot showed better mineralogy identifications in both wells even though 
none of them were powerful due to the existence of gas, clay minerals, and diagenetic feldspar minerals, simultaneously.

True estimations of shale volume, porosity, and effective water saturation allowed us to confidently predict absolute permeability of hydrocarbon bearing formations. Shale volume found by the GR log and calibrated by the Larianov tertiary rocks equation was more or less consistent with the clay volume of thin section and XRD data. Likewise, the effective porosity was estimated by neutron-density logs by removing the micro pores in shale and matched thin section porosity results.

The Mangaa C-1 gas-saturated formation consisted of mainly illite minerals confirmed by the spectral gamma-ray logs and crossplots in the Kahawai-1 well and known from thin sections of the formation in the Karewa-1 well. Also, the Thomas-Stieber method showed that the shale type within the gas formation at both wells was laminated with some dispersed shale in the gas formation. This is not surprising because dispersed shale was thought to be authigenic and might precipitate immediately after dissolution and alteration of feldspar minerals and lithic fragments because of the reactions of these minerals with formation water.

To better estimate the effective water saturation of the gas formation, Simandoux, Schlumberger, Indonesia, and Dual-Water models, as well as the clean matrix Archie equation calculations, were used to minimize clay conductivity effects on the water saturation calculations. After finding shale and sand volumes, effective, clay bound, and 
total porosity, and effective, clay bound, and total water saturation, the lithology logs from water saturation models were created. All lithology logs indicated that four zones (zones B, D, F, and $\mathrm{H}$ ) in the Karewa-1 well and two zones (zones $\mathrm{K}$ and L) in the Kahawai-1 well have high water saturation results.

The bulk volume water plot was used to find the irreducible water saturation zones and the transition zone of the gas formation in two wells. Combining the bulk volume water results with thin section descriptions and lithology logs indicated the reasons for high irreducible water saturations in zones $\mathrm{B}, \mathrm{D}, \mathrm{F}$, and $\mathrm{H}$.

Microporosity and secondary porosity in zones B, D, and $\mathrm{H}$ were recognized as ineffective pores from the bulk volume water analysis and interpreting the invaded zone resistivity log and were removed to find the true bulk volume water values in these zones by adjusting the deep resistivity log. After removing this dissolution porosity, the bulk volume water results became similar to the low irreducible water saturation zones. In zone $\mathrm{F}$, the high degree of calcite cementation decreased porosity and pore throat size. Because of narrowing the pore throat size, high capillarity in zone $F$ caused higher irreducible water saturation within the pores and decreased the permeability of that zone. Zones A, C, E, and G presented low irreducible water saturation and minimum bulk volume water values.

Zone L in the Kahawai-1 well showed abundant silt-sized grains which caused higher irreducible water saturation in the pores. Bulk volume water values were consistent within 
zone L, but were higher than the low irreducible water saturation zone (zone K). Higher bulk volume water results in zone $\mathrm{L}$ was due to smaller grain size. Zone $\mathrm{M}$ showed increasing bulk volume water values and was thought to be the transition zone.

Irreducible water saturation values and effective porosity (shale microporosity and dissolution porosity were removed) were used to estimate the permeability of the gas formation in two wells, using empirical models. Low irreducible water saturation zones $(\mathrm{A}, \mathrm{C}, \mathrm{E}, \mathrm{G}$, and $\mathrm{K})$ showed higher permeability results than diagenetic zones $(\mathrm{B}, \mathrm{D}, \mathrm{F}$, and $\mathrm{H}$ ) which have high irreducible water saturation values. Lower grain size in zone L decreased the permeability due to higher capillarity in the pores.

Pore type characterizations distinguished a low quality zone (zone L), diagenetic zones (zones B, D, F, and H), and high quality zones (zones A, C, E, and G) from each other.

\section{Conclusion}

The primary mineral compositions of the Mangaa C-1 gas saturated formation are quartz, plagioclase and K-feldspar minerals with illite minerals. After the depth shifts of the PEF and the RXO logs were applied, different mineralogy crossplots such as neutron-density, M-N plot, $\varrho_{m a a}-U m a a, \varrho_{m a a}-t_{m a a}$, and PEF-density crossplots were implemented to observe different mineralogy, fluid effects, and even diagenesis effects. Also, in two wells, the Thomas-Stieber method was used to identify different clay types by well logs and thin section data, and at the Kahawai well, the spectral gamma-ray logs and crossplots 
were applied in order to demonstrate different clay minerals within the gas-saturated zone.

For the Mangaa C-1 gas sandstone (1930.9-1941.4m) in the Karewa-1 well, higher clay volume estimations, using the gamma-ray log caused by the potassium feldspar minerals were minimized by Larianov-young rocks equation. The effective porosity was estimated from the density-neutron logs by eliminating the shale effects. Then, the effective water saturation using the Archie equation and from several shaly sand water saturation models were estimated. The results indicated that four zones $(\mathrm{B}, \mathrm{D}, \mathrm{F}$, and $\mathrm{H})$ in the Karewa-1 well and two zones ( $\mathrm{L}$ and $\mathrm{M}$ ) in the Kahawai-1 well have higher water saturation values.

The higher water saturation values in different zones were explained by the invaded zone resistivity log, using bulk volume water analysis, lithology logs, and core descriptions. Zones A, C, E, and G from the Karewa-1 well and zone K presented minimum irreducible water saturation whereas zones B, D, F, and H from the Karewa-1 well and zone L from the Kahawai-1 well displayed higher irreducible water saturation results.

Zone B was altered by diagenesis effects (the dissolution of the feldspar minerals and the precipitation of some authigenic clay minerals (mainly illite)) which resulted in higher irreducible water saturation. Zone D having abundant lithic fragments which were also dissolved in water has high irreducible water saturation, as well. In zone $\mathrm{H}$, the feldspar minerals and lithic fragments were also the main reason for higher irreducible water saturation because dissolution of these minerals corresponded to the forming of isolated 
microporosity and secondary porosity which kept more capillary bound water between grains. Zone $\mathrm{F}$ was recognized as the calcite cementation zone, using the well logs, mineralogy crossplots, and bulk volume water analysis and was interpreted to have lower pore size and fine grain size. Dissolution and alteration of minerals were not expected at zones A, C, E, and G (abundant intergranular pores), and there was no transition zone or free water level encountered in the Karewa-1 well because of the presence of shale under zone $\mathrm{H}$.

As for the Kahawai-1 well, zone L was interpreted to have more bulk volume water because of silt-sized grains. By combining the bulk volume water analysis with the lithology logs, zone $\mathrm{M}$ was recognized as a transition zone which was proven by low gamma-ray and the PEF values. Similar to high quality zones (A, C, E, and G) in the Karewa-1 well, zone K in Kahawai-1 presented low irreducible water saturation with high permeability.

Timur, Morris-Biggs, Coates-Denoo, and Coates-Dumanoir models were applied to the irreducible water saturation zones to estimate absolute permeability of the gas formation. Even though those models, except the Morris-Biggs model, were best suited to medium gravity oil reservoirs, these equations are modified for gas fields, adding the gas density. Therefore, these three models, Timur, Coates-Denoo, and Coates-Dumanoir, were modified in this study to determine better permeability results. Afterwards, by Swanson's empirical equation, these permeability values were attempted to transform to the uncorrected air permeability. Winland (R35) empirical model, flow zone indicator and 
$\mathrm{K} / \mathrm{phi}$ ratio parameters were used to identify different flow units in the gas formation. As a result of these flow unit methods, zones under the diagenesis were attributed to low reservoir quality rocks in Mangaa C-1 gas sandstone in Karewa-1 and Kahawai-1 wells. 


\section{References}

[1] Ali SA, Clark WJ, Moore WR and Dribus JR. Diagenesis and Reservoir Quality. Oilfield Reviews 22, no. 2 (Summer 2010): 14-27.

[2] Amaefule, J.O., Altunaby, M., Tiab, D., Kersey, D.G., Keelan, D.K. 1993. Enhanced Reservoir Description: Using Core Log and Log Data to Identify Hydraulic Flow Units and Predict Permeability in Uncored Intervals/Wells. Paper SPE 26436 presented at the Annual Technical Conference and Exhibition, Houston, 3-6 October.

[3] Archie GE (1942). The Electrical Resistivity as an Aid in Determining Some Reservoir Characteristics. J.Petrol Technol.

[4] Asquith, G. B.; Krygowski, D.; Gibson, C. R. Basic well log analysis, Vol. 16; American association of petroleum geologists Tulsa, 2004.

[5] Buckles, R.S., 1965, Correlating and averaging connate water saturation data: Journal of Canadian Petroleum Technology, v. 9, no. 1, p. 42-52.

[6] Coates, G and Denoo, S. (1981): The Producibility Answer Product. The Technical Review, vol. 29, No2, pp.55-144.

[7] Coates GR and Dumanoir JR: "A New Approach to Improved Log-Derived Permeability,” The Log Analyst (January-February 1974).

[8] Conoco Northland Ltd, Karewa-1 well completion report, Offshore Northland/Tasman, 2002-2003.

[9] Dewan, J. T. Essentials of modern open-hole log interpretation; PennWell Books, 1983.

[10] Hansen RJ, Kamp PJ, 2002, Evolution of the Giant Foresets Formation, northern Taranaki Basin, New Zealand. 2002 New Zealand petroleum conference proceedings. 
[11] Huang W. L., Bishop, A.M. \& Brown, R. W., 1986, Effect of fluid/rock ratio on feldspar dissolution and illite formation under reservoir conditions.

[12] King, P.R. and G.P. Thrasher, 1996, Cretaceous-Cenozoic geology and petroleum systems of the Taranaki Basin, New Zealand: New Zealand, Institute of Geological \& Nuclear Sciences Monograph, Report No. 13, 243 p.

[13] Klinkenberg, L.J. 1941. The Permeability of Porous Media to Liquids and Gases. Drill. \& Prod. Prac. 200.

[14] Kolodzie, S., "Analysis of Pore Throat Size and Use of the Waxman-Smits Equation to Determine OOIP in Spindle Field, Colorado", (1980) SPE Paper 9382.

[15] Larionov, W. W., 1969, Radiometrija skwaschin. Nedra Verlag, Moscow.

[16] Morris RL and Biggs WP: "Using Log-Derived Values of Water Saturation and Porosity,” Transactions of the SPWLA 8th Annual Logging Symposium (1967).

[17] New Zealand Oil \& Gas Services Ltd, Kahawai-1 well completion report. PPL38451. Offshore North Taranaki, 1990.

[18] Pickett, G.I., 1966. A review of current techniques for determination of water saturation from logs: Journal of petroleum Technology, 18: 1425-1433.

[19] Pittman, E.D. 1992 Relationship of Porosity and Permeability to Various Parameters. Derived from Mercury Injection-Capillary Pressure Curves for Sandstone. Bull. American Association of Petroleum Geologists, 76, 191-198.

[20] Poupon, A., Leveaux, J., 1971. Evaluation of water saturation in shaly formations. In: SPWLA 12Annual Logging Symposium. 
[21] Schlumberger. 1991. Log interpretation principles/applications. Schlumberger Educational Services.

[22] Schlumberger, 1972, Log Interpretation, Volume 1 - Principles: Schlumberger Ltd., New York.

[23] Schön J., 2004, Physical Properties of Rocks: Fundamentals and Principles of Petrophysics v. 65.

[24] Simandoux, P., 1963, Dielectric measurements in porous media and application to shaly formation: Revue de L'Institut Français du Pétrole, v. 18, Supplementary Issue, p. $193-215$.

[25] Soto, Rodolfo B., Duarry, Arteaga, Cincitia, Martin, Freddy, Rodriguez, 2010. PoreType Determination from Core data using a new polar-transformation function from hydraulic flow units. SPE, 136805.

[26] Swanson, B.F. 1981. A Simple Correlation Between Permeabilities and Mercury Capillary Pressures. J Pet Technol 33 (12): 2498-2504. SPE-PA.

[27] Thomas, E. \& S. Stieber. 1975. The distribution of shale in sandstones and its effect upon porosity. In SPWLA 16th Annual Logging Symposium, 4-7. Society of Petrophysicists and Well-Log Analysts.

[28] Timur, A.: "An Investigation of Permeability, Porosity, and Residual-Water Saturation Relationship for Sandstone Reservoirs," The Log Analyst, Vol. 9, No. 4, (JulyAugust 1968), pp. 8.

[29] Wyllie, M.R.J., and Rose, W.D., 1950,. Some theoretical considerations related to the quantitative evaluation of the physical characteristics of reservoir rock from electrical log data: J.Pet. Tech., p.189. 


\section{Appendix A: Mineralogy Crossplots}

\section{A.1 M-N plot}

One of the strongest mineralogy crossplot is $\mathrm{M}-\mathrm{N}$ plot which uses sonic, density and neutron logs. For $\mathrm{M}$ number, sonic transit time and bulk density were used. As for $\mathrm{N}$ number, bulk density and neutron limestone porosity were used.

$M=\frac{t_{f}-t}{\varrho_{b}-\varrho_{f}} x 0.01$

$N=\frac{\Phi_{N f}-\Phi_{N}}{\varrho_{b}-\varrho_{f}}$

where

$t_{f}=$ The transit time of the formation fluid (I used $\left.185 \mu \mathrm{sec} / \mathrm{ft}\right)(\mu \mathrm{sec} / \mathrm{ft})$

$t=$ The sonic $\log$ transit time $($ Read from sonic $\log )(\mu \mathrm{sec} / \mathrm{ft})$

$\varrho_{b}=$ Bulk density $($ Read from density $\log )\left(\mathrm{g} / \mathrm{cm}^{3}\right)$

$\varrho_{f}=$ The density of the formation fluid (I used $1.1000 \mathrm{~g} / \mathrm{cm}^{3}$ for Karewa-1 and 1.1144

$\mathrm{g} / \mathrm{cm}^{3}$ for Kahawai-1) $\left(\mathrm{g} / \mathrm{cm}^{3}\right)$

$\Phi_{N f}=$ Neutron porosity of the fluid (I used "1") (decimal)

$\Phi_{N}=$ The neutron porosity for water-saturated limestone (Read from neutron $\log$ ) (decimal) 


\section{A.2 @maa vs. $t_{\text {maa }}$ MID plot}

The apparent matrix transit time and the apparent matrix density values were plotted in this part in order to see mineral and fluid effects.

$\varrho_{\text {maa }}=\frac{\varrho_{b}-\Phi_{t a} \varrho_{f}}{1-\Phi_{t a}}$

$\mathrm{t}_{\mathrm{maa}}=\frac{t-\Phi_{t a} t_{f}}{1-\Phi_{t a}} \quad$ Time-average relationship

where

$\varrho_{b}=$ Bulk density (Read from density $\left.\log \right)\left(\mathrm{g} / \mathrm{cm}^{3}\right)$

$t=$ The sonic log transit time (Read from sonic log) $(\mu \mathrm{sec} / \mathrm{ft})$

$\varrho_{f}=$ The density of the formation fluid (I used $1.1 \mathrm{~g} / \mathrm{cm}^{3}$ for Karewa-1 and $1.1144 \mathrm{~g} / \mathrm{cm}^{3}$

for Kahawai-1) $\left(\mathrm{g} / \mathrm{cm}^{3}\right)$

$t_{f}=$ The transit time of the formation fluid (I used $\left.185 \mu \mathrm{sec} / \mathrm{ft}\right)(\mu \mathrm{sec} / \mathrm{ft})$

$\Phi_{t a}=$ Apparent total porosity (decimal)

\section{A.3 Qmaa vs. $U_{\text {maa }}$ MID plot}

This mineral identification plot can be used to determine lithology, shale effects, diagenesis, and gas effects. To create this plot, PEF and density logs were needed.

$\mathrm{U}_{\mathrm{maa}}=\frac{\mathrm{P}_{e} \varrho_{e}-\Phi_{t a} U_{f}}{1-\Phi_{t a}}$ 
$\varrho_{e}=\frac{\varrho_{b}+0.1883}{1.0704}$

where

$\mathrm{U}_{\text {maa }}=$ The apparent matrix volumetric cross section (barn/cc)

$\mathrm{P}_{e}=$ The photoelectric absorption factor $(\mathrm{b} / \mathrm{e})$

$\varrho_{e}=$ Electron density $\left(\mathrm{g} / \mathrm{cm}^{3}\right)$

$\Phi_{t a}=$ The apparent total porosity (decimal)

$\varrho_{b}=$ Bulk density (Read from density $\left.\log \right)\left(\mathrm{g} / \mathrm{cm}^{3}\right)$

$U_{f}=$ Volumetric section of the fluid

\section{Appendix B: Petrophysical Formation Properties}

\section{B.1 Clay Volume Calculation}

Clay volume was calculated from GR log and was calibrated by Larianov tertiary rocks equation (Larianov, 1969).

$$
\begin{aligned}
& \text { IGR }=\frac{\text { GRLOG }- \text { GRMIN }}{\text { GRMAX-GRMIN }} \\
& V S H=0.083 *\left(2^{(3.7 * I G R)}-1\right)
\end{aligned}
$$

where

IGR = Gamma Ray Index (Linear) (decimal)

$\mathrm{GR}_{\mathrm{LOG}}=$ Gamma ray value $($ Read from gamma-ray log) $(\mathrm{API})$

$G R_{M I N}=$ Minimum gamma ray value from clean zone (I used 60 API) (API) 
$G R_{M A X}=$ Maximum gamma ray value from shale zone (I used 107 API) (API)

$\mathrm{V}_{\mathrm{SH}}=$ Larianov equation for tertiary (young) rocks (decimal)

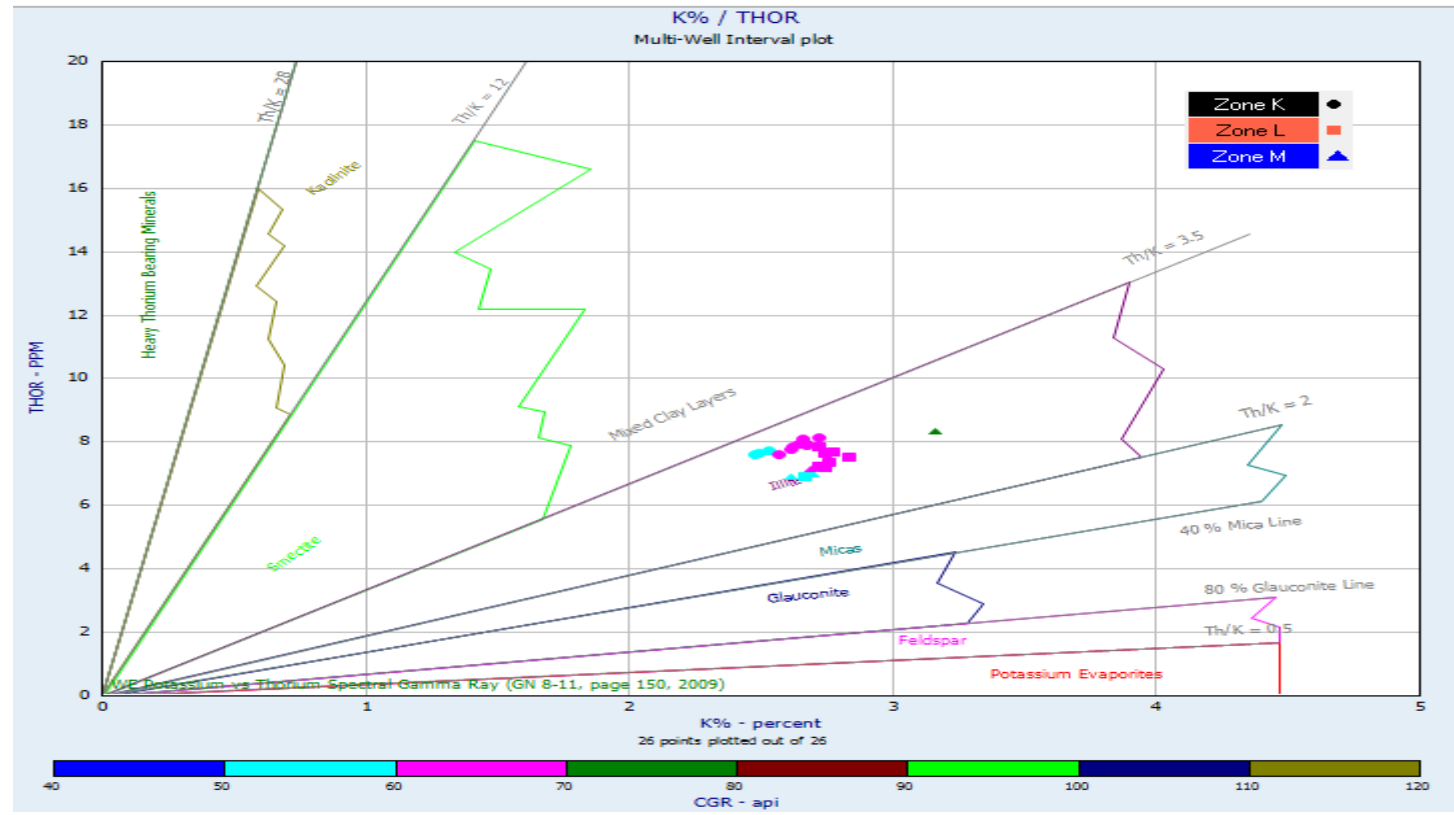

Figure B-1 Kahawai-1 well (Zone K, L, and M)-Potassium-thorium logs crossplot (different version).

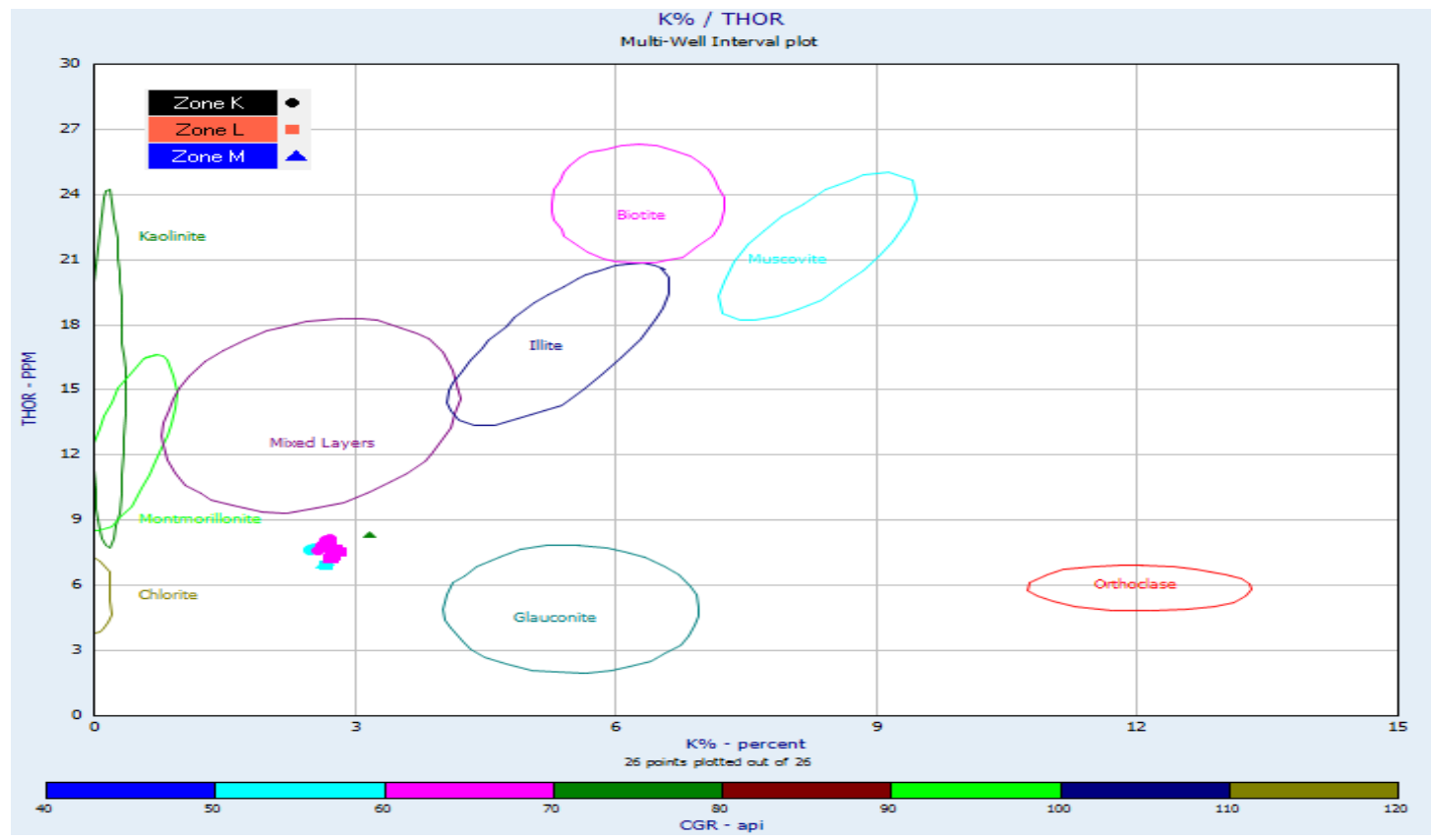

Figure B-2 Kahawai-1 well (Zone K, L, and M)-Potassium-thorium logs crossplot. 


\section{B.2 Effective and Total Porosity}

Density porosity was calculated from the formation bulk density ( $\rho b)$, the matrix density ( $\rho m a)$, and fluid density ( $\rho f 1)$.

$\Phi_{D}=\frac{\rho_{m a}-\rho_{b}}{\rho_{m a}-\rho_{f l}}$

where,

$\Phi_{\mathrm{D}}=$ Density porosity (decimal)

$\rho_{\text {ma }}=$ Matrix density $\left(\mathrm{I}\right.$ used $\left.2.70 \mathrm{~g} / \mathrm{cm}^{3}\right)\left(\mathrm{g} / \mathrm{cm}^{3}\right)$

$\rho_{b}=$ Formation bulk density $($ Read from FDC $\log )\left(\mathrm{g} / \mathrm{cm}^{3}\right)$

$\rho_{\mathrm{fl}}=$ Fluid density (I used $1.1 \mathrm{~g} / \mathrm{cm}^{3}$ for Karewa-1 and $1.1144 \mathrm{~g} / \mathrm{cm}^{3}$ for Kahawai-1 well)

$\left(\mathrm{g} / \mathrm{cm}^{3}\right)$

Density porosity and lithology corrected neutron log porosity values were corrected for the shale effects within the sandstone.

$\Phi_{d c}=\Phi_{D}-\left(V_{S H} * \Phi_{d s h}\right)$

$\Phi_{n c}=\Phi_{n s}-\left(V_{S H} * \Phi_{n s h}\right)$

where

$\Phi_{d}=$ Density porosity (decimal)

$\Phi_{d c}=$ Clay-corrected density porosity (decimal)

$\Phi_{n c}=$ Clay-corrected neutron porosity (decimal)

$\mathrm{V}_{s h}=$ Larianov equation for tertiary (young) rocks (decimal) 
$\Phi_{d s h}=$ Density shale porosity at nearby shale, at $1253 \mathrm{~m}$ (decimal)

$\Phi_{n s}=$ Neutron porosity (Limestone to sandstone converted) (decimal)

$\Phi_{n s h}=$ Neutron shale porosity at nearby shale, at $1253 \mathrm{~m}$ (decimal)

Effective porosity was calculated from the shale-corrected density porosity and the shalecorrected neutron porosity. Estimating the total shale porosity from shale density porosity and shale neutron porosity at nearby shale, the total gas porosity was calculated.

$$
\begin{aligned}
& \Phi_{e}=\sqrt{\frac{\left(\Phi_{d c}^{2}+\Phi_{n c}^{2}\right)}{2}} \\
& \Phi_{t s h}=\delta * \Phi_{d s h}+(1-\delta) * \Phi_{n s h} \\
& \Phi_{t}=\Phi_{e}+\left(\mathrm{V}_{s h} * \Phi_{t s h}\right)
\end{aligned}
$$

where

$\Phi_{e}=$ Effective porosity (decimal)

$\Phi_{t s h}=$ Total shale porosity (decimal)

$\delta=$ Field-dependent constant which is between 0.5 and 1.0 (I took 0.7)

$\Phi_{t}=$ Total porosity (decimal)

$\mathrm{V}_{s h}=$ Larianov equation for tertiary (young) rocks (decimal)

$\Phi_{d s h}=$ Shale porosity from density porosity (Estimated from nearby overlying shale at $1925.3 \mathrm{~m})($ decimal $)$

$\Phi_{n s h}=$ Shale porosity from neutron porosity (Estimated from nearby overlying shale at $1925.3 \mathrm{~m})($ decimal $)$ 


\section{B.3 Water Saturation Models}

Effective water saturation of the gas saturated shaly sand Mangaa C-1 formation was estimated by the Archie and non-Archie shaly sand models, Simandoux, Schlumberger, Indonesia, and Dual-Water in order to get rid of the effects of clay conductivity.

\section{B.3.1 Archie Water Saturation}

Archie (Archie, 1942) equation was calculated without adding a clay conductivity factor.

$S w_{\text {archie }}=\sqrt[n]{\frac{a * R w}{\Phi e^{m} * \mathrm{Rt}}}$

where

$\mathrm{Sw}_{\text {archie }}=$ Archie water saturation (decimal)

$\Phi_{\mathrm{e}}=$ Effective porosity (decimal)

$\mathrm{R}_{\mathrm{w}}=$ Resistivity of the formation water (From the Pickett plot) (ohm-m)

$\mathrm{R}_{\mathrm{t}}=$ True resistivity of the formation (Calibrated from LLD log) (ohm-m)

$\mathrm{m}=$ Cementation exponent (I used " 2.23 " from the Pickett plot))

$\mathrm{n}=$ Saturation exponent (I used " 2 ")

$a=$ Tortuosity exponent (I used " 1 ”)

\section{B.3.2 Simandoux Water Saturation}

Simandoux (Simandoux, 1963) equation includes $\mathrm{R}_{\text {sh }}$ and Vsh parameters in order to decrease the shale effect on the water saturation results. 
$S w e_{s i m}=\frac{0.4 * R w}{\Phi e^{m}} *\left(\sqrt{\left(\frac{V s h}{R s h}\right)^{2} *\left(\frac{5 * \Phi e^{m}}{R t * R w}\right)}-\frac{V s h}{R s h}\right)$

where

Swe $_{\text {sim }}=$ Simandoux effective water saturation (decimal)

$\mathrm{V}_{\mathrm{SH}}=$ Larianov equation for tertiary (young) rocks (decimal)

$R_{\text {sh }}=$ Shale resistivity (Estimated from nearby overlying shale at $\left.1925.3 \mathrm{~m}\right)(\mathrm{ohm}-\mathrm{m})$

$\Phi_{\mathrm{e}}=$ Effective porosity (decimal)

$\mathrm{R}_{\mathrm{w}}=$ Resistivity of the formation water (From the Pickett plot) (ohm-m)

$\mathrm{R}_{\mathrm{t}}=$ True resistivity of the formation (ohm-m)

$\mathrm{m}=$ Cementation exponent (I used " 2.23 " from the Pickett plot))

\section{B.3.3 Schlumberger Water Saturation}

Schlumberger (Schlumberger, 1972) model is (1-Vsh) added version of the Simandoux equation to make the shale volume more dominant on the equation.

$S w e_{s c h}=\frac{0.4 *(1-V s h) * R w}{\Phi e^{m}} *\left(\sqrt{\left(\frac{V s h}{R s h}\right)^{2} *\left(\frac{5 * \Phi e^{m}}{R t *(1-V s h) * R w}\right)}-\frac{V s h}{R s h}\right)$

where

Swe $_{\text {sch }}=$ Schlumberger effective water saturation (decimal)

$\mathrm{V}_{\mathrm{SH}}=$ Larianov equation for tertiary (young) rocks (decimal)

$\mathrm{R}_{\mathrm{sh}}=$ Shale Resistivity (Estimated from nearby overlying shale at $\left.1925.3 \mathrm{~m}\right)(\mathrm{ohm}-\mathrm{m})$

$\Phi_{\mathrm{e}}=$ Effective porosity (decimal) 
$\mathrm{R}_{\mathrm{w}}=$ Resistivity of the formation water (From the Pickett plot) (ohm-m)

$\mathrm{R}_{\mathrm{t}}=$ True resistivity of the formation (ohm-m)

$\mathrm{m}=$ Cementation exponent (I used "2.23" from the Pickett plot))

\section{B.3.4 Indonesia Water Saturation}

Indonesia (Poupon and Leveaux, 1971) water model was also used in this study by considering the shale resistivity and the shale volume in addition to standard parameters, cementation component, tortuosity component, true formation resistivity, and water resistivity.

$S w e_{\text {ind }}=\frac{\frac{1}{R t}}{\left(\left(\frac{\left.V s h^{\left(1-\frac{V s h}{2}\right.}\right)}{\sqrt{R s h}}\right)+\left(\sqrt{\frac{\Phi \mathrm{e}^{m}}{a * R w}}\right)\right)}$

where

Swe $_{\text {Ind }}=$ Indonesia effective water saturation (decimal)

$\mathrm{m}=$ Cementation exponent (I used " 2.23 " from the Pickett plot))

$\mathrm{R}_{\mathrm{t}}=$ True resistivity of the formation (ohm-m)

$\mathrm{V}_{\mathrm{SH}}=$ Larianov equation for the tertiary (young) rocks (decimal)

$\mathrm{R}_{\mathrm{sh}}=$ Shale resistivity (Estimated from nearby overlying shale at $\left.1925.3 \mathrm{~m}\right)(\mathrm{ohm}-\mathrm{m})$

$\Phi_{\mathrm{e}}=$ Effective porosity (decimal)

$\mathrm{R}_{\mathrm{w}}=$ Resistivity of the formation water (From the Pickett plot) (ohm-m)

$\mathrm{a}=$ Tortuosity exponent (I used "1") 


\section{B.3.5 Dual-Water Saturation}

Dual-Water model (Dewan, 1983) was used in order to estimate the clay bound, effective and total water saturation.

$$
\begin{aligned}
& S b=V_{S H} *\left(\Phi_{\mathrm{tsh}} / \Phi_{\mathrm{t}}\right) \\
& R b=R s h *\left(\Phi \mathrm{tsh}^{2}\right) \\
& R w a=R t *\left(\Phi \mathrm{t}^{2}\right) \\
& \left.R w=R c l *\left(\Phi \mathrm{t}^{2}\right) \text { or (Read from the Pickett plot. }\right) \\
& \text { Swdual }=b+\sqrt{\mathrm{b}^{2}+(\mathrm{Rw} / \text { Rwa })} \\
& \mathrm{b}=\mathrm{S} b * \frac{\left(1-R_{w} / R_{b}\right)}{2} \\
& \text { Swedual }=\frac{(\text { Swdual }-\mathrm{Sb})}{(1-\mathrm{Sb})}
\end{aligned}
$$

where

Swe $_{\text {dual }}=$ Dual-Water effective water saturation (decimal)

$\mathrm{Sw}_{\text {dual }}=$ Dual-Water total water saturation (decimal)

$\mathrm{S}_{\mathrm{b}}=$ Clay bound water saturation (decimal)

Vsh $=$ Larianov equation for tertiary (young) rocks (decimal)

$\Phi_{\text {tsh }}=$ Total shale porosity (decimal)

$\Phi_{\mathrm{t}}=$ Total porosity (decimal)

$\mathrm{R}_{\mathrm{b}}=$ Resistivity of clay bound water (ohm-m)

$\mathrm{R}_{\mathrm{sh}}=$ Shale resistivity (Estimated from nearby overlying shale at $\left.1925.3 \mathrm{~m}\right)(\mathrm{ohm}-\mathrm{m})$ 
$\mathrm{R}_{\mathrm{wa}}=$ Apparent resistivity of the formation water of the shaly sand reservoir (ohm-m)

$\mathrm{R}_{\mathrm{t}}=$ True resistivity of the formation (Read from the logs) (ohm-m)

$\mathrm{R}_{\mathrm{W}}=$ Calculated resistivity of the water at nearby clean water formation or read from the

Pickett plot (ohm-m)

$\mathrm{R}_{\mathrm{cl}}=$ Resistivity of nearby clean water formation (ohm-m)

\section{Appendix C: Bulk Volume Water and Flow Zone Indicator}

\section{C.1 Bulk Volume Water and Bulk Volume Water Irreducible}

Bulk volume water was determined from the effective water saturation and the effective porosity.

$\mathrm{BVW}=$ Swe $*$ Фe

where

$\mathrm{BVW}=$ Bulk volume water (decimal)

Swe $=$ Effective water saturation (decimal)

$\Phi_{\mathrm{e}}=$ Effective porosity (decimal)

At irreducible water saturation, BVW gives the lowest values and was called as "Bulk Volume Water Irreducible (BVI)”. BVI should be constant or nearly constant for the same lithology and grain size at irreducible water saturation (Asquith, 1985).

$\mathrm{BVI}=\mathrm{Swi} * \Phi \mathrm{e}$ 
where

$\mathrm{BVI}=$ Bulk volume water irreducible (decimal)

Swi $=$ Irreducible water saturation (decimal)

$\Phi_{\mathrm{e}}=$ Effective porosity (decimal)

\section{C.2 Grain size from Bulk Volume Water}

The mean grain size of the formation might be determined by the bulk volume water. I created the following equation from the chart (Asquith, 1985) showing the grain size classification with the bulk volume water.

The mean grain size $(\mathrm{mm})=0.0002 * B V W^{-2.154}$

$\left(\mathrm{R}^{2=} 0.994\right)$

where

$\mathrm{BVW}=$ Bulk volume water (decimal) 


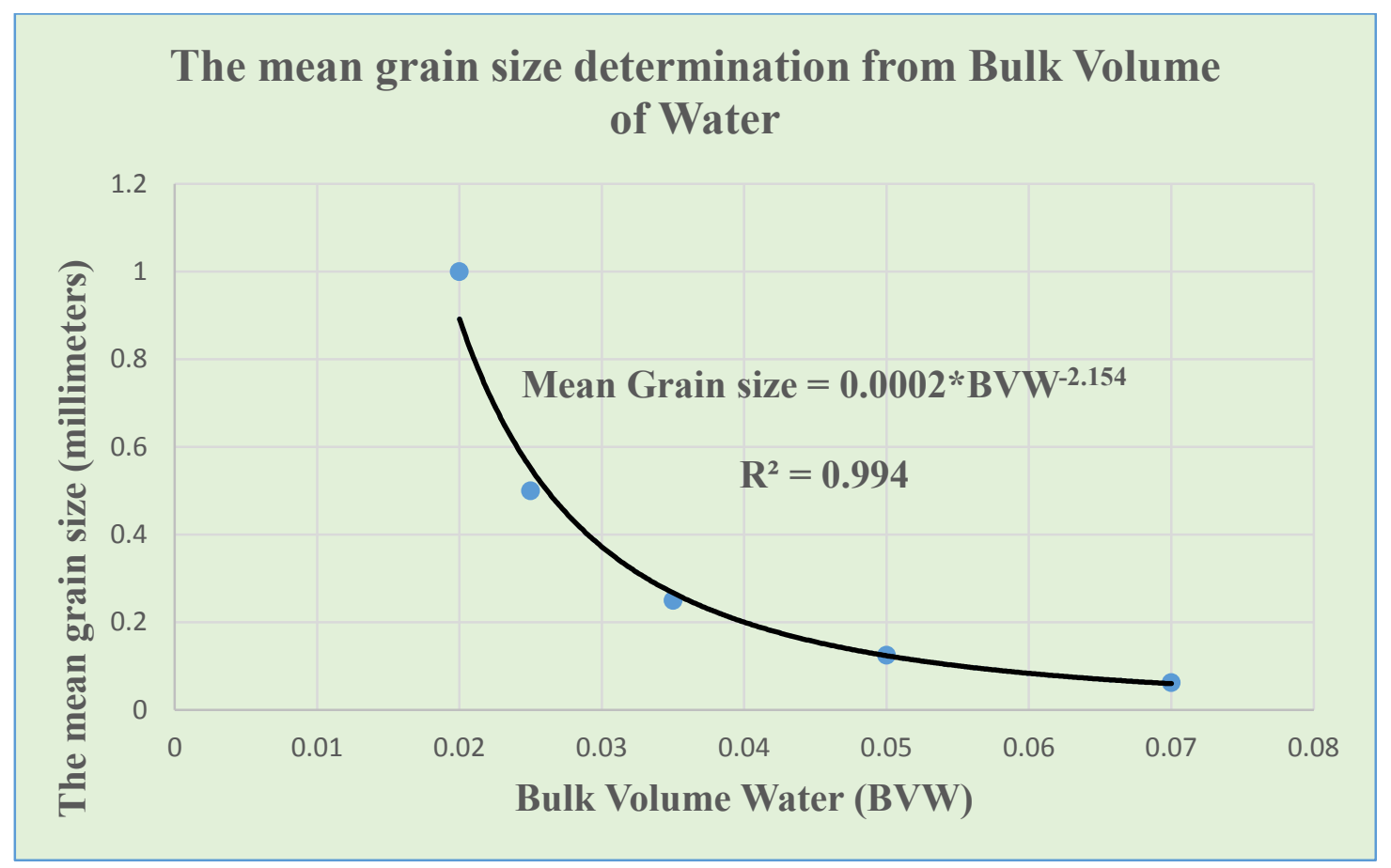

Figure C-1 The mean grain size determination from bulk volume of water using the table created by Asquith (1985).

\section{Appendix D: Permeability Calculations}

\section{D.1 Permeability Calculations}

There are four different permeability models used in this study which use the irreducible water saturation and effective porosity.

\section{D.1.1 Timur Absolute Permeability}

Wyllie and Rose (1950) created a generalized equation to estimate the intrinsic permeability of the rocks by using the effective porosity and the irreducible water saturation. One of the most common formula using the Wyllie-Rose equation is Timur model. 
Timur (1968) used 155 sandstone cores of the different oil areas in the USA and estimated the permeability of the rocks for the medium gravity oil at laboratory studies. Timur permeability model uses the Wyllie-Rose equation with three constants. The constants of this permeability model are called a, b, and c. This equation is only valid for the formations at irreducible water saturation.

Timur permeability is a laboratory measurement and give good results for only oil fields. According to the Dewan's book (Dewan, J. T., 1983), the results of the empirical permeability models using the Wyllie-Rose equation must be corrected for the gas reservoirs. Multiplying the results of the permeability models for medium gravity oil fields by the gas density (Assumed to be $0.1 \mathrm{~g} / \mathrm{cm}^{3}$ ) will give better results for the gas reservoirs (Dewan, J. T., 1983). Therefore, except the Morris-Biggs gas equation which is suitable for the gas reservoirs, I used the gas density to modify the medium gravity oil models, Timur, Coates-Denoo, and Coates-Dumanoir models

$$
\begin{aligned}
& K_{\text {TIMoil }}=\left(100 * \frac{\Phi \mathrm{e}^{2.25}}{S w i}\right)^{2} \quad \text { for medium gravity oil } \\
& K_{\text {TIM }}=K_{\text {TIMoil }} * \rho_{g} \text { for gas }
\end{aligned}
$$

where

$\mathrm{K}_{\mathrm{T} \mathrm{IMoil}}=$ Timur absolute permeability for oil (millidarcies)

$\mathrm{K}_{\mathrm{T} \mathrm{IM}}=$ Timur gas absolute permeability (millidarcies)

$\Phi_{\mathrm{e}}=$ Effective porosity (decimal) 
$\mathrm{S}_{\mathrm{wi}}=$ Irreducible water saturation of the formation of the interest (decimal)

$\rho_{g}=$ Gas density (Assumed to be $\left.0.1 \mathrm{~g} / \mathrm{cm}^{3}\right)\left(\mathrm{g} / \mathrm{cm}^{3}\right)$

\section{D.1.2 Morris-Biggs Gas Absolute Permeability}

Another permeability model is Morris-Biggs Gas equation. Morris and Biggs (1967) presented the permeability equations for both oil and gas reservoirs by using the WyllieRose equation. Morris-Biggs gas permeability calculations in the fully gas saturated zone (at irreducible water saturation) are slightly different than the permeability determined from Timur model. Unlike Timur model, Morris-Biggs model gives the permeability equation for the gas fields and is not needed to be corrected.

Tixier (1949) also created the permeability equation empirically by using the WyllieRose equation, but the permeability results were almost same with the permeability calculations of the Morris-Biggs gas equation. Therefore, I only displayed the permeability results from the Morris-Biggs equation, using the irreducible water saturation and the effective porosity of the gas reservoirs.

$K_{M B G}=6241 * \frac{\Phi e^{6}}{S w i^{2}}$

where

$\mathrm{K}_{\mathrm{MBG}}=$ Morris - Biggs gas absolute permeability (millidarcies)

$\Phi_{\mathrm{e}}=$ Effective porosity (decimal)

Swi $=$ Irreducible water saturation of the formation of the interest (decimal) 


\section{D.1.3 Coates-Denoo Absolute Permeability}

Like Timur and Morris-Biggs models, Coates-Denoo (1981) model included the effective porosity and the irreducible water saturation to calculate the absolute permeability of the formation. Another similarity of the Coates-Denoo permeability to Timur model was that the absolute permeability must be corrected from medium gravity oil to gas by the gas density of the formation. Multiplication of the gas density with the Coates-Denoo absolute permeability will correspond to better absolute permeability predictions for the gas reservoir.

Kcoil $=\left(100 * \frac{\Phi e^{2 \cdot *(1-S w i)}}{S w i}\right)^{2} \quad$ for medium gravity oil

$K_{C}=K_{\text {Coil }} * \rho_{g} \quad$ for gas

where

$\mathrm{K}_{\text {Coil }}=$ Coates-Denoo absolute permeability for oil (millidarcies)

$\mathrm{K}_{\mathrm{C}}=$ Coates-Denoo gas absolute permeability (millidarcies)

$\Phi_{\mathrm{e}}=$ Effective porosity (decimal)

Swi $=$ Irreducible water saturation of the formation of the interest (decimal)

$\rho_{g}=$ Gas density (Assumed to be $\left.0.1 \mathrm{~g} / \mathrm{cm}^{3}\right)\left(\mathrm{g} / \mathrm{cm}^{3}\right)$

\section{D.1.4 Coates-Dumanoir Absolute Permeability}

Coates and Dumanoir (1974) presented an empirical relationship for the permeability estimations of the medium gravity oil reservoirs from the irreducible water saturation and 
the effective porosity. Rather than only using the effective porosity and the irreducible water saturation, textural parameter $(\mathrm{w})$ was included on the equation which was assumed to be equal to the cementation and saturation components. Similarly, multiplying the gas used for the medium gravity oil will density of the formation with the absolute permeability correspond to the true absolute permeability of the gas reservoir.

$K_{C D o i l}=\left(\left(\frac{300}{w^{4}}\right) *\left(\frac{\Phi e^{w}}{S w i^{w}}\right)\right)^{2} \quad$ for medium gravity oil

$K_{C D}=K_{C D o i l} * \rho_{g}$ for gas

where

$\mathrm{K}_{\mathrm{CDoil}}=$ Coates - Dumanoir absolute permeability for oil (millidarcies)

$\mathrm{K}_{\mathrm{CD}}=$ Coates - Dumanoir gas absolute permeability (millidarcies)

$\Phi_{\mathrm{e}}=$ Effective porosity (decimal)

Swi $=$ Irreducible water saturation of the formation of the interest (decimal)

$\mathrm{W}=$ Textural parameter $\sim \mathrm{m}$ (cementation exponent) $\sim \mathrm{n}$ (saturation exponent $)(\mathrm{I}$ used 2.23 for "w")

$\rho_{g}=$ Gas density (Assumed to be $\left.0.1 \mathrm{~g} / \mathrm{cm} 3\right)\left(\mathrm{g} / \mathrm{cm}^{3}\right)$

\section{D.2 Multi-linear Regression Absolute Permeability}

I finally used multi-linear regression to create the permeability equation from the conventional well $\log$ s for the Mangaa C-1 gas formation in Taranaki basin. To apply the multi-linear regression, Timur gas permeability with gamma ray, true resistivity, and density logs were used because these three logs showed the highest influence on the log- 
derived permeability results. Created regression equation is not valid for quite low permeability zones of the gas reservoir and gave negative values, but the rest of the multilinear regression permeability results of the formation were pretty similar to the logderived permeability results.

I used the multi-linear regression equation created for the Mangaa C-1 gas saturated formation.

$K_{\text {multisch }}=(1.88462726-0.69889826 * F D C+0.0033509 * R t-0.00514935 *$

GRI (Darcy) $\left(\mathrm{R}^{2}=0.88663\right)$

where

$\mathrm{FDC}=$ Bulk density $\log \left(\mathrm{g} / \mathrm{cm}^{3}\right)$

$\mathrm{R}_{\mathrm{t}}=$ True resistivity of the formation (ohm-m)

GRI $=$ Gamma-ray $\log (\mathrm{API})$

\section{D.3 Air Permeability from Swanson equation}

Air permeability is the permeability of the rocks measured at laboratory conditions. Klinkenberg (1941) determined that due to the gas slippage effects, the permeability measured at laboratory conditions changes with the fluid types (different gas types) especially at low mean pressures, but the permeability is the property of a rock and cannot be different with different fluids. 
At laboratories, gas or liquid might be used to examine the permeability of the rocks. Unlike the liquid, gas molecules have finite velocity on the pore walls, which causes higher flow rate (Klinkenberg, 1941; Schön, 2004). Then, due the gas slippage, air permeability is overestimated in comparison to liquid permeability which has zero velocity on the pore walls (laminar flow) (Klinkenberg, 1941; Schön, 2004).

I assumed that the absolute permeability of the gas reservoir found by Timur, MorrisBiggs, Coates-Denoo, and Coates-Dumanoir models was the true absolute permeability of gas reservoir and was needed to be converted to the uncorrected air permeability to use the empirical R35 correlations for pore type classifications of the formation.

To convert our true absolute permeability results to the uncorrected air permeability (uncorrected for Klinkenberg gas slippage effects), I used Swanson empirical equation. Swanson (1981) generated the empirical relationships to estimate the air permeability and brine permeability from the laboratory studies. These empirical equations are correlated to establish a relationship to convert the brine permeability to the uncorrected air permeability (Swanson, 1981). Instead of the brine permeability in the equation, I used the absolute permeability of gas reservoir estimated by the empirical models to convert to the uncorrected air permeability in order to use them on Winland's equation. In other words, liquid permeability (no Klinkenberg effect) was thought to be true absolute permeability of core and might be assumed to be equal to the estimated absolute permeability of the gas reservoir in this study. 
Kair $=\left(\frac{K_{\text {brine }}}{0.292}\right)^{(1 / 1.186)}$

where

$\mathrm{K}_{\text {air }}=$ Uncorrected air permeability (millidarcies)

$\mathrm{K}_{\text {brine }}=$ Liquid permeability (It is assumed to be the true absolute permeability) (millidarcies)

\section{D.4 Permeability and PEF log crossplot}

Permeability results were plotted with photo-electric factor log because in the diagenetic zones, if the diagenesis is detrimental, higher PEF values will mean less stable minerals (quartz) and more unstable minerals (feldspar minerals) for clastic reservoirs. According to the Bowen's reaction series, unstable minerals (feldspar minerals) tend to alter more easily with diagenesis process to transform to more stable minerals (quartz). Therefore, I knew that quartz has quite lower PEF values than feldspar minerals (plagioclase or Kfeldspar), calcite, dolomite, most of the clay minerals, and heavy minerals, higher PEF values will decrease the permeability of the formation because of the diagenetic feldspar minerals and precipitating authigenic clay cements which are the resultant products of the diagenetic feldspar minerals. Therefore, in this study, the PEF log which fluid phases do not have a big impact on will be a powerful tool to compare the permeability of the formation which is the property of rocks. 


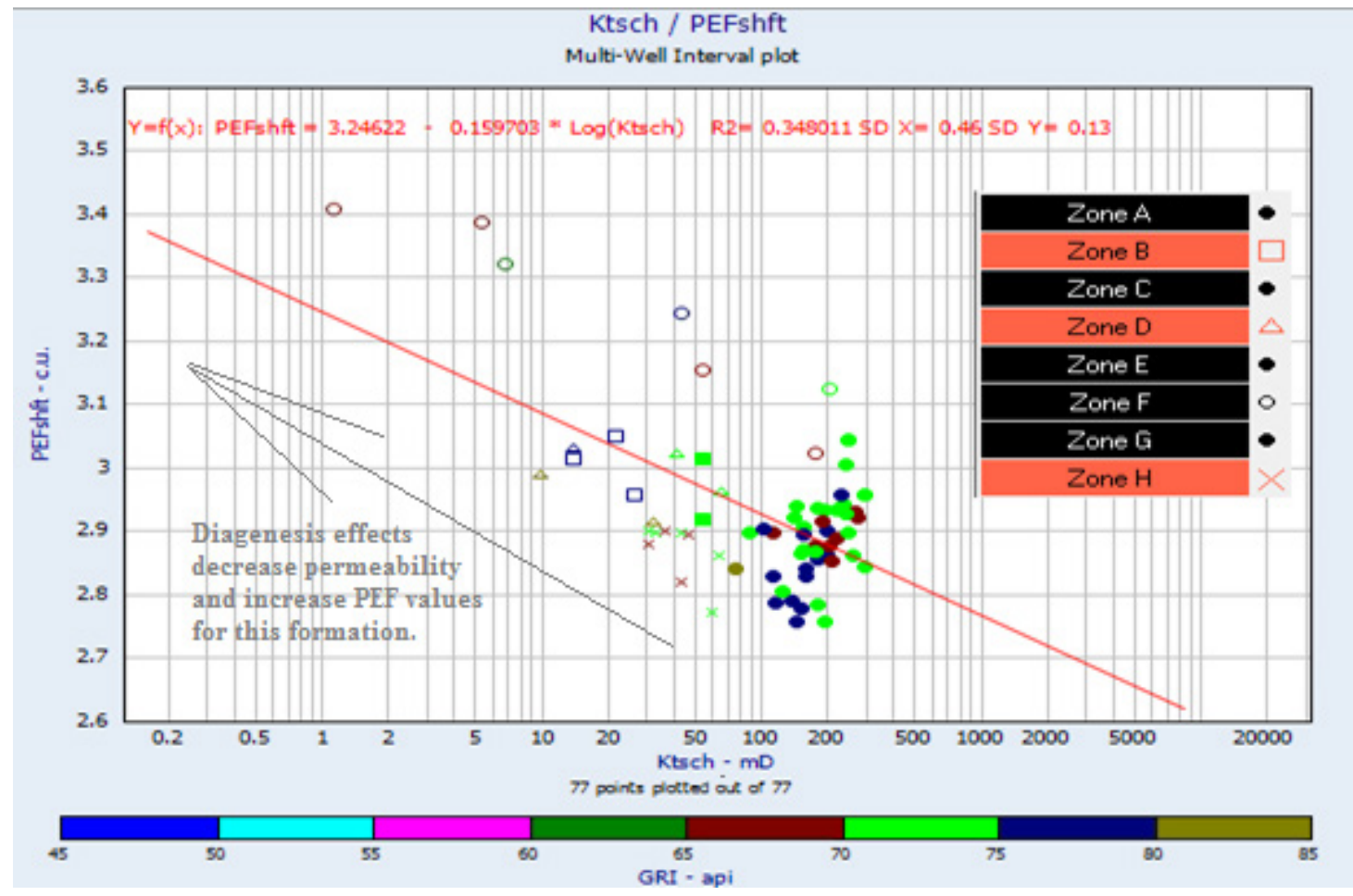

Figure D-1 Karewa-1 well (Zones A to H). PEF log and Timur permeability (Ktsch) found by the Schlumberger water saturation results. The diagenetic minerals (displaying higher PEF values) in the zones (Zones B, D, F, and H) decreased the permeability.

\section{Appendix E: Flow Unit Characterizations}

\section{E.1 Flow Zone Indicator (FZI) and Reservoir Quality Index (RQI)}

Flow zone indicator is a good parameter to identify different reservoir flow units at irreducible water saturation and can be estimated by the ratio of the reservoir quality index and normalized porosity found by Amaefule et al. (1993).

$$
\begin{aligned}
& R Q I=0.0314 * \sqrt{\frac{K}{\Phi \mathrm{e}}} \\
& \Phi \mathrm{z}=\frac{\Phi \mathrm{e}}{1-\Phi \mathrm{e}}
\end{aligned}
$$


$F Z I=\frac{R Q I}{\Phi_{Z}}$

where

$\mathrm{RQI}=$ Reservoir quality index (micron)

$\mathrm{K}=$ Absolute permeability (millidarcies)

$\Phi e=$ Effective porosity (decimal)

$\Phi \mathrm{z}=$ Pore volume to total rock volume (decimal)

FZI = Flow zone indicator (micron)

\section{E.2 R35 (Winland) empirical correlation}

Winland created an equation by using core samples of clastic and carbonate rocks in order to identify the pore throat size at $\% 35$ mercury saturation by mercury injection capillary pressure test. Winland included uncorrected core permeability and core porosity to estimate the port size.

$\left.R 35=10^{(0.732+0.588 * \log (\text { Kair })-0.864 * \log (\text { (qore })}\right)$

where

$\mathrm{R} 35=$ Port size (Pore throat size corresponding to $35 \%$ mercury saturation measured by mercury injection capillary pressure experiment) (micron)

$\mathrm{K}_{\text {air }}=$ Uncorrected air permeability (millidarcies)

$\Phi$ core $=$ Core porosity (percent) 


\section{E.3 R35 (Pittman) empirical correlation}

Pittman (1992) used 202 sandstone samples of fourteen formations between Ordovician and Tertiary ages and applied multi-linear regression analyses by considering Winland's work to estimate the pore throat radii at different mercury saturation values. The best results were observed at $35 \%$ mercury saturation. Like Winland's equation, Pittman's correlation used the air permeability and the porosity to estimate the various rocks with different pore throat size (Pittman, 1992). By using the dominant pore throat size at 35\% mercury saturation, the different flow units, rock types, and diagenetic zones were attempted to be observed in Pittman's plot.

Pittman's port size results were almost identical to the results calculated by Winland's correlation. Pore throat size at $\% 35$ mercury saturation calculated by Pittman's equation give slightly lower values than the Winland's results.

$\left.R 35=10^{(0.255+0.565 * \log (\text { Kair })-0.523 * \log (\text { ( } \text { core })}\right)$

where

R35 = Port size (Pore throat radius corresponding to 35\% mercury saturation measured by mercury injection capillary pressure experiment) (micron)

$\mathrm{K}_{\mathrm{air}}=$ Uncorrected air permeability (millidarcies)

Фcore $=$ Core porosity (percent) 


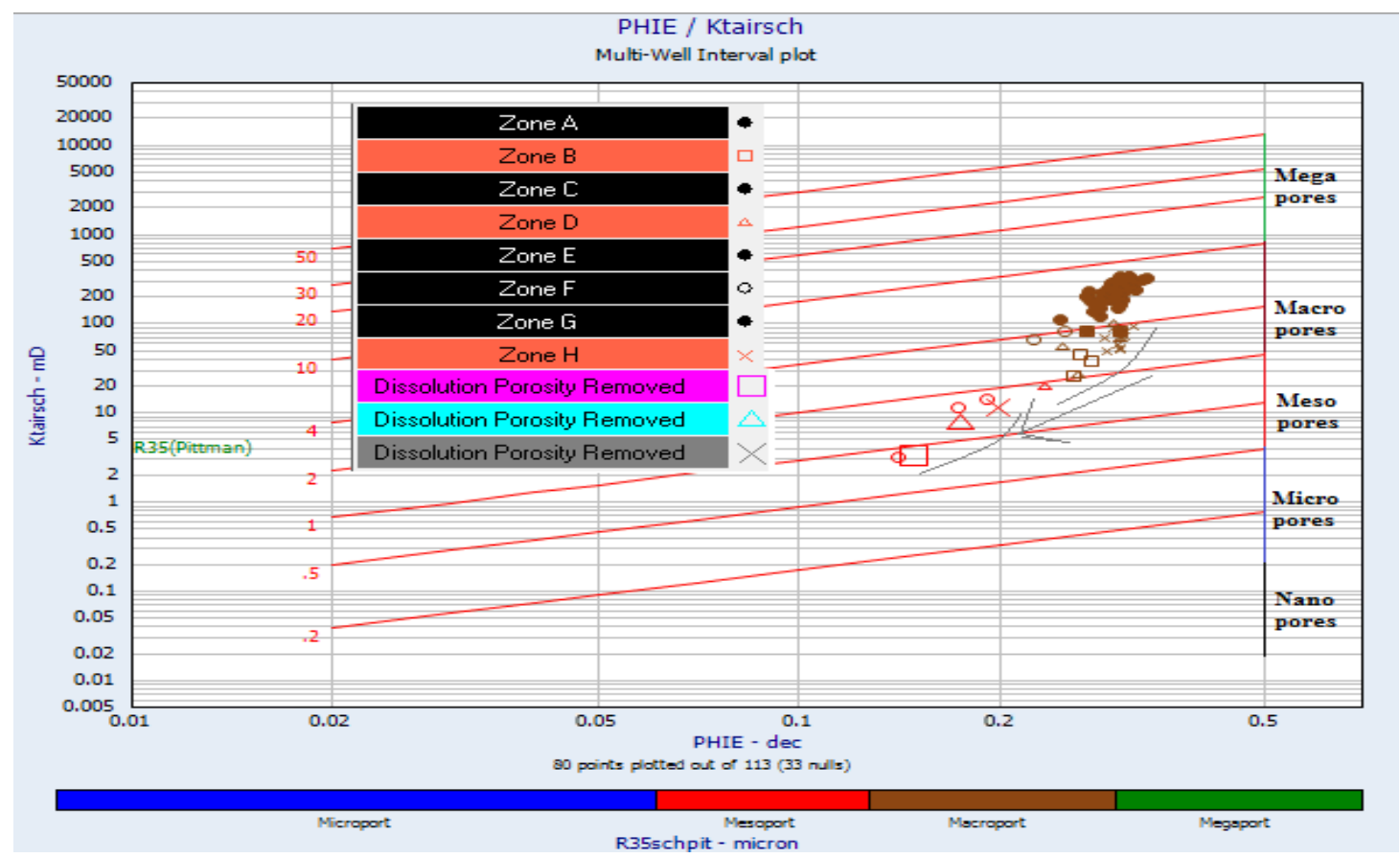

Figure E-1 Karewa-1 well (Zones A to H). Pittman (R35) plot. (a) Pore throat size at 35\% mercury saturation (R35) from Timur air permeability (Ktairsch) (Linear lines).

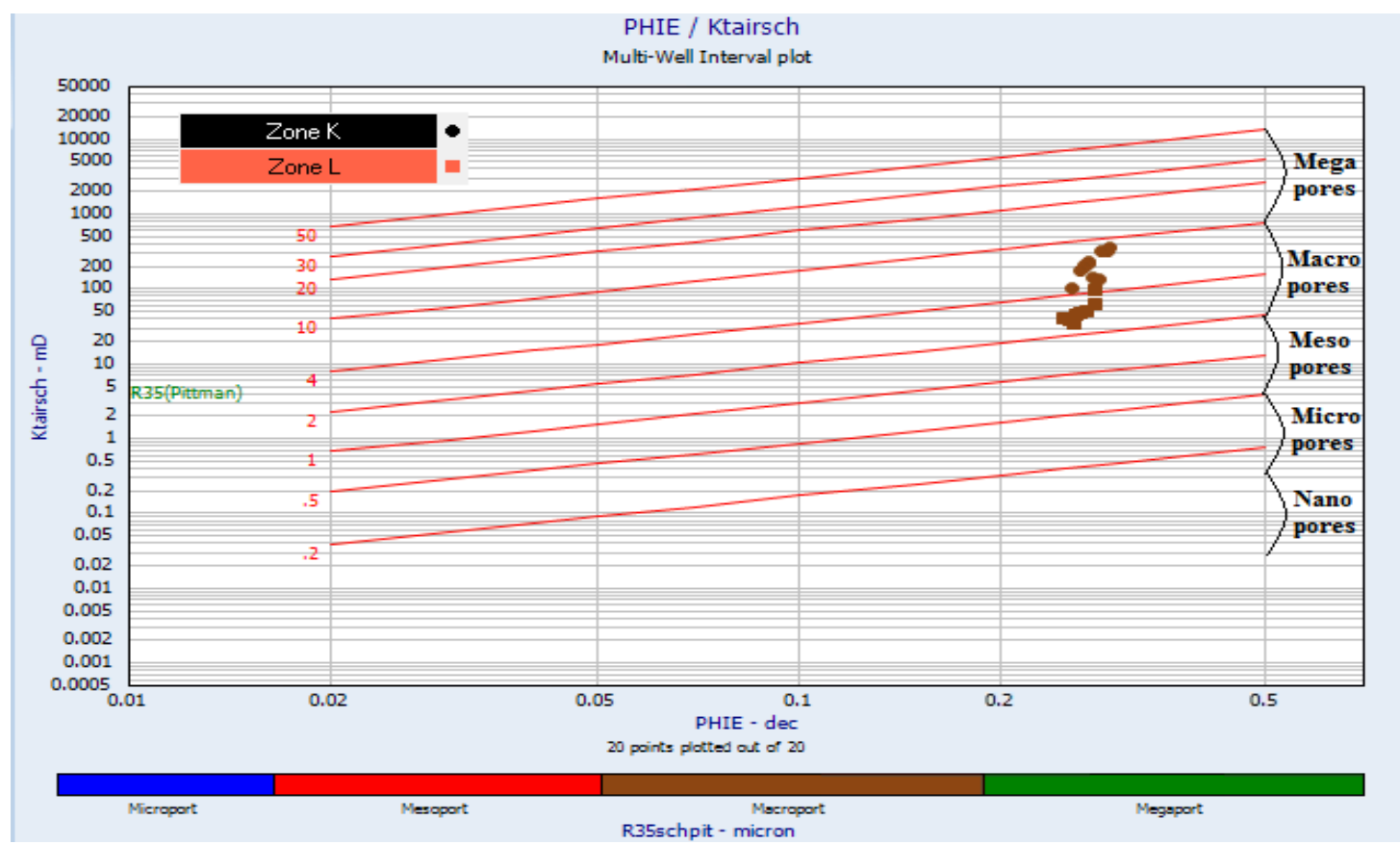

Figure E-2 Kahawai-1 well (Zone K and M). Pittman (R35) plot. (a) Pore throat size at $35 \%$ mercury saturation (R35) from Timur air permeability (Ktairsch) (Linear lines). 